\title{
FY 2006 Summary Report: Next Generation Nuclear Plant (NGNP) Project
}

September 2006

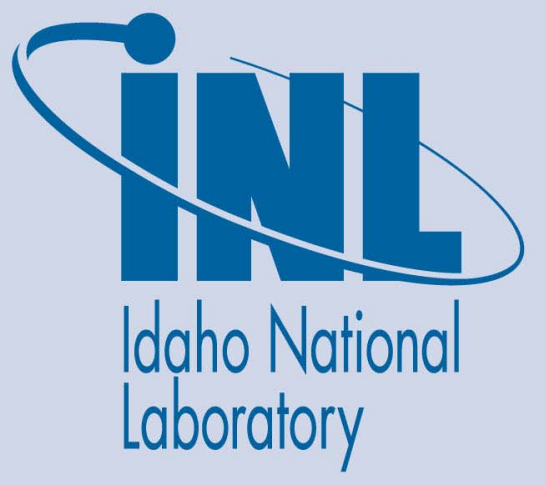

The INL is a U.S. Department of Energy National Laboratory operated by Battelle Energy Alliance 
INL/EXT-06-11915

\section{FY 2006 Summary Report: Next Generation Nuclear Plant (NGNP) Project}

Idaho National Laboratory Oak Ridge National Laboratory Argonne National Laboratory

September 2006

\section{Idaho National Laboratory Idaho Falls, Idaho 83415}

Prepared for the U.S. Department of Energy Office of Nuclear Energy Under DOE Idaho Operations Office Contract DE-AC07-05ID14517 
This page intentionally left blank. 


\section{Contents}

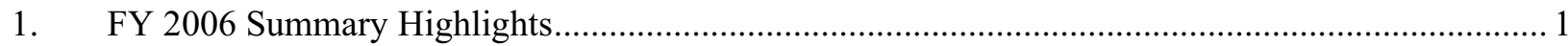

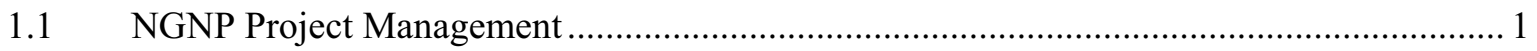

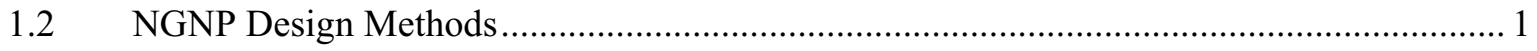

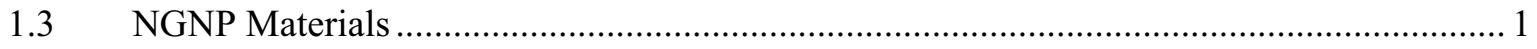

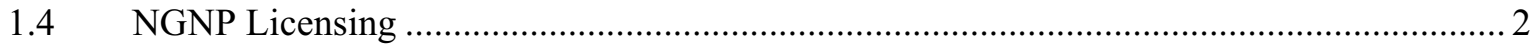

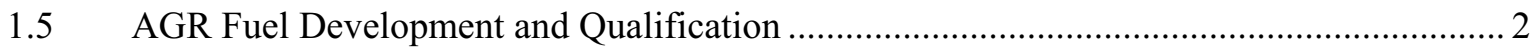

1.6 Preconceptual Engineering Services Subcontract ...................................................... 3

2. Significant Accomplishments - Program Management ........................................................... 5

3. Significant Accomplishments - NGNP Design Methods........................................................... 6

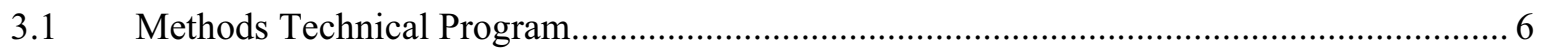

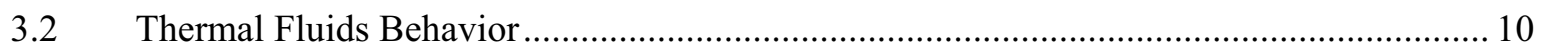

3.2.1 Particle Image Velocimetry Experiments to Measure Flow Phenomena in a Scaled Model of a VHTR Lower Plenum .......................................................... 10

3.2.2 Experimental Modeling of VHTR Plenum Flows During Normal Operation and Pressurized Conduction Cooldown .................................................................. 11

3.2.3 NSTF Facilities Plan for Water-Cooled VHTR RCCS: Normal Operational

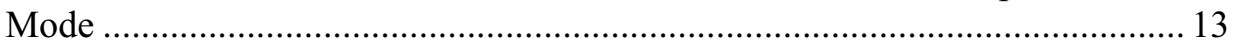

3.2.4 Investigations of the Applications of CFD to Flow Expected in the Lower Plenum of the Prismatic VHTR ......................................................................... 13

3.2.5 Practices and Procedures for Performing CFD Analyses................................. 16

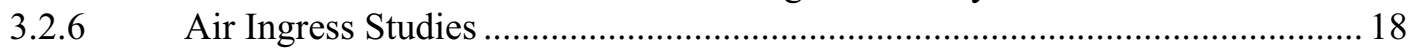

3.2.7 Systems Analysis Code Development......................................................... 21

3.3 Reactor Physics Development and Validation ........................................................ 21

3.3.1 ANL Reactor Physics: Enhancement of REBUS-3/DIF3D ........................... 21

3.3.2 Generation of Effective Reflector Cross Sections............................................. 22

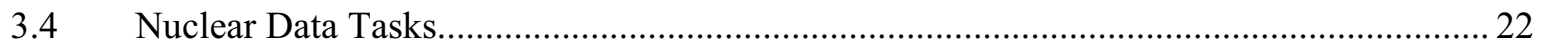

3.4.1 DOE GEN4/AFC Physics and Nuclear Data Working Group ......................... 22

3.4.2 IPNS Differential Cross Section Measurements ...............................................2 23

3.4.3 Integral Nuclear Data Benchmark Evaluation............................................. 23 


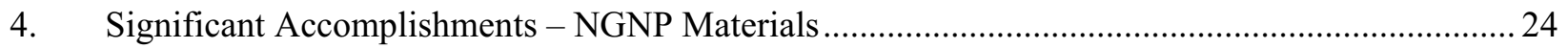

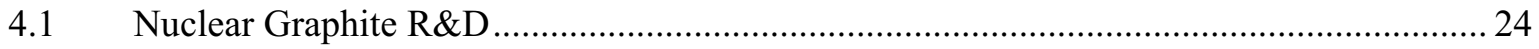

4.1.1 AGC-1 Gas System Design and Installation ................................................. 24

4.1.2 AGC-1 Graphite Creep Capsule Design and Fabrication …...............................25

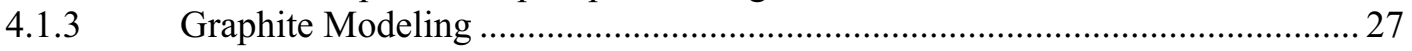

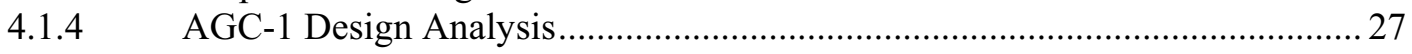

4.1.5 Preliminary Design of the AGC-1 Sizing and Dry Storage Apparatus ............. 28

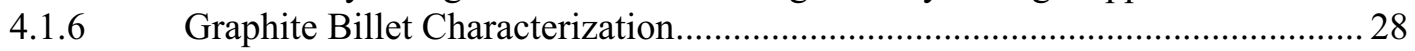

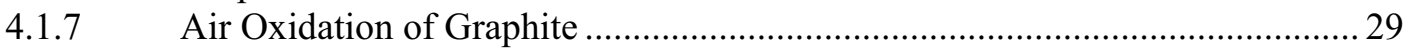

4.2 High-Temperature Alloy R\&D and Design Methodology …...................................... 30

4.2.1 Aging and Environmental Effects on Inconel 617 and Haynes 230 ................. 30

4.2.2 Testing and Characterization of CMS Alloy 617 and Alloy 230 …................. 31

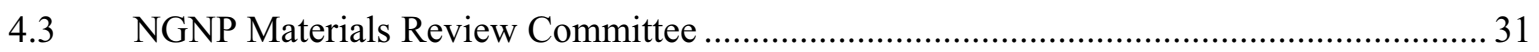

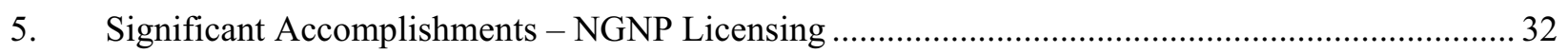

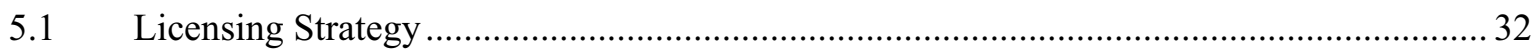

5.1.1 Choice of NRC Regulations (Customized Part 50 vs. New Part 53) ................. 32

5.1.2 Two-Step (Part 50) or One-Step (Part 52) Licensing Structure ......................... 33

5.1.3 Effect of Commercial Partnership................................................................. 34

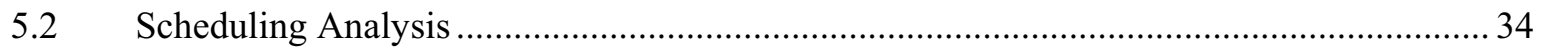

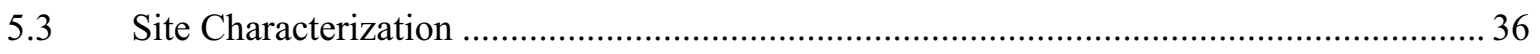

5.3.1 New Production Reactor (NPR) Site E ..................................................... 36

5.3.2 FY-07 Site Selection/Characterization Activities ............................................. 37

6. Significant Accomplishments - Advanced Gas Reactor (AGR) Fuel Development and

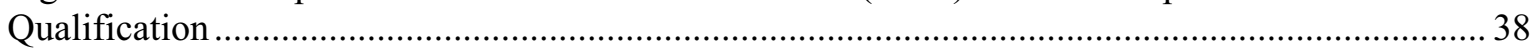

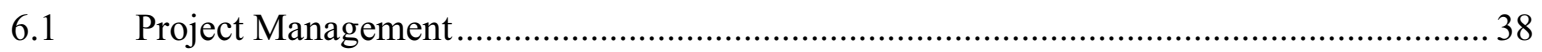

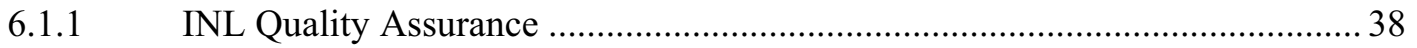

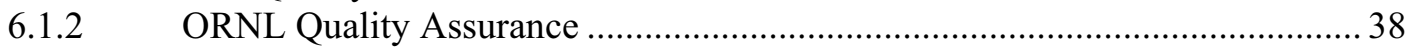

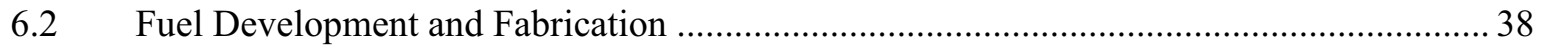

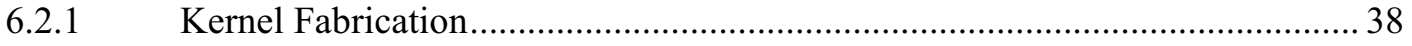

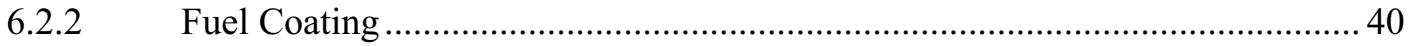

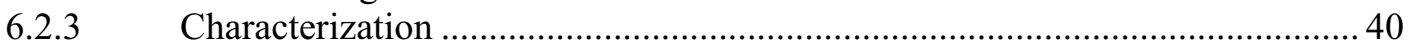

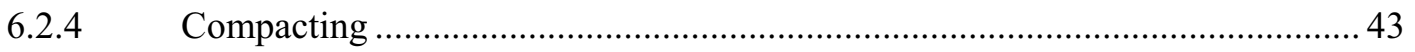




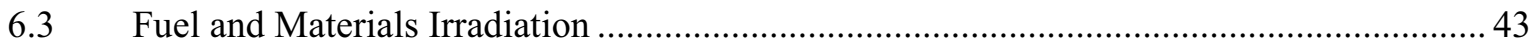

6.4 Safety Testing and Post Irradiation Examination .................................................... 51

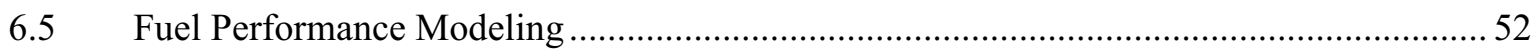

6.6 Fission Product Transport and Source Term ................................................................ 54

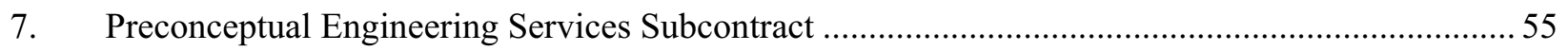

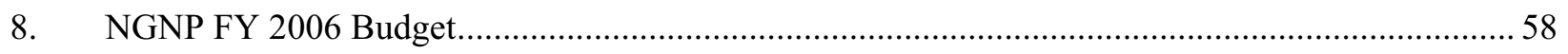

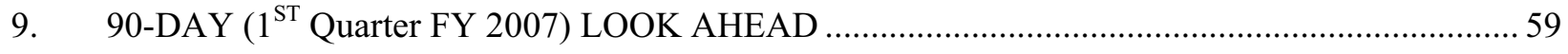

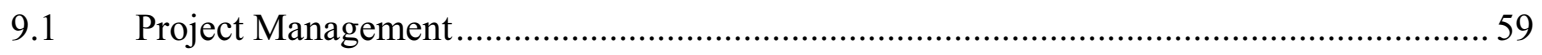

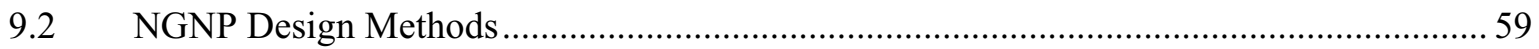

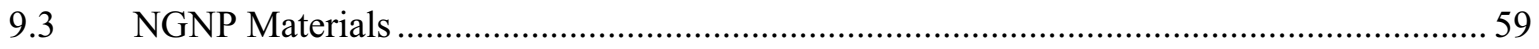

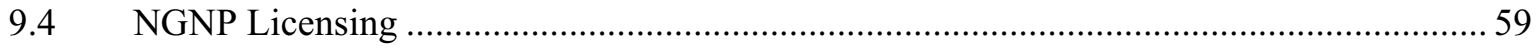

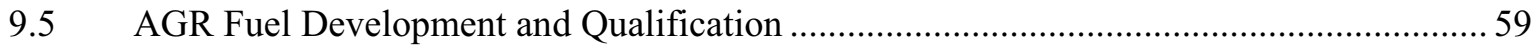

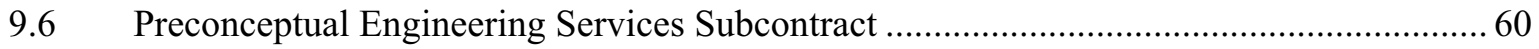

\section{Figures}

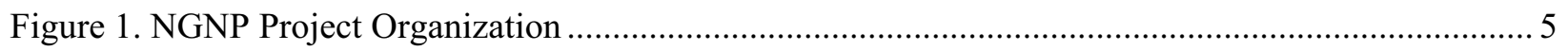

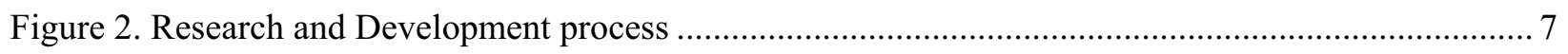

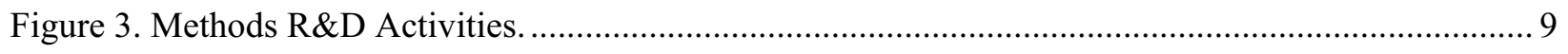

Figure 4. Experimental hardware: model of slice of lower plenum showing support columns and flow

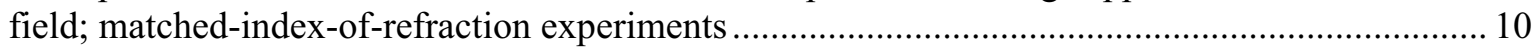

Figure 5. Typical velocity data, in x-direction, for MIR experiment recorded by particle tracking velocimeter.

Figure 6. Upper plenum model design under consideration for future experimental studies ................... 12

Figure 7. Lower plenum model design under consideration for future experimental studies.................... 13

Figure 8. Contours of turbulence intensity in the lower plenum showing a plan view of flow toward the

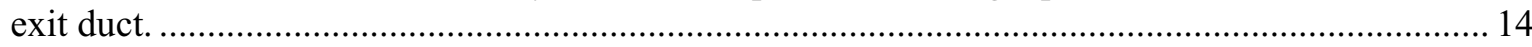

Figure 9. Geometry and grid used to investigate flow in a staggered tube bundle................................ 15 
Figure 10. Computations for the (a) mean velocity in the $\mathrm{x}$-direction and (b) the turbulent shear stress for $\mathrm{x}=0$ for steady and unsteady simulations.

Figure 11. Illustration of the flow region from the prismatic reference VHTR design lower plenum. ...... 16

Figure 12. Preliminary results for the velocity magnitude along the mid-plane of the model................... 16

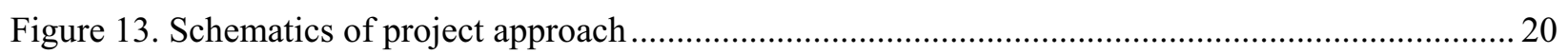

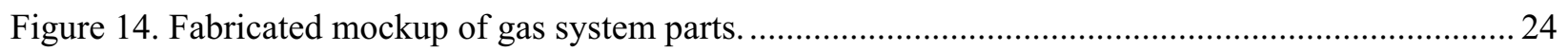

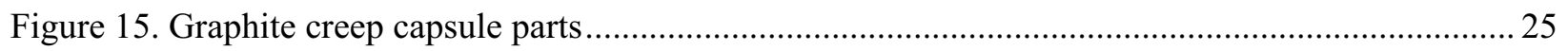

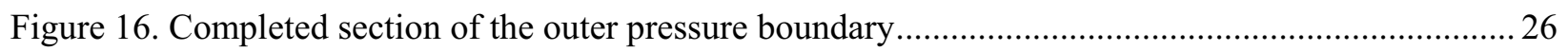

Figure 17. ATR machine shop performing developing the tooling to broach a single grove.................... 26

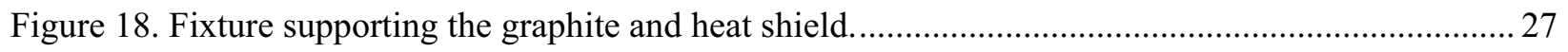

Figure 19. Three dimensional image of flux distribution in the ATR South flux trap.............................. 28

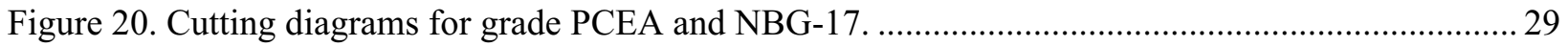

Figure 21. Arrangement of coupons in the INL furnace .................................................................. 30

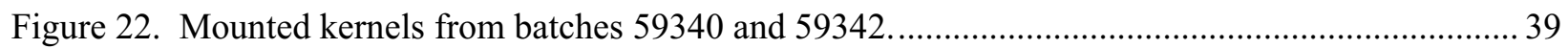

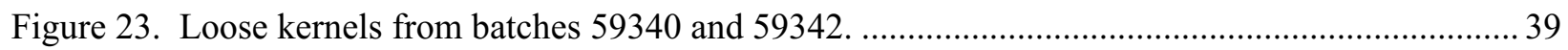

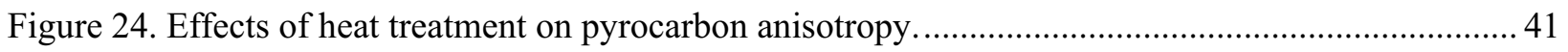

Figure 25. X-ray images of archive compacts from AGR-1 baseline compact lot LEU01-46T-Z............ 42

Figure 26. X-ray images of archive compacts from AGR-1 baseline compact lot LEU01-46T-Z............ 42

Figure 27. X-ray images of archive compacts from AGR-1 Variant 2 compact lot LEU01-48T-Z.......... 42

Figure 28. Expanded image of LEU01-46T-Z03 showing SiC coating layer........................................ 43

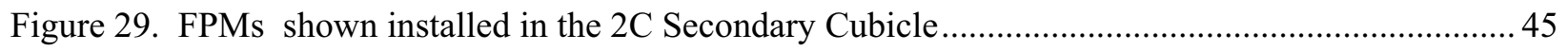

Figure 30. Single FPM showing the gross monitor (with shielding installed - located next to the tubing channel) and the spectrometer shield with the liquid nitrogen dewar. ........................................ 45

Figure 31. Filter Panel in the subpile corridor contains the filters and valving to redirect any capsule to

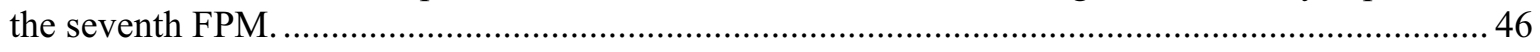

Figure 32. Distribution Panel in the subpile corridor - it contains the valving to obtain a grab sample from any capsule, and the zeolilte filter for the exhaust of all capsule gas lines prior to entering the ATR stack exhaust. 
Figure 33. Inside of FPM control cabinet showing the electronics supporting each of the seven FPMs. . 47

Figure 34. Straightness of the test train is checked after each weld joint. Adjustment is accomplished by striking an arc on the weld to "pull" the assembly back in line.

Figure 35 . The fueled portion of the test train has 13 welds and is straight to within $0.020 \mathrm{inch}$.

Figure 36. The next phase of the assembly is to install the pipe that will connect the test train to the reactor vessel wall.

Figure 37. The thermocouple connectors are assembled after the thermocouple wires and gas lines are

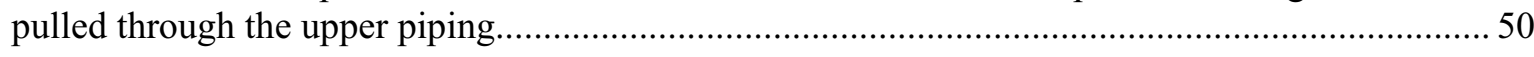

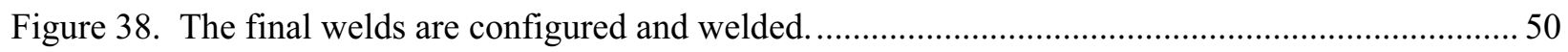

Figure 39. The gas lines are connected and the thermocouple connectors are hooked up before bolting the flange closed. The completed head has 14 gas line connections and 18 thermocouple connections.51

Figure 40. The test train is now ready for insertion in the reactor. ................................................... 51

Figure 41. Cs release from irradiation experiment FRJ2-K13, Capsule 2 ............................................ 53

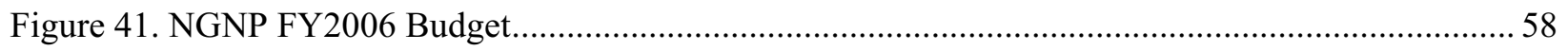

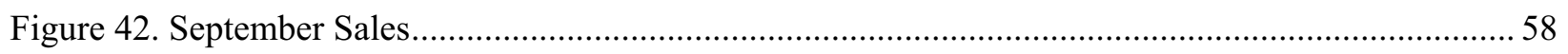

\section{Tables}

Table 1. Advanced Reactor Licensing Framework (10 CFR Part 53) .................................................. 33

Table 2. Customized 10 CFR Part 50 Approach.............................................................................. 33

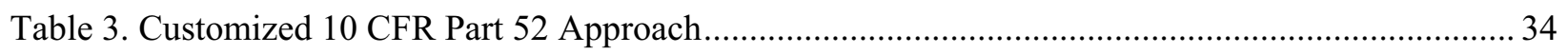

Table 4. Characterization results for initial four batches of kernels for coater scale up tests.................... 38

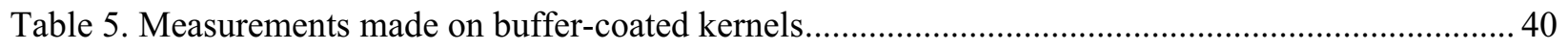


This page intentionally left blank. 


\section{FY 2006 Summary Highlights}

This report summarizes the work completed research during Fiscal Year 2006 for the Very High Temperature Reactor (VHTR) / Next Generation Nuclear Plant (NGNP) project and the results of the Advanced Gas Reactor Fuel Development and Qualification Program. Additional details can be found in the referenced reports, which are available on the Gen-IV web site:

http://comm.gen4forum.org/QuickPlace/core/Main.nsf/h_Toc/4df38292d748069d0525670800167212/?O penDocument

Fiscal Year 2006 NGNP monthly reports are stored under "Documents/NGNP/FY06 NGNP Milestones and Deliverables." The reports are organized by Milestone ID, but can be sorted by "Due Date," "Date Issued," "Title," and "Author."

\subsection{NGNP Project Management}

- Established a project structure better suited to respond to the anticipated needs of NGNP in 2007 and beyond.

- Established a set of Technical and Functional Requirements that will serve as the bases for the Conceptual Design phase.

- A Corrective Action Plan in response to a Quality Assurance Audit was developed and submitted to DOE for concurrence.

\section{$1.2 \quad$ NGNP Design Methods}

- Between March 2006 and August 2006, a number of interactions took place between the NGNP Methods Program personnel and both the vendors and the thermal gas-cooled reactor community to discuss the direction being taken in the methods research and development planning. It was determined that all of the "gaps" and "issues and inadequacies" identified by the interactions are being addressed either directly by formulating the practices and procedures to be used for planned verification and validation or are planned to be implemented at some stage in the NGNP Methods R\&D Program.

- Planning and design work was completed to study experimental modeling of flow and thermal mixing phenomena of importance during normal or reduced power operation and during a loss of forced reactor cooling (pressurized conduction cooldown) scenario.

- Enhancements have been made to the REBUS-3/DIF3D code suite to facilitate its use for the design and analysis of prismatic VHTRs.

\subsection{NGNP Materials}

- Completed all Level 2 milestones and deliverables.

- Completed initial AGC-1 specimen characterization. 
- Completed mock up testing of the AGC-1 hardware, including fabrication of the pressure boundary and graphite body, test welding of the heat shield material, and assembly of an operational set up.

- Completed 5000 hours of in-air aging tests of Alloy 617 at 800 and $1000 \mathrm{C}$.

- Completed 500 hours of automated control in the low velocity helium loop.

- Completed initial off-normal heat treatment and welding for Grade 91 steels.

\subsection{NGNP Licensing}

- Choice of NRC Regulations - Analysis of the current NRC reactor licensing structures continues to support the position that the 10 CFR Part 50 licensing process will allow the NGNP project to start facility construction sooner than if 10 CFR Part 52 were used. However, if design development time can be significantly reduced, then use of 10 CFR Part 52 may be considered.

- Scheduling Analysis - A comparative analysis looking at the effects of different variables on licensing timetables was requested by DOE-NE. This work is underway.

- Site Characterization - A large number of site characterization that were developed by the New Production Reactor (NPR) project (in 1980s) still exist. If usable, these records could save large amounts of funding and time. We are in the process of determining the location and condition of these documents.

\subsection{AGR Fuel Development and Qualification}

- Assembly of the AGR-1 test train was completed; installation of the gas control system was completed; and, installation of the fission product monitors was completed.

- The final AGR-1 fuel data package and Source Inspection 5 Report was completed.

- Engineering Design Files (EDFs) for each thermal analysis were completed to support the AGR-1 Experiment Safety Assurance Package (ESAP) review process.

- The AGR-1 Experiment Safety Analysis Plan (ESAP) was completed and approved by the INL Safety and Operational Review Committee (SORC).

- Operating procedures and test train drawings were completed and utilized to train ATR operators on the AGR-1 experiment.

- The fission product monitors and gas control system were installed in the ATR 2C Secondary Cubicle and system operation testing was initiated. The final testing will be completed during the next ATR outage after the experiment has been installed and flow can be established through all of the experiment capsules.

- A Progress Report on FBCVD Process Modeling for the Advanced Gas Reactor Fuel Development and Qualification Program-Computer Simulation of TRISO Fuel Particle Coating, Rev. 0 was issued (ORNL/CF-06/06). 
- DOE-NE QA completed an audit of the ORNL program the week of September 18. The audit team identified two notable practices, six observations, and four findings with one finding remedied prior to the conclusion of the audit.

- Review comments on EDF-7202, Test Plan for Validation of AGR 6-inch Diameter Coater Design, were resolved and the test plan was issued.

- Phase 2 kernel fabrication development tests were completed. The Phase 2 development tests showed that good quality kernels could be produced over a wide range of broth parameters, and that the "ideal broth zone" established for UO2 kernel formation was also valid for UCO kernel formation.

- The BWXT particle characterization assessment was issued.

- Revisions to the AGR-3 and AGR-4 Fuel Specification and the AGR-3 \& -4 Sampling Plan were issued.

- Revision 1 of EDF-6666 Six-inch TRISO Fuel Coater Design for AGR-2 was issued to update and expand the appendices containing drawings of the coater crucibles planned to be tested.

- A revision to the coater crucible design was issued.

- A “TRISO Particle Fabrication for AGR-3 and AGR-4” report was issued.

- Fabrication of the 425- $\mu \mathrm{m}$ natural uranium UCO kernels for coater tests was initiated.

- A “Coater Scale-up Support Activities" report was issued.

\subsection{Preconceptual Engineering Services Subcontract}

- On March 13, 2006, work began to prepare the Statement of Work for the Preconceptual Engineering Services Subcontract. On June 22, 2006 an Expression of Interest (EOI) was issued to industry with a response date of July 14, 2006. Ten national and international companies/teams responded. Of these ten companies/teams, six were qualified to receive the Request For Proposals (RFP). The RFP was issued on July 26, 2006 to the six qualified companies with two companies opting out. Four proposals were received on August 21, 2006. These technical proposals were evaluated and oral presentations were completed and 3 teams were determined to be qualified. A subcontract award to Westinghouse Electric Company team was made on September 28, 2006. Letters of Intent to award subsequent subcontracts to the AREVA team and General Atomics team were also sent out. The subcontract award and Letters of Intent achieved the BEA NGNP Project $\$ 350,000$ PEMP milestone that was due by September 30, 2006.

- Currently the NGNP project has initiated the Westinghouse Electric Company subcontract with a notice to proceed working to award the two subsequent subcontracts to AREVA and General Atomics.

- October 11th Addendum \#3 was issued to AREVA and General Atomics requesting a reduced Statement of Work and associated work plan focused on their team's strengths. 
- October 18th NGNP engineering met at Cambridge Massachusetts with the Westinghouse design team and approved their work plan and gave them the "notice to proceed".

- October 20th AREVA submitted the first draft of a modified work plan and negotiations began toward a mid November award. On October 31 a teleconference is scheduled to finalize the work plan and associated costs and statement of work.

- General Atomics is working to submit a draft of their estimate of the reduced statement of work and associated work plan on November 3rd. 


\section{Significant Accomplishments - Program Management}

During the months of August and September 2006, a great deal of effort was paid to setting up a project structure better suited to respond to the anticipated needs of NGNP in 2007 and beyond. Likely, the long-term project financial viability was evaluated, and it was recognized that early involvement of system vendors and end-users was essential to make the transition from a research program to a project. The necessity of an integrated approach to the science and engineering accomplishments was also realized, resulting in one of the deliverables established for FY-07: A set of Technical and Functional Requirements by the fourth quarter, which will serve as the bases for the Conceptual Design phase, envisioned for FY-08. Figure 1 illustrates the new NGNP project organization; related R2A2s can be found in the Project Library on the NGNP QuickPlace at http://team.inel.gov/QuickPlace/ngnp/Main.nsf/h_Library/505538F1EB2B9DBF0525670800167214/?Op enDocument\&Form=h_PageUI\&StartAtFirstPage.

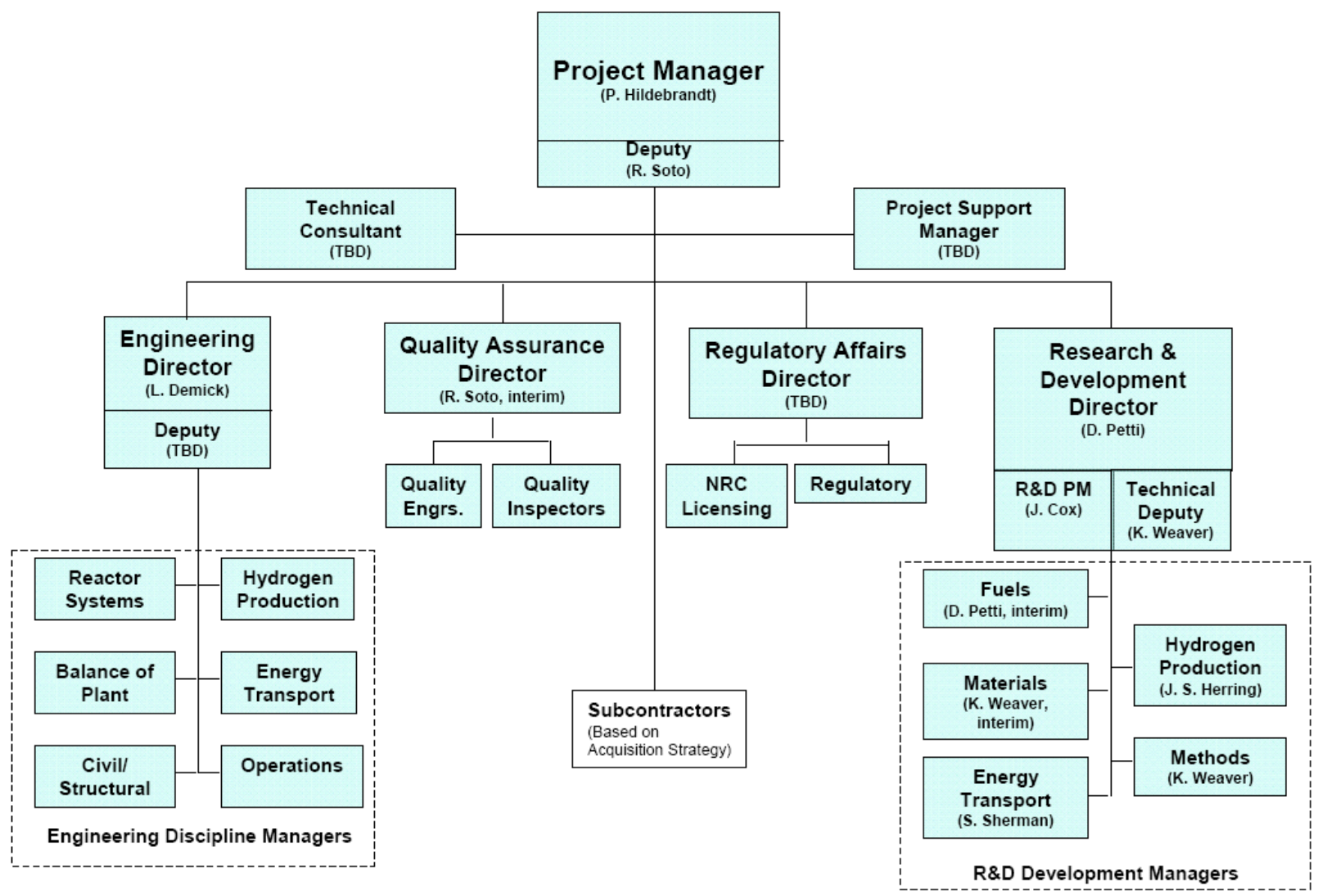

Figure 1. NGNP Project Organization

The response to a Quality Assurance Audit performed by DOE took significant resources, NGNP and INL in general, since it pointed to potential deficiencies in several areas deemed important to the success of the project, although their relevance for future activities was greater than for the current project stage. A Corrective Action Plan was developed and submitted to DOE for concurrence. 


\section{Significant Accomplishments - NGNP Design Methods}

The NGNP Methods work accomplished during Fiscal Year 2006 (FY-06) was centered in four distinct areas: planning, thermal-fluids behavior, reactor physics and nuclear data. The work accomplished in each of these areas is summarized below.

\subsection{Methods Technical Program}

One of the great challenges of designing and licensing the Very High Temperature Reactor (VHTR) is to confirm that the intended VHTR analysis tools can be used confidently to make decisions, and to assure all that the reactor systems are safe and meet the performance objectives of the Generation IV (Gen-IV) Program. The research and development (R\&D) projects defined in the Next Generation Nuclear Plant (NGNP) Design Methods Development and Validation Program will ensure that the tools used to perform the required calculations and analyses can be trusted. The Methods R\&D tasks are designed to ensure that the calculational envelope of the tools used to analyze the VHTR reactor systems encompasses, or is larger than, the operational and transient envelope of the VHTR itself.

The Methods R\&D focuses on the development of tools to assess the neutronic and thermal fluid behavior of the plant. The fuel behavior and fission product transport models are discussed in the Advanced Gas Reactor (AGR) program plan. Various stress analysis and mechanical design tools will also need to be developed and validated, and will ultimately also be included in the Methods R\&D Program Plan.

The calculational envelope of the neutronics and thermal-fluids software tools intended to be used on the NGNP is defined by the scenarios and phenomena that these tools can calculate with confidence. The software tools can only be used confidently when the results they produce have been shown to be in reasonable agreementa with first-principle results, thought-problems, and data that describe the "highly ranked" phenomena inherent in all operational conditions and important accident scenarios for the VHTR.

The R\&D process itself is outlined in Figure 2. The requirements associated with scenario identification, defining the phenomena identification and ranking tables (PIRT), completing the required development, and performing the necessary validation studies must all be completed prior to performing the required analyses confidently.

Presently, the status of the methods to be used for analyzing the VHTR is as follows:

- The current software and methods are not ready to perform design and analysis to the Gen-IV standards that will be required by the NGNP. Considerable validation, and probably development, of the necessary software tools are required.

- The above conclusion also applies to present software capabilities to perform NGNP licensing calculations to achieve Gen-IV system objectives.

- The practices and procedures acceptable for both validating and developing the necessary software tools for the NGNP must be defined and implemented to the satisfaction of the community.

\footnotetext{
${ }^{a}$ Reasonable agreement is achieved when the calculation generally lies within the uncertainty band of the data used for validation and always shows the same trends as the data. Code deficiencies are minor.
} 
Scenario Identification: Operational and accident scenarios that require analysis are identified

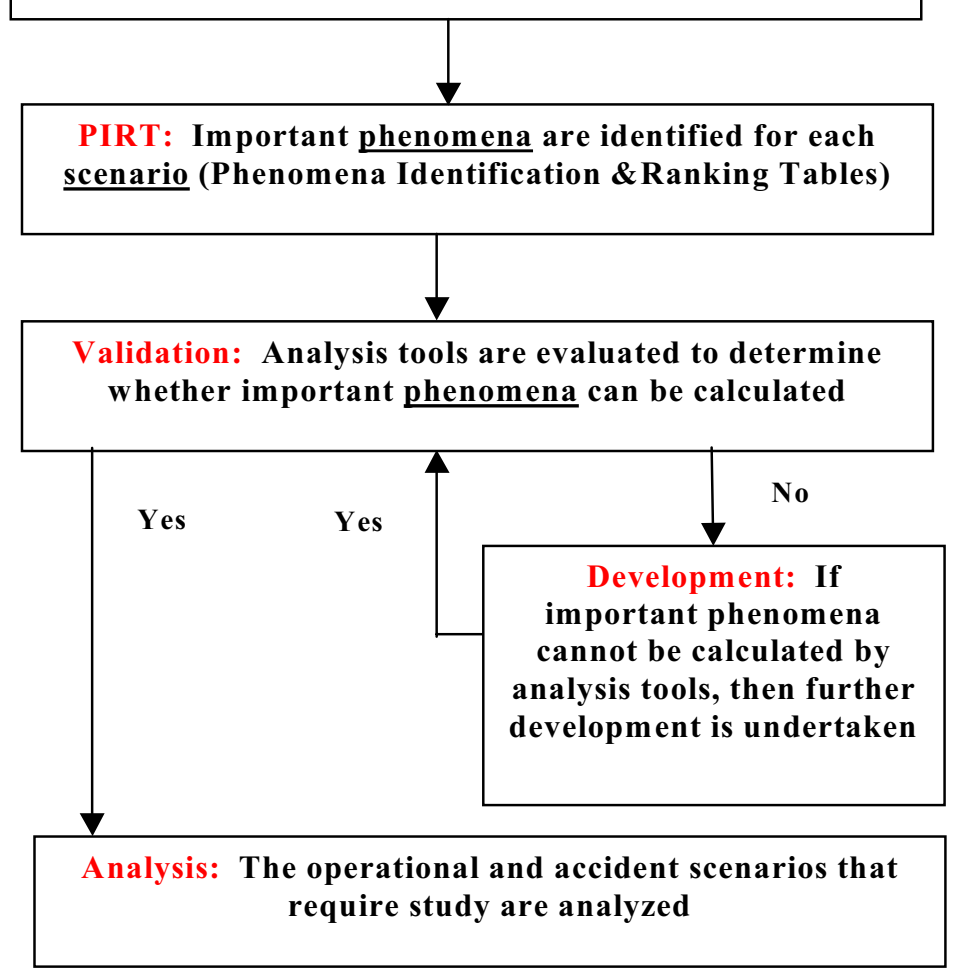

Figure 2. Research and Development process

These conclusions are true because: (a) the key phenomena for the most challenging scenarios that must be analyzed for the to-be-selected VHTR have not been identified yet, (b) software tools that have a low calculational uncertainty will be required to analyze the behavior of the VHTR to enable the plant to operate at a high efficiency with a competitive economic margin, and (c) most of the software tools that will be used have not been validated for the scenarios and phenomena that must be analyzed. For example, although systems analysis software has been validated for selected cases, a full validation has not been performed, nor are the data available that will enable a full validation to be performed. Also, computational fluid dynamics (CFD) software, which will be widely used to analyze the VHTR behavior, has never been used in large measure to perform auditing, design, or licensing calculations for a nuclear plant.

The VHTR design has not yet been selected. Consequently, the R\&D process is focused on scenarios and "highly ranked" phenomena that have already been identified as important by the advanced gas-cooled reactor community for the designs being considered as candidates for the VHTR. This approach has resulted in a VHTR-specific Phenomena Identification and Ranking Table (PIRT) from which the methods R\&D is being defined using the following assumptions:

- The selected VHTR design could be either a pebble-bed or a block-type reactor.

- The calculational and experimental needs, and consequently the required $\mathrm{R} \& \mathrm{D}$, are focused in eight distinct areas based on the relative state of the software in each. The areas are: 
(i) Basic differential and integral nuclear cross-section data measurement and evaluation, including mathematically rigorous sensitivity studies of the effects of uncertainties in the differential nuclear data and other independent design variables on key integral reactor properties (the task of characterizing the effects of the nuclear fuel, fission products, moderator, and other relevant materials on the system reactivity, neutron flux distribution, and power production)

(ii) Reactor assembly cross-section preparation (the task of translating the fundamental data characterized in area (i) into formats and states useful for analysis)

(iii) Discrete ordinates transport (the process of approximating the neutron flux in a tractable manner for analysis)

(iv) Nodal diffusion (calculation of the energy and spatial flux profiles, reaction rates, reactivity changes, etc.)

(v) Reactor kinetics (calculation of spatial changes in flux and power level as functions of time during postulated transients)

(vi) Thermal-fluids (the models that describe the fluid behavior and heat transfer behavior during steady-state and transient conditions for the scenarios of interest)

(vii) Fuel behavior

(viii) Fission product transport (determination of fission product movement once fission products have escaped from the confines of the fuel).

The Methods R\&D is tailored to follow the guidance and timelines defined by the Energy Policy Act of 2005. That is, between now and perhaps until 2011, Methods R\&D will be performed to enable analyses to be performed that can characterize the behavior of the candidate VHTR designs. The period beginning from the passage of the Energy Policy Act until the design is selected is Phase 1. Phase 2 will begin when Phase 1 is completed. During Phase 2, validation of the software tools will be completed using data directly scaled to the NGNP design. The operational, off-normal, and accident behavior of the design will be analyzed.

The commercial companies (for example Areva, Ltd and PBMR, Pty) that are currently designing the future gas-cooled reactors are still, in large measure, using legacy analysis tools to describe the operating and accident characteristics of their designs, and they intend to use them for licensing purposes. Recent visits by NGNP Program Methods personnel to the headquarters of Areva, Ltd and PBMR, Pty have allowed important interactions between the commercial researchers and the national laboratory researchers to occur. The outcome of these interactions has clarified that the R\&D ongoing at the national laboratories is on track to produce high-quality NGNP design and evaluation methods that are independent of the commercial companies, and are in keeping with Gen-IV system objectives. These tools will be available for use by the U.S. Department of Energy (DOE) and the U.S. Nuclear Regulatory Commission (NRC). In addition, these software tools may also be used by the vendors via agreements with the DOE.

Between March 2006 and August 2006, a number of interactions have taken place between the NGNP Methods Program personnel and both the vendors and the thermal gas-cooled reactor community. In general, the findings were the same in all of these meetings. The NGNP Design Methods Workshop 
was convened in Salt Lake City, Utah, on August 22 and 23, 2006 to discuss the direction being taken in the methods research and development planning. The audience was composed of technical staff from the NRC, three national laboratories, two vendors, a consulting firm, and three universities. The experts from these organizations were about equally divided between the reactor physics and thermal fluids areas.

The Workshop was convened to review the R\&D activities presently ongoing in the NGNP Design and Evaluation Methods Development Program as well as the future plans of the program. The discussion centered on whether any "gaps" between the NGNP methods needs and the present research and development tasks/plans exist. If gaps were identified, the workshop would then focus on how the gaps would be eliminated.

During the Workshop, it was determined that presently all of the "gaps" and "issues and inadequacies" identified by the Workshop participants are being addressed either directly by formulating the practices and procedures that are to be used for planned verification and validation or are planned to be implemented at some stage in the NGNP Methods R\&D Program.

In general, the activities associated with Methods $R \& D$ are divided into 5 distinct areas (as shown in Figure 3): (1) PIRT, (2) nuclear data R\&D, (3) neutronics methods validation R\&D, (4) thermal-fluids methods validation R\&D, and (5) analysis and evaluation.

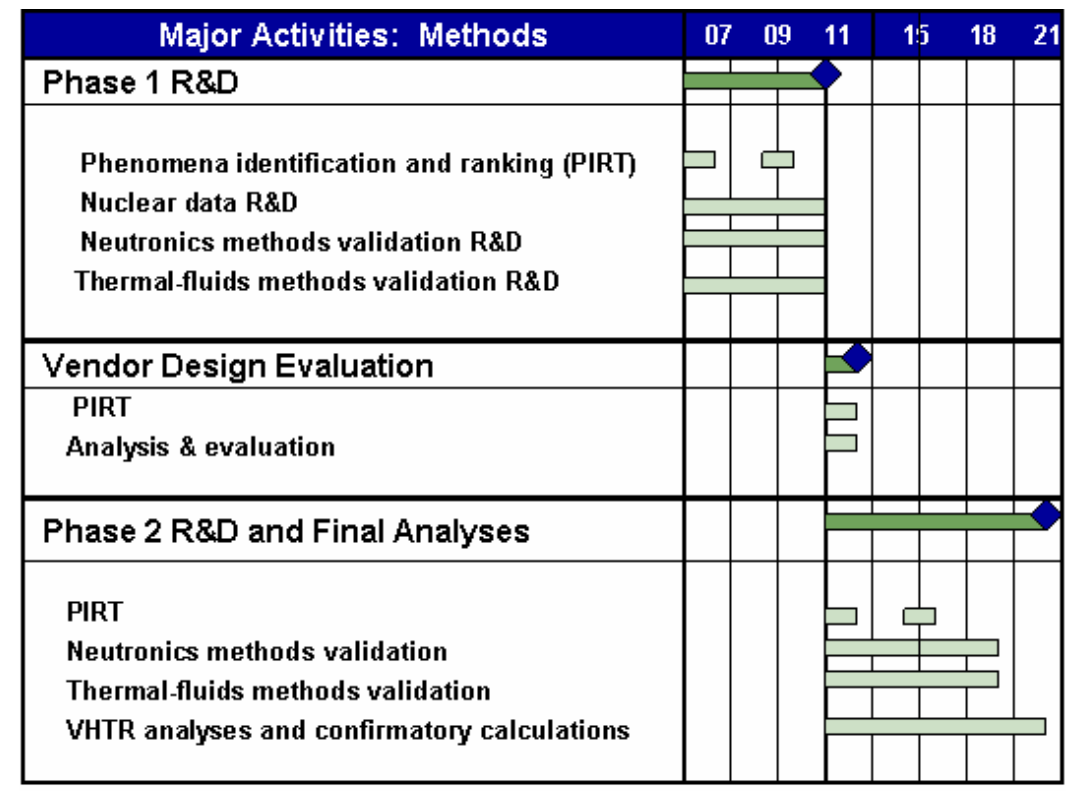

Task completion

Figure 3. Methods R\&D Activities.

For FY-07 and 08, the highest-priority R\&D is aimed at: properly calculating the thermal-fluid conditions in the lower plenum during normal operation, developing and validating neutronics techniques that are necessary for analyzing both prismatic and pebble-bed reactors, and analyzing the behavior of the plant during depressurized conduction cooldown (DCC) and pressurized conduction cooldown (PCC) accident scenarios. 
Subsequent years will sharpen the focus in these and other areas that require analyses with low uncertainties for the most challenging scenarios identified by the PIRTs. The PIRTs form the heart of the Methods R\&D effort in that the R\&D needs are both identified and prioritized. Hence, the PIRTs used to govern the R\&D needs will be updated throughout the cycle leading to the construction of the VHTR at the INL.

\subsection{Thermal Fluids Behavior}

Work accomplished in six areas (thermal-fluids experiments, thermal-fluids experimental planning, computational fluid dynamics (CFD) validation studies, CFD practices and procedures, air ingress studies, and systems analysis code development) is summarized in the following paragraphs.

\subsubsection{Particle Image Velocimetry Experiments to Measure Flow Phenomena in a Scaled Model of a VHTR Lower Plenum}

A report of experimental data collected at the Matched-Index-of-Refraction (MIR) Laboratory for the INL Standard Problem on measurements of flow phenomena occurring in a lower plenum of a typical prismatic VHTR concept reactor to assess CFD code is described (see Figure 4). Background on the experimental setup and procedures is provided along with several samples of data obtained from the 3-D PIV system, and an assessment of experimental uncertainty is provided. Data collected in this study include 3-dimensional velocity-field descriptions of the flow in all four inlet jets and the entire lower plenum with inlet jet Reynolds numbers (ReJet) of approximately 4300 and 12,400. These investigations have generated over 2 terabytes of data that has been processed to describe the various velocity components in formats suitable for external release and archived on removable hard disks. The processed data from both experimental studies is available in multi-column text format.

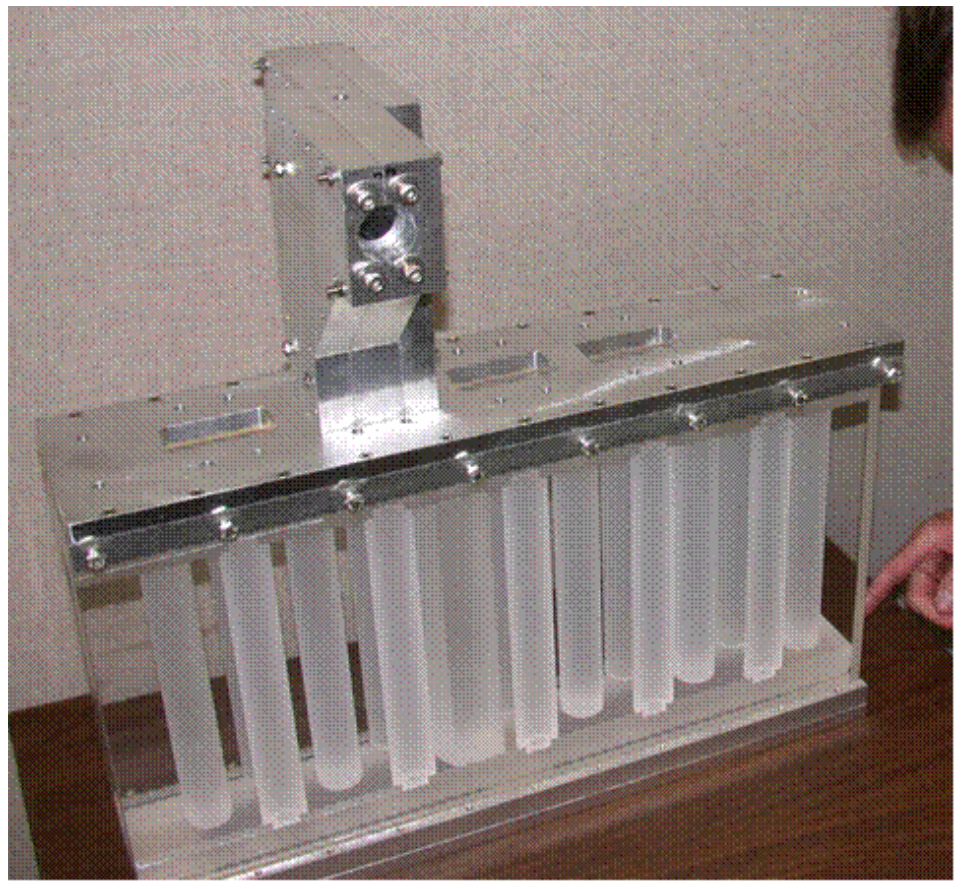

Figure 4. Experimental hardware: model of slice of lower plenum showing support columns and flow field; matched-index-of-refraction experiments 
The model design and flow facility produced satisfactory flow conditions as required by previous scaling studies and model design. As a result of the experiments described in this report, the objectives of developing benchmark databases for the assessment of CFD solutions of the momentum equations, scalar mixing and turbulence models for typical prismatic VHTR plenum geometries in the limiting case of negligible buoyancy and constant fluid properties have been met. Additionally, the data obtained from these experiments meets the requirements of a standard problem.

Preliminary measurements of velocity components have been compiled for a low-power case of ReJet $\sim 4300$, and detailed measurements of the flow filed for the maximum achievable flow rate in the present MIR Flow facility of ReJet $\sim 12400$ have also been completed (see Figure 5). The data have been documented to identify and report uncertainty of the measurements and collected into various formats suitable for release to the CFD community and others as necessary.

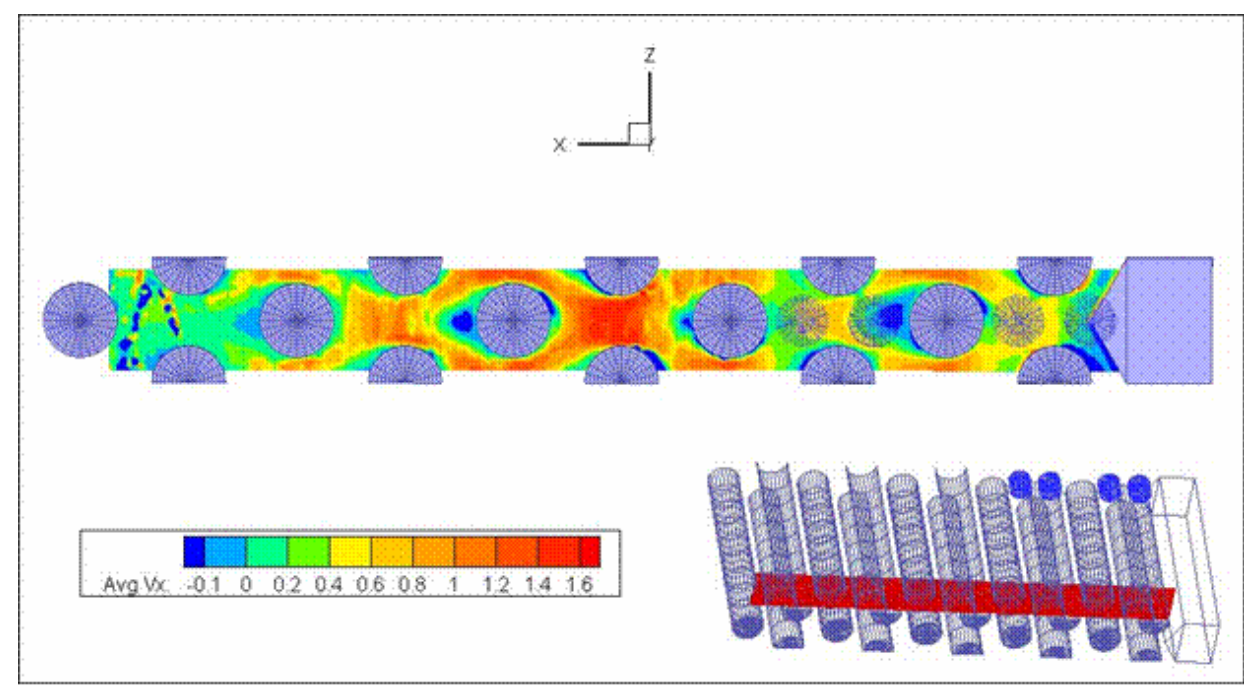

Figure 5. Typical velocity data, in x-direction, for MIR experiment recorded by particle tracking velocimeter.

\subsubsection{Experimental Modeling of VHTR Plenum Flows during Normal Operation and Pressurized Conduction Cooldown}

Planning and design work was completed to study experimental modeling of flow and thermal mixing phenomena of importance during normal or reduced power operation and during a loss of forced reactor cooling (pressurized conduction cooldown) scenario. The objectives of the experiments are, (1), provide benchmark data for assessment and improvement of codes proposed for NGNP designs and safety studies, and, (2), obtain a better understanding of related phenomena, behavior and needs.

Physical models of VHTR vessel upper and lower plenums which use various working fluids to scale phenomena of interest are presented and the recommended water-flow models are described in more detail. The models may be used to both simulate natural convection conditions during pressurized conduction cooldown and turbulent lower plenum flow during normal or reduced power operation. Benchmark data that will be provided by the experiments are:

- Lower plenum temperature distribution during turbulent forced convection (the "hot streaking" or "thermal striping" problem). 
- Lower plenum velocity and temperature fields during the decay heat period of a pressurized conduction cooldown (laminar natural circulation flows).

- Upper plenum velocity and temperature fields during a pressurized conduction-cooldown (laminar natural circulation flows).

Typical upper and lower plenum experimental models presently being considered are shown in Figures 6 and 7.

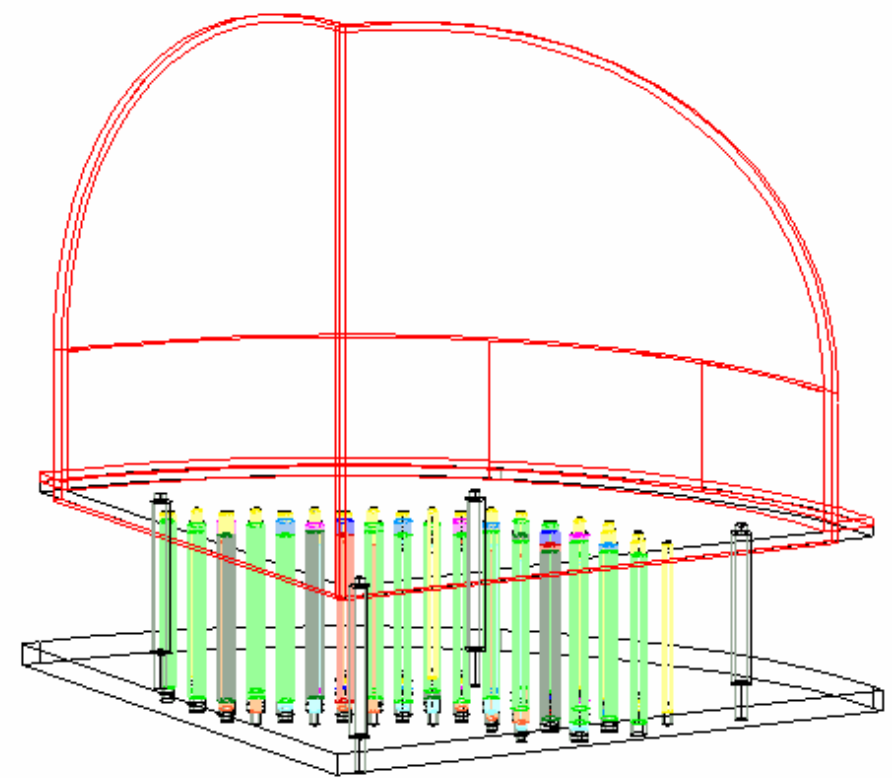

Figure 6. Upper plenum model design under consideration for future experimental studies 


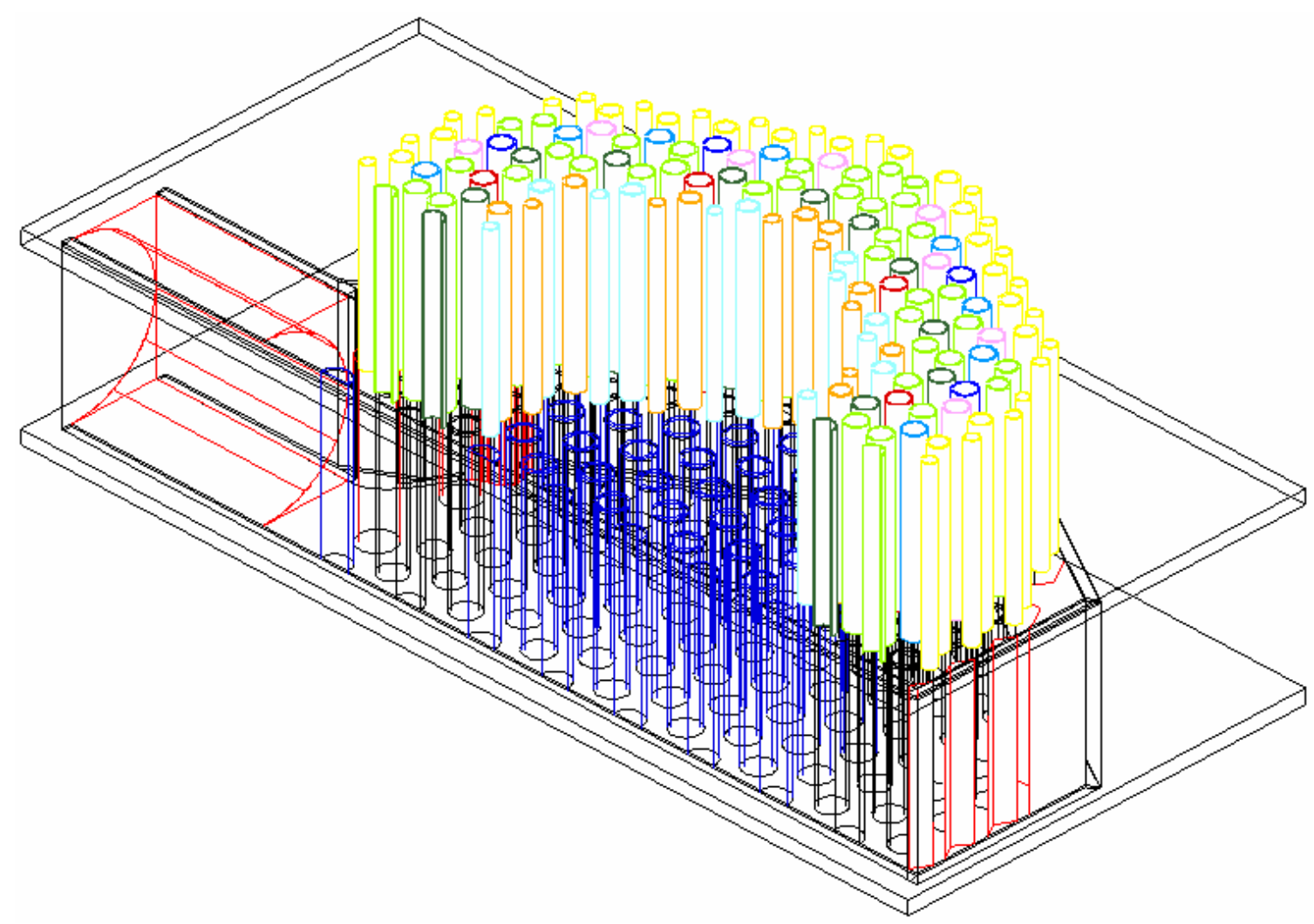

Figure 7. Lower plenum model design under consideration for future experimental studies

\subsubsection{NSTF Facilities Plan for Water-Cooled VHTR RCCS: Normal Operational Mode}

Engineering plans are outlined for mechanical and instrumentation modifications to the Natural convection Shutdown Test Facility (NSTF) to ensure that sufficiently detailed temperature, heat flux, velocity and turbulence profiles are obtained to adequately qualify the software for the expected operational Reactor Cavity Cooling System (RCCS) ranges. The supporting scaling and scoping cavity analysis activities for the RCCS carried out in parallel with this experiment planning task, in addition to results available in the open literature, indicate that: (a) strong 3-D effects results in large heat flux, temperature, and heat transfer variations around the standpipe wall; (b) there are large differences in the heat transfer coefficients predicted by turbulence models and heat transfer correlations, and this underscores the need of experimental work to validate the thermal performance of the RCCS; (c) there are complicated two - phase flow issues (i.e., steam flashing in the upper regions of the test section, and the possibility of nucleate boiling in the heated section ) that complicate the system analysis; and (d) scaled tests at the NSTF would embody all important fluid flow and heat transfer phenomena in the RCCS, in addition to covering the entire parameter ranges that characterize these phenomena.

\subsubsection{Investigations of the Applications of CFD to Flow Expected in the Lower Plenum of the Prismatic VHTR}

The VHTR will either be a prismatic (block) or pebble bed design. However, a prismatic VHTR reference design, based on the General Atomics Gas Turbine-Modular Helium Reactor has been developed for preliminary analysis purposes. Numerical simulation studies reported herein are based on this reference design. In the lower plenum of the prismatic reference design, the flow will be introduced 
by dozens of turbulent jets from the core above. The jet flow will encounter rows of columns that support the core. The flow from the core will have to turn ninety degrees and flow toward the exit duct as it passed through the forest of support columns. Due to the radial variation of the power density in the core, the jets will be at various temperatures at the inlet to the lower plenum. This presents some concerns, including that local hot spots may occur in the lower plenum. This may have a deleterious effect on the materials present as well as cause a variation in temperature to be present as the flow enters the power conversion system machinery, which could cause problems with the operation of the machinery.

In the past, systems analysis codes have been used to model flow in nuclear reactor systems. It is recognized, however, that such codes are not capable of modeling the local physics of the flow to be able to analyze for local mixing and temperature variations. This has led to the determination to use CFD codes that are generally regarded as having the capability of accurately simulating local flow physics. Accurate flow modeling involves determining appropriate modeling strategies needed to obtain accurate analyses. These include determining the fineness of the grid needed, the required iterative convergence tolerance, which numerical discretization method to use, and which turbulence model and wall treatment should be employed. It also involves validating the computer code and turbulence model against a series of separate and combined flow phenomena and selecting the data used for the validation. The report CFD software validation of jets in crossflow describes progress made to identify proper modeling strategies for simulating the lower plenum flow for the task which was designed to investigate the issues pertaining to the validation process.

The flow phenomenon previously chosen to investigate is flow in a staggered tube bank because it is shown by preliminary simulations to be the location of the highest turbulence intensity in the lower plenum. Figure 8 shows preliminary computations of flow in the lower plenum and the exit hot duct, colored by turbulence intensity from a plan view. The commercial CFD code FLUENT ${ }^{\circledR}$ was used to make the simulations.

The flow geometry for flow in tube banks for which there are experimental data is displayed in the next figure. The flow entering at the left is set to the same values as the flow exiting at the right. The same is true for the top and bottom.

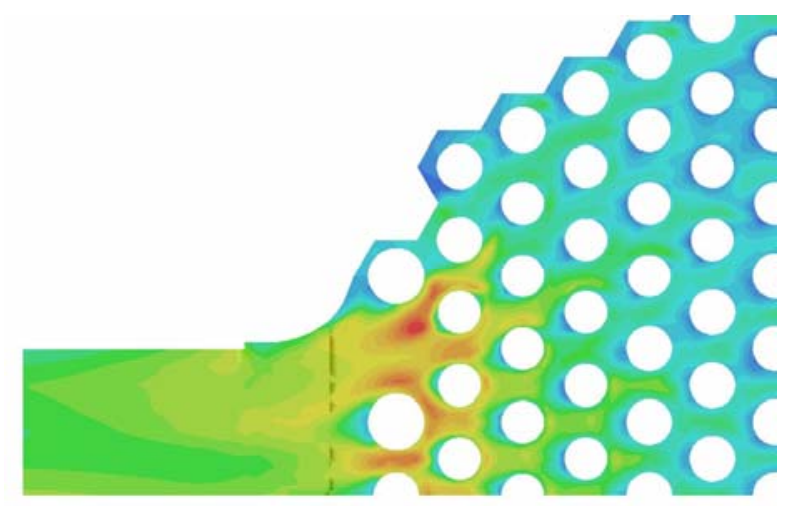

Figure 8. Contours of turbulence intensity in the lower plenum showing a plan view of flow toward the exit duct.

Numerical simulations were previously obtained assuming that the flow shown in Figure 9 is steady. Various turbulence models were employed along with strategies to reduce numerical error to allow appropriate comparisons of the results. It was determined that the sophisticated Reynolds stress model (RSM) provided the best results. It was later determined that the flow is an unsteady flow wherein 
circulating eddies grow behind the tube and 'peel off' alternately from the top and the bottom of the tube. Additional calculations show that the mean velocity is well predicted when the flow is modeled as an unsteady flow.

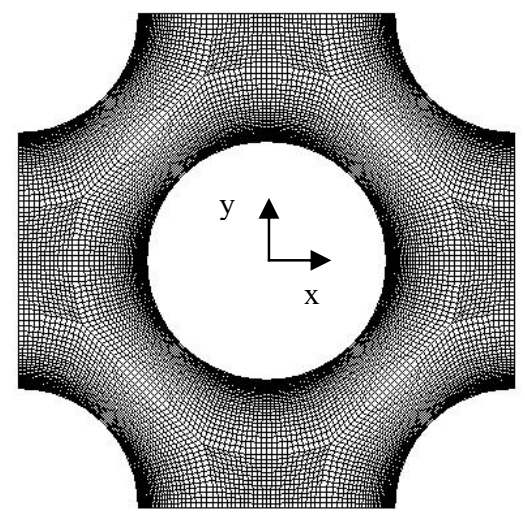

Figure 9. Geometry and grid used to investigate flow in a staggered tube bundle.

Figure 10 compares steady (red) results with unsteady (blue) results against experimental data (green symbols). The results for $U$ at the left are clearly superior for the unsteady computations; the unsteady computations for the turbulence stress on the right are similar to those for the steady calculations, showing the same trends. It is clear that strategies must be employed to reduce numerical errors before comparing simulation results to the data, and that the correct physics must be simulated to achieve reasonable agreement between simulations and experiment.

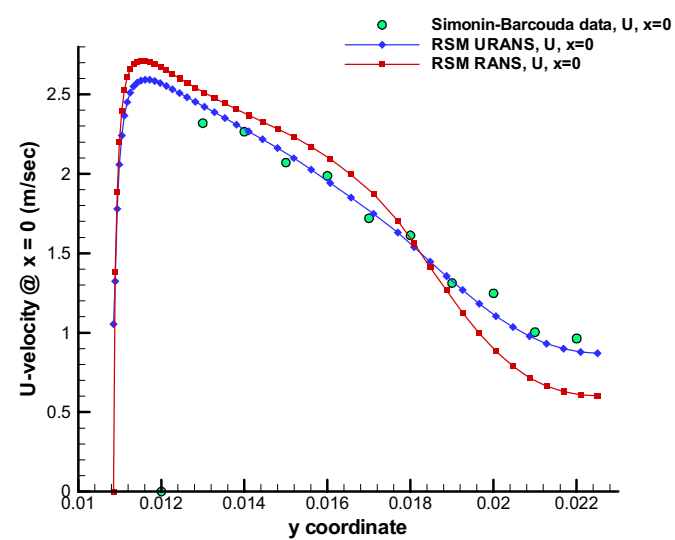

(a)

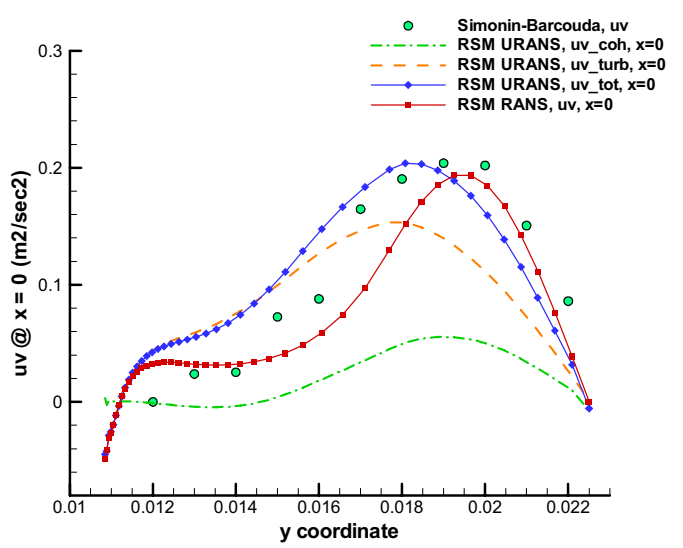

(b)

Figure 10. Computations for the (a) mean velocity in the x-direction and (b) the turbulent shear stress for $\mathrm{x}=0$ for steady and unsteady simulations.

In addition to the above numerical studies, this report (CFD software validation of jets in crossflow) details preliminary efforts to model a larger region of the lower plenum, consisting of an array of five cylindrical support posts and half-posts in a confined channel with flow entering through 4 inlet jets above the plenum. Figure 11 illustrates a model of the flow region. The 4 inlet jet ports on the top of the model are clearly visible; the flow exits the model to the right through an extended outlet. The progress to date for the CFD predictions of flow through a flow test model representing a section of the 
VHTR lower plenum is reported herein. Information obtained from these simulations will be used for the final CFD solutions and to guide experimentation. Experimental data obtained in the INL MatchedIndex-of-Refraction facility will comprise a benchmark to assess CFD models for applicability to analyze flow in the VHTR lower plenum. Two CFD codes, FLUENT ${ }^{\circledR}$ and NPHASE, were run for the identical geometry and inlet conditions. NPHASE employs a steady-state Reynolds-Averaged Mavier-Stokes (RANS) computation with a $\mathrm{k} \sim \varepsilon$ turbulence model. Unsteady RANS (URANS) computations with a $\mathrm{k} \sim \varepsilon$ turbulence model were run using FLUENT ${ }^{\circledR}$. The final set of experimental data was not available in time to be incorporated into the inlet profiles, so assumed data profiles were used. Once the final data is available, the methodology is in place to use actual test data. This report (CFD software validation of jets in crossflow) presents preliminary results from the CFD computations, including velocity, pressure, and turbulence quantities. Figure 12 shows preliminary results for the velocity magnitude along the midplane of the model. Analysis of results and recommendations for the experimental setup are also given.

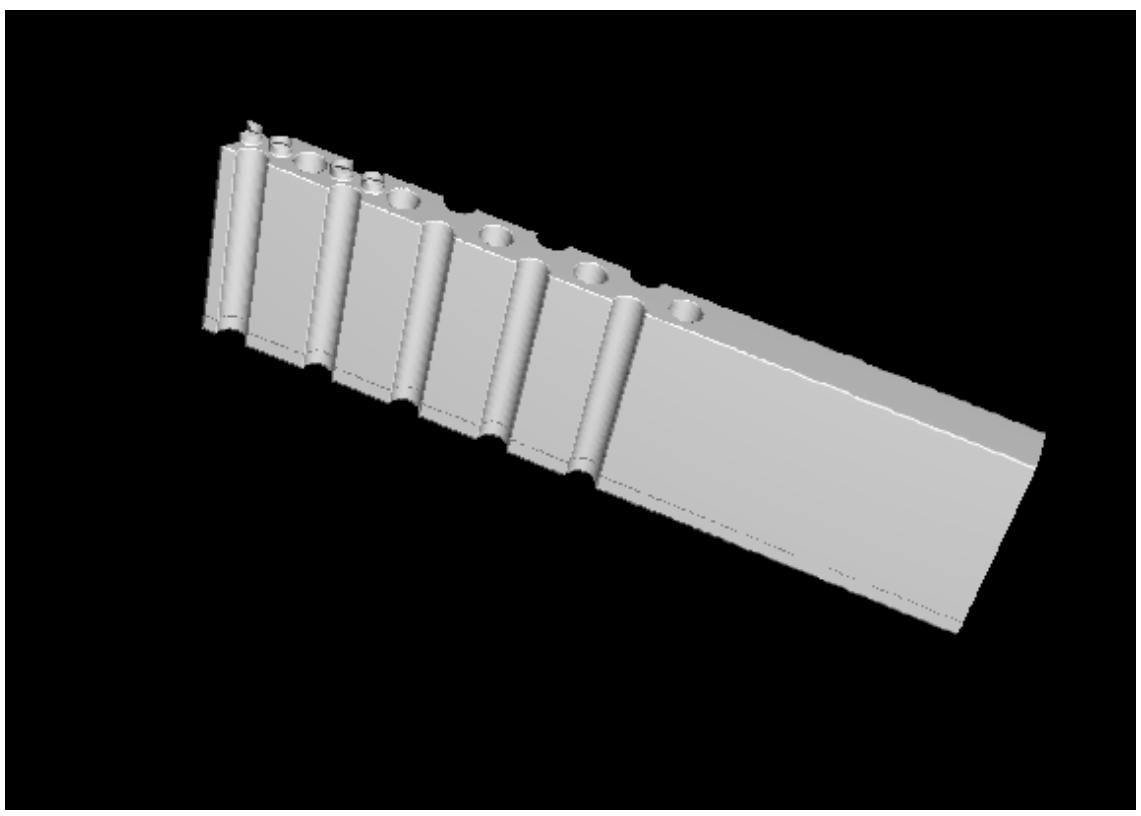

Figure 11. Illustration of the flow region from the prismatic reference VHTR design lower plenum.

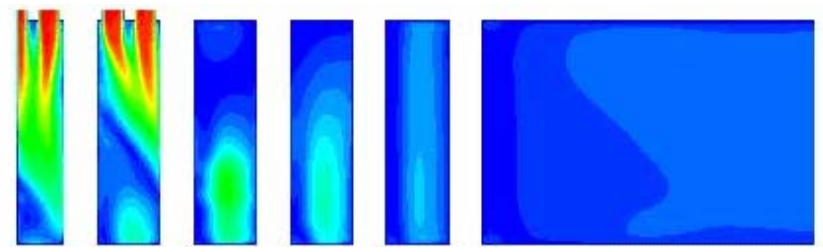

Figure 12. Preliminary results for the velocity magnitude along the mid-plane of the model.

\subsubsection{Practices and Procedures for Performing CFD Analyses}

Traditionally, nuclear reactor safety analysis has been performed using systems analysis codes such as RELAP5, which was developed at the INL. Goals established by the Gen-IV program, especially the desire to increase efficiency, has lead to an increase in operating temperatures for the reactors. This increase pushes reactor materials to operate towards their upper temperature limits relative to structural integrity. Because there will be some finite variation of the power density in the reactor core, there will 
be a potential for local hot spots to occur in the reactor vessel. Hence, it has become apparent that detailed analysis will be required to ensure that local 'hot spots' do not exceed safety limits. It is generally accepted CFD codes are intrinsically capable of simulating fluid dynamics and heat transport locally because they are based on 'first principles.' Indeed, CFD analysis has reached a fairly mature level of development, including the commercial level. However, CFD experts are aware that even though commercial codes are capable of simulating local fluid and thermal physics, great care must be taken in their application to avoid errors caused by such things as inappropriate grid meshing, low-order discretization schemes, lack of iterative convergence and inaccurate time-stepping. Just as important is the choice of a turbulence model for turbulent flow simulation. Turbulence models model the effects of turbulent transport of mass, momentum and energy, but are not necessarily applicable for wide ranges of flow types. Therefore, there is a well-recognized need to establish practices and procedures for the proper application of CFD to simulate flow physics accurately and establish the level of uncertainty of such computations.

The present document represents contributions of CFD experts on what the basic practices, procedures and guidelines should be to aid CFD analysts to obtain accurate estimates of the flow and energy transport as applied to nuclear reactor safety. However, it is expected that these practices and procedures will require updating from time to time as research and development affect them or replace them with better procedures. The practices and procedures are categorized into five groups. These are:

1. Code Verification

2. Code and Calculation Documentation

3. Reduction of Numerical Error

4. Quantification of Numerical Uncertainty (Calculation Verification)

5. Calculation Validation.

These five categories have been identified from procedures currently required of CFD simulations such as those required for publication of a paper in the ASME Journal of Fluids Engineering and from the literature. Code verification refers to the demonstration that the equations of fluid and energy transport have been correctly coded in the CFD code. Code and calculation documentation simply means that the equations and their discretizations, etc., and boundary and initial conditions used to pose the fluid flow problem are fully described in available documentation. Reduction of numerical error refers to practices and procedures to lower numerical errors to negligible or very low levels as is reasonably possible (such as avoiding use of first-order discretizations). The quantification of numerical uncertainty is also known as calculation verification. This means that estimates are made of numerical error to allow the characterization of the numerical results with a certain confidence level. Numerical error in this case does not include error due to models such as turbulence models. Calculation validation is the process of comparing simulation results to experimental data to demonstrate level of agreement. Validation does include the effects of modeling errors as well as numerical and experimental errors.

A key issue in the validation process of numerical results is the existence of appropriate experimental data to use for validation purposes. It has become apparent that much of the experimental database for fluid flows is not adequate or has large errors associated with it. It has been recognized that appropriate validation data sets must meet some minimal set of criteria, such as completeness and estimation of experimental uncertainty. Hence, the report CFD software validation of jets in crossflow 
includes a section on experimental accuracy and guidelines for future experiments that will provide suitable validation data for CFD calculations.

Finally, whether the numerical analysis achieves some acceptance level is not addressed in these practices and procedures. Acceptance level, in fact, is a management or regulatory body determination based on their needs and requirements. The present report represents the current thinking and recommendations of the several authors as well as experts cited from the literature. It is expected that improvements and/or updates based on future research and investigation will be made to the guidelines herein presented.

\subsubsection{Air Ingress Studies}

The VHTR is envisioned as a single- or dual-purpose reactor for electricity and hydrogen generation. The concept has average coolant temperatures above $900^{\circ} \mathrm{C}$ and operational fuel temperatures above $1250^{\circ} \mathrm{C}$. The concept provides the potential for increased energy conversion efficiency and for high-temperature process heat application in addition to power generation. However, the very high temperatures of this reactor concept can be detrimental to safety if a loss-of-coolant accident (LOCA) occurs. Following the loss of coolant through the break and coolant depressurization, air will enter the core through the break by molecular diffusion and ultimately by natural convection, leading to oxidation of the in-core graphite structure and fuel. The oxidation will accelerate heatup of the reactor core and the release of toxic gasses $\left(\mathrm{CO}\right.$ and $\left.\mathrm{CO}_{2}\right)$ and fission products.

Prior to the start of this project, a multi-dimensional multi-component mixture analysis code (GAMMA) has been developed for safety analysis of HTGR air-ingress by collaboration of Korean/U.S. In the real situation, graphite oxidation is affected not only by temperature, concentration and flow rate, but by the moisture, geometrical and burn-off effects that are neglected in the original oxidation model in the GAMMA code. Therefore, for more realistic and accurate prediction of air-ingress, those effects should be considered in the improved models of GAMMA.

The GAMMA code's Verification and Validation (V\&V) is performed using Ogawa's circular tube test, Japanese Inverse U-tube air ingress experiment, and HTTR-simulated air ingress experiment. The improved model showed better prediction than the original one for any validation tests because the improved GAMMA contains more advanced physical chemical models accounting for various important parameters such as geometry effects, moisture effects, and burn-off effects.

Plant simulations of GT-MHR and PBMR were preformed with the improved GAMMA. It turns out that most of chemical reaction occurs in the bottom reflector, and the effect of chemical models is most significant in this region. The improved GAMMA produces lower temperature in the bottom reflector than the original one, while the difference of the maximum temperature in the core between the improved and original GAMMA is very small.

Coupling between RELAP5-3D and GAMMA was developed in the PC-Windows environment. It consists of two major codes, RELAP5-3D Executive and GAMMA. The objectives of this work were to develop and improve the original chemical reaction model in the GAMMA code, especially the graphite oxidation model for more realistic prediction to simulate the air-ingress accident.

The work plan consisted of two major tasks:

- Task 1- Improvement of air ingress modeling in GAMMA code 
- Task 2- Coupling of RELAP 5 and GAMMA code

In Task 1, three chemical reactions in GAMMA-code were updated; (1) graphite oxidation, (2) Boudouard reaction and (3) CO combustion reaction. There are many factors that affect graphite oxidation: (1) temperature, (2) oxygen concentration, (3) air flow conditions, (4) moisture, (5) shape and size of graphite structure, (6) degree of burn-off. These effects are complicatedly mixed, and influence two main oxidation mechanisms: kinetics and mass diffusion. In the original GAMMA code, other important effects were ignored besides temperature, oxygen concentration and air flow effect. But, moisture, effect of shape, size and degree of burn-off are required to evaluate the rate of oxidation and product gases accurately. In the present work, the original model was improved to consider the neglected effects.

To verify and validate the improved chemical model, the calculation results were compared with the air-ingress benchmark experiments. Ogawa U-tube, Ogawa circular tube, and HTTR experiments were utilized for validation, and the improved model was successfully validated. In addition, the improved GAMMA code was applied to assess the system behaviors during the air ingress accident following the complete break of main pipes. Analysis of the air ingress accident for PBMR 268MWt and GT-MHR $600 \mathrm{MWt}$ was then preformed.

For Task 2, a key accomplishment was the RELAP5-3D and GAMMA time step coupling. Time step coupling is a fundamental issue to couple other variables such as source terms and pressure terms.

To achieve these goals, two codes were merged into one. There are several techniques to merge two or more codes, for example hard wired coupling, PVM (parallel virtual machine) coupling, DLL (dynamic link library) coupling and so on. Among those methods, the DLL coupling method was chosen to successfully couple RELAP5-3D and GAMMA. 


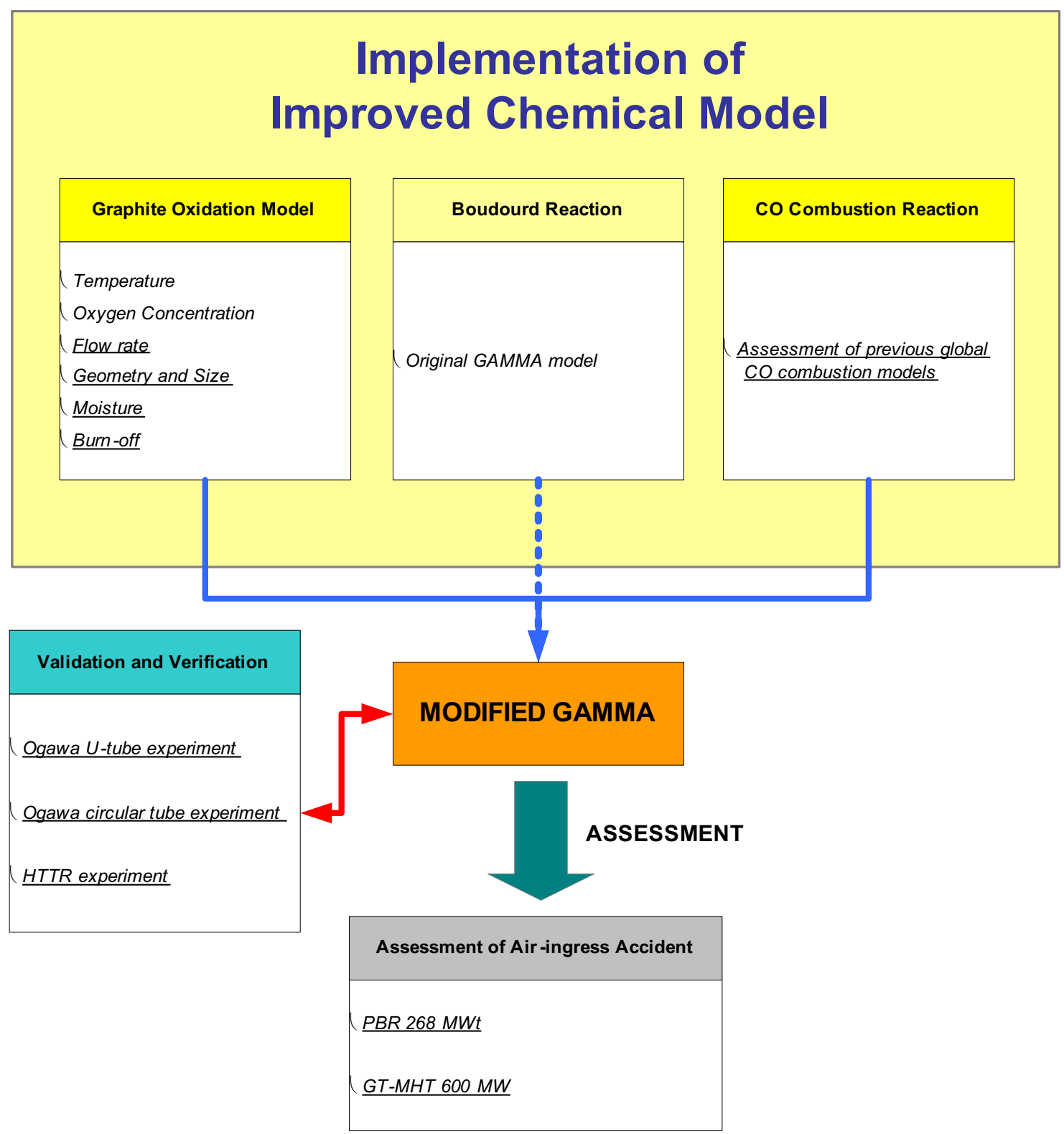

Figure 13. Schematics of project approach

In RELAP5-3D, the time step control module (DTSTEP) determines the time step size, controls output editing, and determines whether the transient advancements should be terminated. During program execution, this module displays such information as CPU time, problem time, time step size, and advancement number on the standard output, usually a terminal screen. In GAMMA, the

GAMMA_UPDATE module is used to control the time step and display problem time, time step, pressure error, velocity error and so on. Once the time step transfers from GAMMA to RELAP5-3D, RELAP5-3D examines its acceptance. If modified time step is acceptable, it can be used, but if it fails, RELAP5-3D iterates by itself until it can get a proper time step. Then RELAP5-3D gives that value to GAMMA again, and GAMMA does main calculation and saves its result. In the end, GAMMA proposes new time step for the next iteration. With this technique, RELAP5-3D and GAMMA have same time step and operate in the same time frame. 


\subsubsection{Systems Analysis Code Development}

Systems analysis development $R \& D$ was centered on (a) performing verification studies on the Phase 1 improvements to the 2-dimensional conduction model, and (b) modifications of the RELAP5-3D software to improve the prediction of heat transfer in the coolant channels such as those proposed for the prismatic variant of the VHTR.

The verification studies, performed to study the Phase 1 improvements to the 2-D conduction model, showed that the model is performing as designed. The summary report documents both this finding as well as the changes to the coding that were needed to achieve the Phase 1 objective.

The work accomplished to modify the RELAP5-3D code to improve the prediction of heat transfer in coolant channels consisted of specifying a new geometry, "institutionalizing" the Gnielinski heat transfer correlation for turbulent flow, providing for a transition from laminar to turbulent flow, and modifying the Users Manual accordingly. The changes were verified by comparing code-calculated results to those produced by a spreadsheet programmed with identical equations. The new model was applied to several legacy assessment cases involving heated tubes with acceptable results.

\subsection{Reactor Physics Development and Validation}

\subsubsection{ANL Reactor Physics: Enhancement of REBUS-3/DIF3D}

A report entitled Enhancement of REBUS-3/DIF3D for Whole-Core Neutronic Analysis of Prismatic Very High Temperature Reactor, ANL-GenIV-076 was issued. The abstract contained the following:

Enhancements have been made to the REBUS-3/DIF3D code suite to facilitate its use for the design and analysis of prismatic VHTRs. A new cross section structure, using table-lookup, has been incorporated to account for cross section changes with burnup and fuel and moderator temperatures. For handling the new cross section format, the NEUTRONXS, COMPACTSCAT, and GENERALISOTOPE modules have been developed in REBUS-3 using FORTRAN 90/95 object-oriented data structures.

These modules provide a cross section storage procedure, construct microscopic cross section data for all isotopes, and contain a single block of banded scattering data for efficient data management. In addition, fission products except I, Xe, Pm, and Sm, can be merged into a single lumped fission product to save storage space, memory, and computing time during REBUS-3 fuel cycle analysis without sacrificing depletion solution accuracy.

A simple thermal-hydraulic (thermal-fluid) feedback model has been developed for prismatic VHTR cores and implemented in REBUS-3 for temperature feedback calculations. The axial conduction term was neglected in the formulation because of its small gradient, compared to the corresponding radial temperature gradient. With the simple model, the average fuel and graphite temperatures are accurately estimated compared to reference STAR-CD results. The feedback module is currently working for the non-equilibrium fuel cycle analysis option of REBUS-3. Future work should include the extension of this capability to the equilibrium cycle option of the code and additional verification of the feedback module.

For the simulation of control rods in VHTR cores, delta-macroscopic cross sections have been defined to account for the effect of control rod insertion. The REBUS-3 code has been modified to use the cross sections when control rods are inserted in a calculation node. 
In order to represent asymmetric core blocks (e.g., fuel blocks or reflector blocks containing asymmetric absorber rods), surface-dependent discontinuity factors based on nodal equivalence theory have been introduced into the nodal diffusion theory option of the DIF3D code (DIF3D-nodal) to systematically correct the nodal cross sections. In parallel, the discontinuity factors based on the Simplified Equivalence Theory (SET) have been incorporated for all nodal options: DIF3D-nodal and DIF3D-VARIANT (nodal transport capability).

Two-and three-dimensional core calculations have been performed using the routines developed and modified in this work and the cross sections generated from single fuel block and one-dimensional or two-dimensional fuel-reflector model. Generally, REBUS-3/DIF3D results for the core multiplication factor and power distribution are found to be in good agreement with MCNP results particularly when discontinuity factors are applied. It is also shown that the DIF3D-VARIANT option provides a better spatial solution in its diffusion approximation than the DIF3D-nodal option. In addition, it is observed that the worth of control rods can be estimated within an acceptable range compared to MCNP results. However, the core power tilt needs to be improved by introducing surface-dependent discontinuity factors. It is thus concluded that future work should include the incorporation of nodal equivalence parameters for the DIF3D-VARIANT option or the improvement of the spatial approximation of the DIF3D-nodal option.

\subsubsection{Generation of Effective Reflector Cross Sections}

An ANL level 3 report on the Status of Reactor Physics Activities on Cross Section Generation and Functionalization for the Prismatic Very High Temperature Reactor, and Development of SpatiallyHeterogeneous Codes, ANL-GenIV-075, was completed. It was noted that the cross section generation methodology and procedure for design and analysis of the prismatic VHTR core have been addressed for the DRAGON and REBUS-3/DIF3D code suite. Approaches for tabulation and functionalization of cross sections have been investigated and implemented. The cross sections are provided at different burnup and fuel, and moderator temperature states. In the tabulation approach, the multigroup cross sections are tabulated as a function of the state variables so that a cross section file is able to cover the range of core operating conditions. Cross sections for points between tabulated data points are fitted simply by linear interpolation.

\subsection{Nuclear Data Tasks}

\subsubsection{DOE GEN4/AFC Physics and Nuclear Data Working Group}

The semiannual meeting of the DOE Gen-IV/AFCI/GNEP Physics Working Group, organized, hosted and chaired by INL, was held in Idaho Falls June 20-21st. Dr. Frank Goldner and Dr. John Boger from DOE-NE-HQ were in attendance, along with participants from INL, Oak Ridge, Los Alamos, and Argonne National Laboratories. Minutes for the meeting were approved by Mike Cappiello, the AFC National Technical Director for Transmutation Science, and transmitted to DOE-HQ, completing this activity.

INL participated in the DOE Office of Science Workshop on Physics and Related Computational Science R\&D for advanced fuel cycles, August 10-12, 2006 in Bethesda MD, and presented present an invited talk on the IPNS nuclear data initiative. DOE-SC will issue a request for proposals (RFP) based on the workshop report. INL will submit a proposal for nuclear data measurements that is responsive to this RFP. DOE-SC has established a very quick schedule for the proposal submittal and review process in anticipation of releasing funding for successful proposals by the middle of FY-07. 


\subsubsection{IPNS Differential Cross Section Measurements}

After consultation with DOE-HQ, a nominal amount of VHTR funding from savings in other parts of the Methods Work Package was reprogrammed for repair and maintenance of the INL nuclear physics apparatus at IPNS pending further decisions on use of this capability for nuclear data measurements of use to VHTR (and possibly GNEP). This work is on-going, and will need to continue in FY-07.

\subsubsection{Integral Nuclear Data Benchmark Evaluation}

The PROTEUSb facility at the Paul Scherrer Institute (PSI) in Villigen, Switzerland, configuration can be changed in order to represent a wide variety of nuclear reactor types, but it is designed to make experimental results easy to obtain. PROTEUS is a zero-power research reactor based on a cylindrical graphite annulus with a central cylindrical cavity. The graphite annulus remains basically the same for all experimental programs, but the contents of the central cavity are changed according to the type of reactor being investigated. Through most of its service history, PROTEUS has represented light-water reactors, but from 1992 to 1996 PROTEUS was configured as a pebble-bed reactor (PBR) critical facility and designated as HTR-PROTEUS. During this period, thirteen critical configurations were assembled and various reactor physics experiments were conducted.

These experiments included measurements of criticality, differential and integral worth of control rod and safety rod, kinetics, reaction rates, water ingress effects, and small sample reactivity effects. These experiments are described in the report for this milestone Evaluation of the HTR-PROTEUS Experiments for the International Reactor Physics Evaluation Project, which can be accessed on the GenIV web site.

HTR-PROTEUS was constructed, and the experimental program was conducted, for the purpose of providing experimental benchmark data for assessment of reactor physics computer codes. Considerable effort was devoted to benchmark calculations as a part of the HTR-PROTEUS program. References 1-2 of the above mentioned report provide detailed data for use in constructing models for codes to be assessed. Reference 3 of the report is a comprehensive summary of the HTR-PROTEUS experiments and the associated benchmark program. This document draws freely from these references. However, Section 2 of the report, in which the uncertainties associated with parameters measured in the experiment program are evaluated, reports new calculations. Also, the computational model described in Section 4 of the report was developed for this evaluation, and the results obtained are not exactly the same as previously reported results.

\footnotetext{
${ }^{\mathrm{b}}$ http://proteus.web.psi.ch/project/facilities/reactor.htm
} 


\section{Significant Accomplishments - NGNP Materials}

\subsection{Nuclear Graphite R\&D}

\subsubsection{AGC-1 Gas System Design and Installation}

The metal fabrication of the operational mock up was completed. The graphite body for the mock up will be ordered next fiscal year. Figure 14 shows the fabricated mock up parts. This mock up will be used to gain operational experience to program ATR's digital control system controlling the experiment.
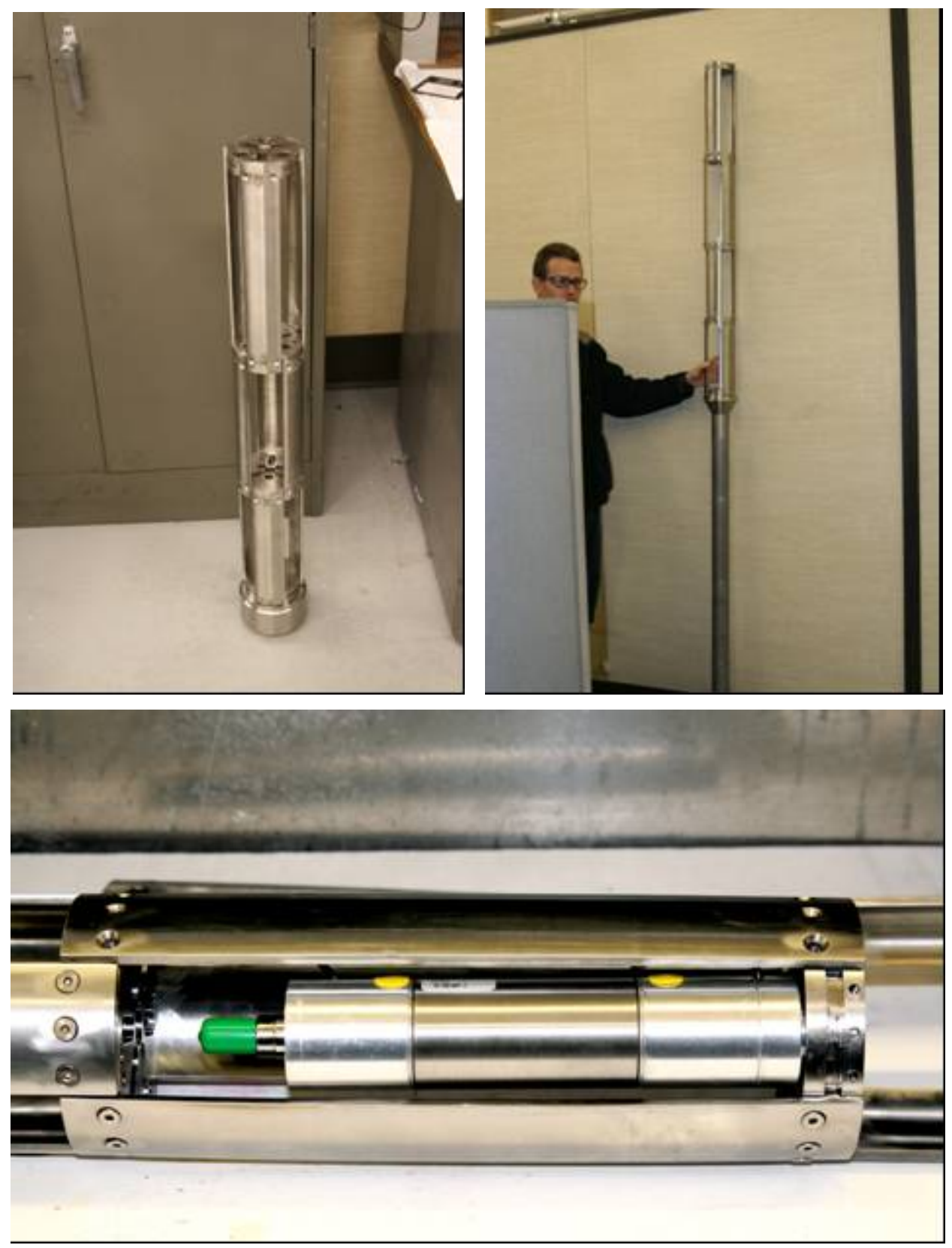

Figure 14. Fabricated mockup of gas system parts. 


\subsubsection{AGC-1 Graphite Creep Capsule Design and Fabrication}

SGL has completed the fabrication of the preliminary design graphite mock up parts. The parts have been received by the INL. These graphite parts will be used in the fabrication mock up which tests the vendors capabilities to fabricate and deliver the part within specified tolerances. The upper in-core graphite body developed a crack during fabrication. The crack was attributed to a thin wall thickness. SGL and INL held a telecom and agreed upon a thicker minimum wall thickness which will alleviate similar concerns during fabrication of the actual part. The thicker minimum wall thickness will be incorporated into the final design. Figure 15 illustrates the graphite parts.
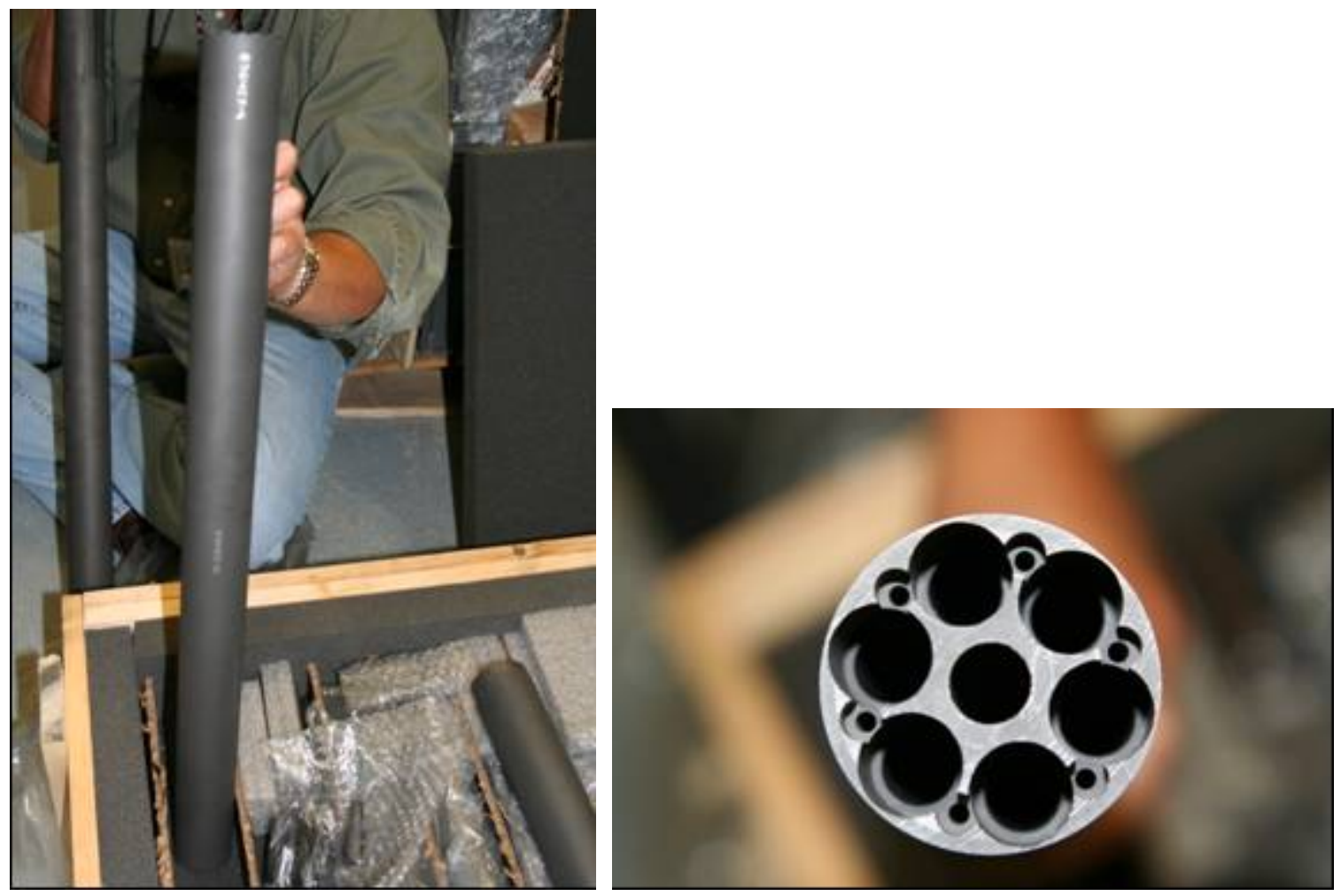

Figure 15. Graphite creep capsule parts

The ATR machine shops have completed the fabrication mock up of the outer pressure boundary. The mock up required the fabrication of two, one foot blank tubes. These tubes were machined from solid bars to reduce stress relieving. The tubes were broached by the ATR machine shop. After broaching, the two pieces were welded using an automatic welder. A special interior copper heat sink was fabricated to ensure the welding would no fill or distort the broached groves. The runout on the weld section was 0.005 of an inch. Figure 16 shows the completed section of outer pressure boundary. 

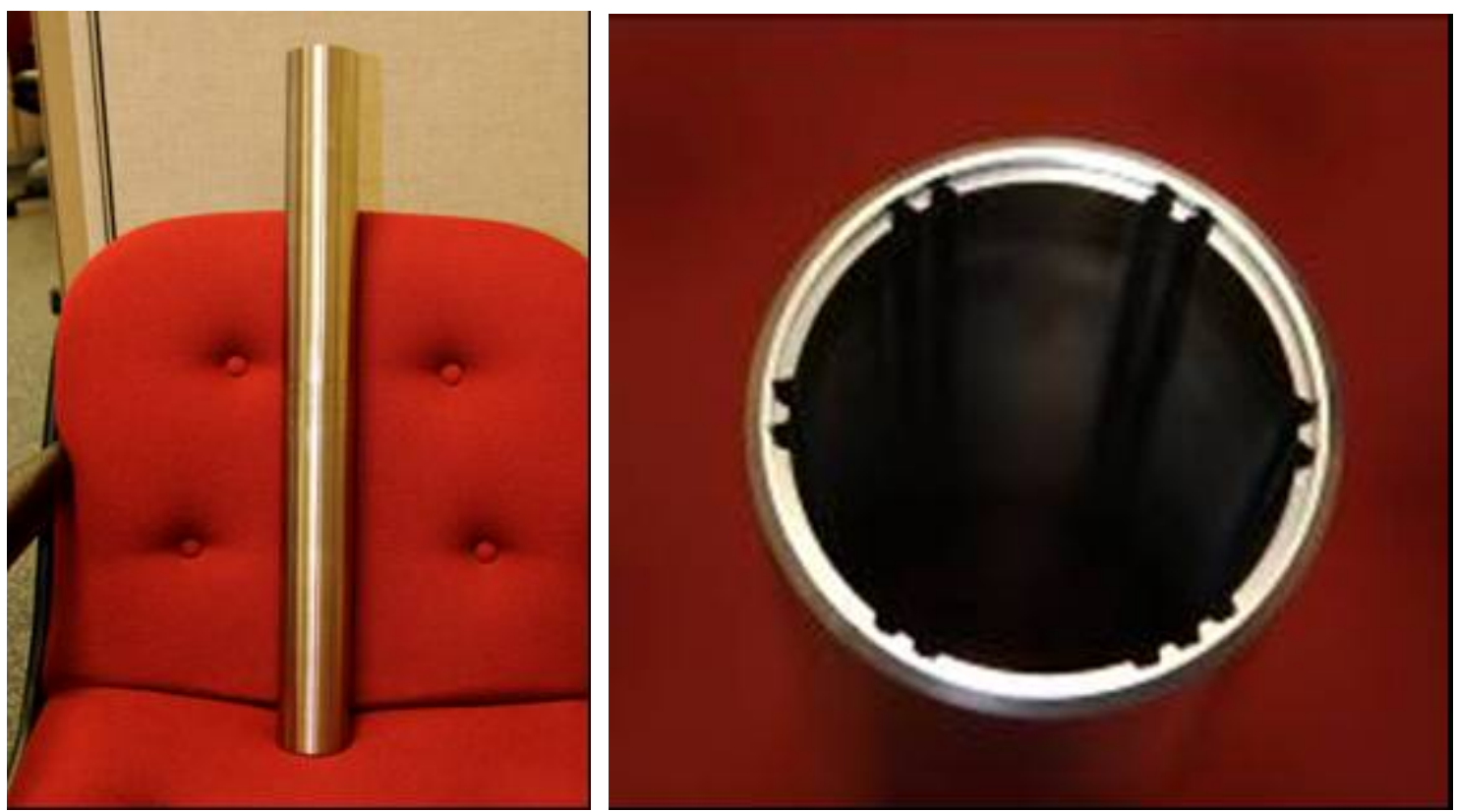

Figure 16. Completed section of the outer pressure boundary

The actual outer pressure boundary will have a length of approximately 4.5 feet. Fabrication of this piece demonstrated these techniques could be used, and the broaching could be accomplished over the entire 4.5 foot length. It also demonstrated that by eliminating the welded joint, superior product would result. Commercial broachers usually do not broach over lengths of one foot. A commercial broacher was identified who would broach all thirteen groves at the same time over the entire length. This operation will require a 30 to 60 ton press to push the tool through the tube. The disadvantage of this operation would be potential distortion of the tube beyond specification. For this reason, the ATR machine shop is developing the tooling to broach a single grove, and then repeating the operation thirteen times, thus preserving the ovality requirement of the tube. Figure 17 shows the ATR machine shop performing this operation on a different experiment pressure boundary mock up.
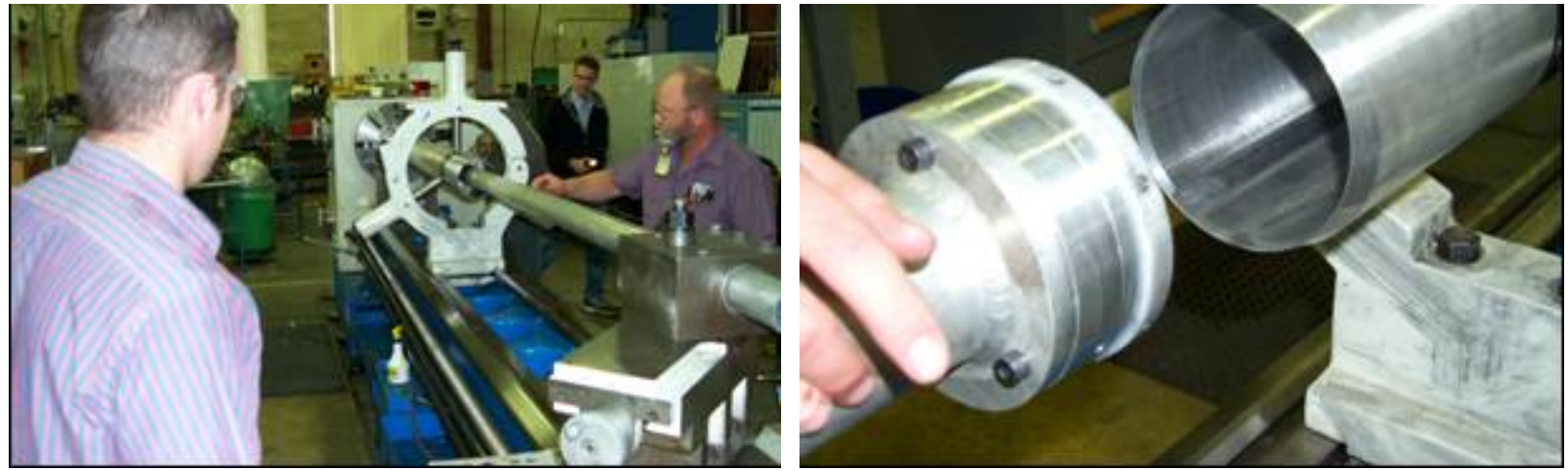

Figure 17. ATR machine shop performing developing the tooling to broach a single grove.

The Haynes 230 heat shield is being fabricated by Axsys Technologies in Cullman, Alabama. Axsys has determined that extra machining steps are necessary to meet the specification of the contract. These extra machining steps were not anticipated during the original estimate on the contract, and delivery of the heat shield is not expected until late October. 
A fixture has been designed and built to support the heat shield during the laser welding. This fixture will support the graphite and heat shield in the vertical position. Figure 18 shows this fixture.

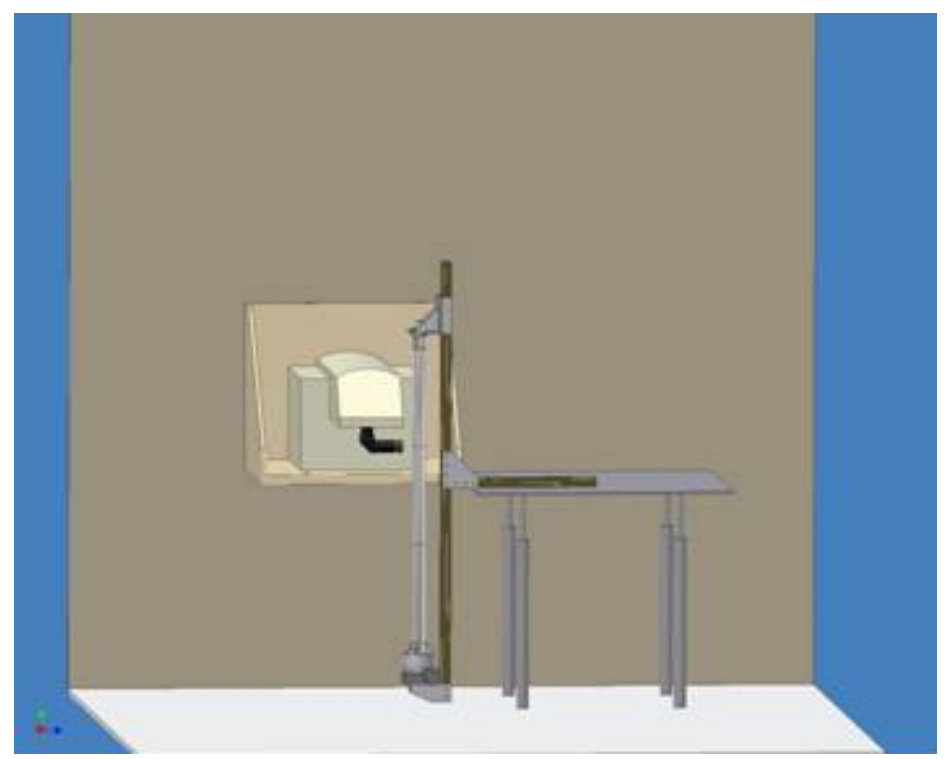

Figure 18. Fixture supporting the graphite and heat shield.

\subsubsection{Graphite Modeling}

The joint report Modeling the Multiaxial Failure Probability of Nuclear Grade Graphite, ONRL/TM-2006/527 was issued. The report discusses previous unpublished work on H-451 graphite and the application of the Burchell model explaining the results.

\subsubsection{AGC-1 Design Analysis}

The report AGC-1 Experiment and Final Preliminary Design Report, INL/EXT-05-00622 Revision 2 was issued at the end of August.

The MCNP to ABAQUS translator is working on the local workstation. ABAQUS was installed on the same workstation along with a dedicated license. As the INL site license has a limited number of seats, this will benefit both the AGR and AGC programs. In addition, timely completion of the work will require a dedicated ABAQUS license. Figure 19 is a three dimensional figure of the experiment showing the flux distribution in the ATR South flux trap as modeled in MCNP. 


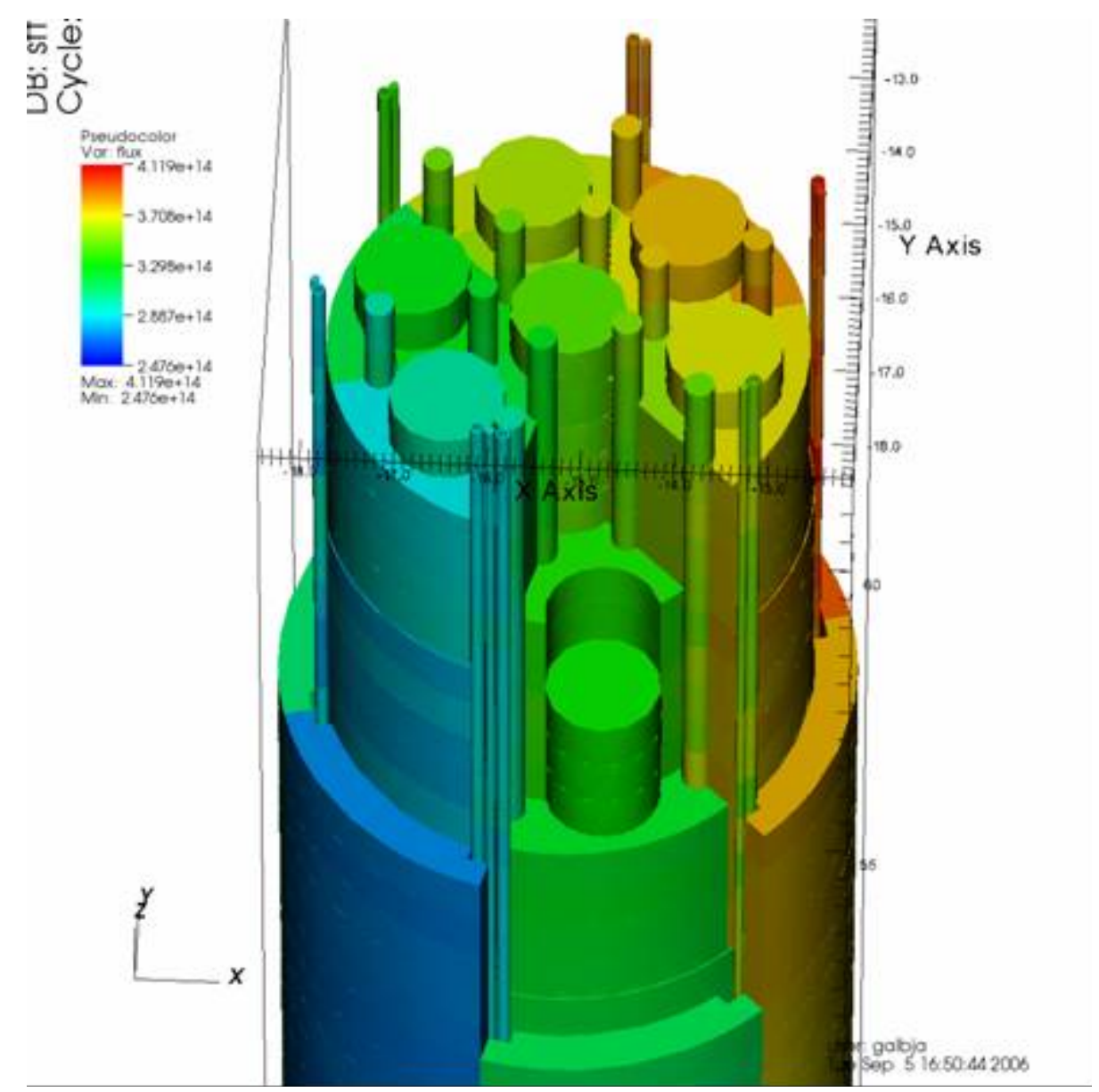

Figure 19. Three dimensional image of flux distribution in the ATR South flux trap

\subsubsection{Preliminary Design of the AGC-1 Sizing and Dry Storage Apparatus}

A different approach has been identified using the high bay dry cell below the ATR main floor. This operation will allow the capsule to be sectioned in the vertical position in a dry hot cell. This operation will require that vertical shielding be installed with a remote operated band saw. The shielded section will then be lifted out of the dry cell directly into a cask on the ATR main floor. Preliminary design will be begin next fiscal year.

\subsubsection{Graphite Billet Characterization}

Current candidate graphite grades for the core structures of NGNP include grades NBG-17, NBG18, PCEA and IG-430. Both NBG-17 and NBG-18 are manufactured using pitch coke, and are vibrationally molded. These medium grain products are produced by SGL Carbon SAS (France). Tayo Tanso (Japan) produces IG-430 which is a petroleum coke, isostatically molded, nuclear grade graphite. And PCEA is a medium grain, extruded graphite produced by UCAR Carbon Co. (USA) from petroleum coke.

An experimental program has been initiated to develop physical and mechanical properties data for these current candidate graphites. The results will be judged against the requirements for nuclear grade 
graphites set forth in ASTM standard D 7219-05 "Standard Specification for Isotropic and Near-isotropic Nuclear Graphites".

Physical properties data including thermal conductivity and coefficient of thermal expansion, and mechanical properties data including tensile, compressive and flexural strengths will be obtained using the established test methods covered in D-7219 and ASTM C 781-02 "Standard Practice for Testing Graphite and Boronated Graphite Components for High-Temperature Gas-Cooled Nuclear Reactors". Various factors known to affect the properties of graphites will be investigated. These include specimen size, spatial location within a graphite billet, specimen orientation (ag and wg) within a billet, and billetto-billet variations.

The current status of the graphite characterization program is in Status of Initial Assessment of Physical and Mechanical Properties of Graphite Grades for NGNP Applications, ORNL-GEN4/LTR-06023. To date billets of the four graphite grades have been procured, and detailed cut up plans for obtaining the various specimens have been prepared. Particular attention has been given to the traceability of each specimen to its spatial location and orientation within a billet. Figure 20 shows cutting diagrams for grade PCEA and NBG-17 in the report.
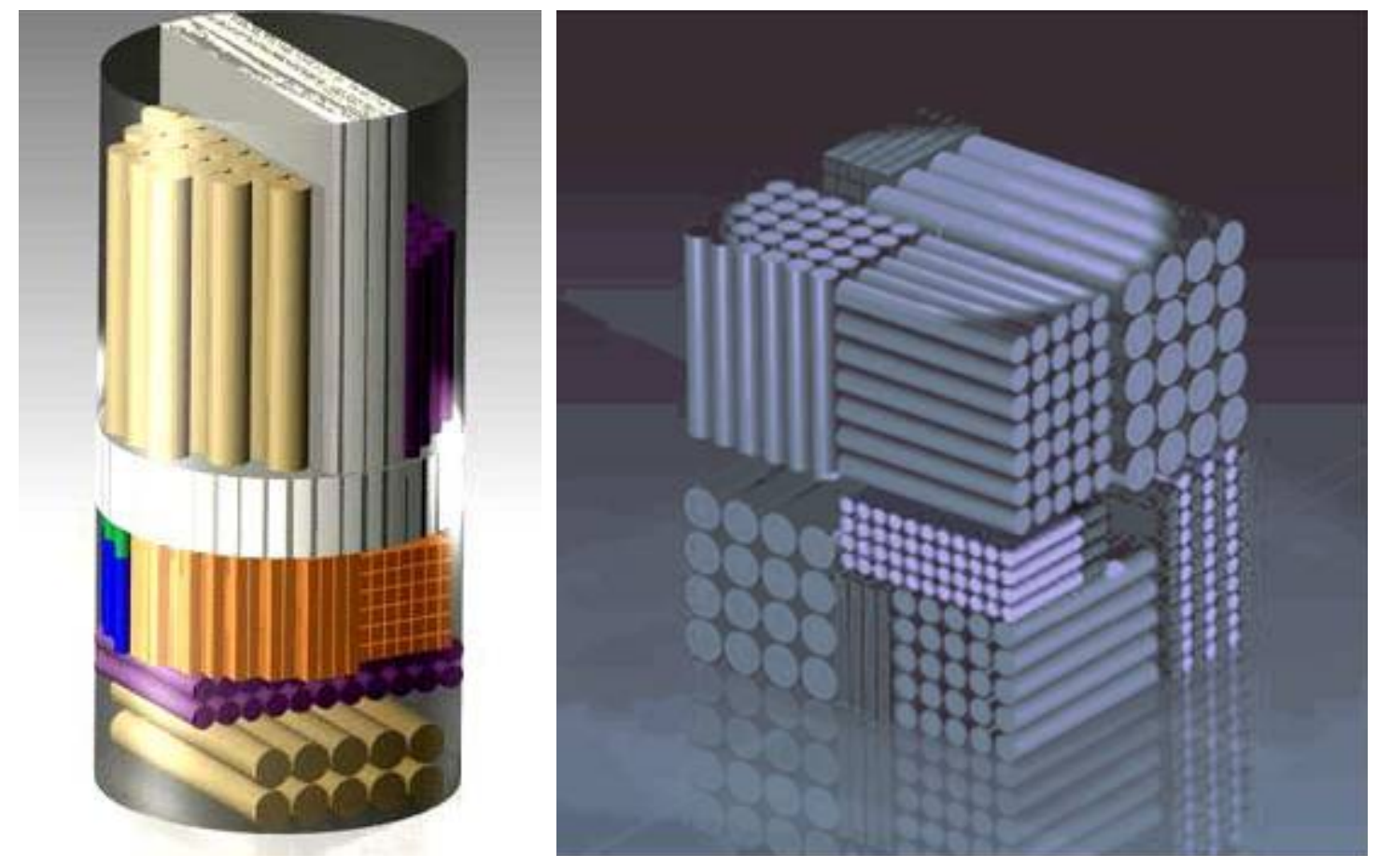

Figure 20. Cutting diagrams for grade PCEA and NBG-17.

\subsubsection{Air Oxidation of Graphite}

The furnace was completed, and three samples were tested. Further testing was suspended until funding is available to resume the work. 


\subsection{High-Temperature Alloy R\&D and Design Methodology}

\subsubsection{Aging and Environmental Effects on Inconel 617 and Haynes 230}

For the gas-cooled reactors have been built and operated for extended periods, the helium coolant in the primary circuit has been found to contain low levels of impurities after steady-state operation that can lead to an environmental degradation of the high temperature alloys used for internals and heat exchangers. Depending on the impurity concentration and the temperature, high temperature alloys can undergo oxidation, carburization, or decarburization. The concentration of $\mathrm{H} 2 \mathrm{O}$ and $\mathrm{CO}$ is of particular interest because they essentially control the oxygen partial pressure and carbon activity, respectively. The optimum coolant chemistry for long-term stability of high temperature alloys is slightly oxidizing and results in formation of a tenacious and protective $\mathrm{Cr} 2 \mathrm{O} 3$ scale.

The most critical metallic component of the Next Generation Nuclear Plant (NGNP) is the heat exchanger. Inconel 617 is the primary candidate alloy for this application because of its superior creep resistance. The mechanisms of environmental interaction between this alloy and prototype Very High Temperature Reactor (VHTR) helium chemistries have been extensively studied. A modified type of Ellingham diagram that maps the ranges of carbon activity and oxygen partial pressure that result in each of the degradation mechanisms has been developed. The NGNP materials program has designed and built three test loops to extend previous studies on environmental effects of prototype impure helium on Inconel 617 by increasing temperatures and using test coupons that incorporate fusion welds in controlled impurity experiments. In addition, parallel studies have been initiated with a less well-characterized alloy, Haynes 230. The goal of this work is to determine the range of gas chemistries that give rise to stable oxide formation for these alloys at temperatures up to $1000^{\circ} \mathrm{C}$. Figure 21 details the arrangement of coupons in the INL furnace.

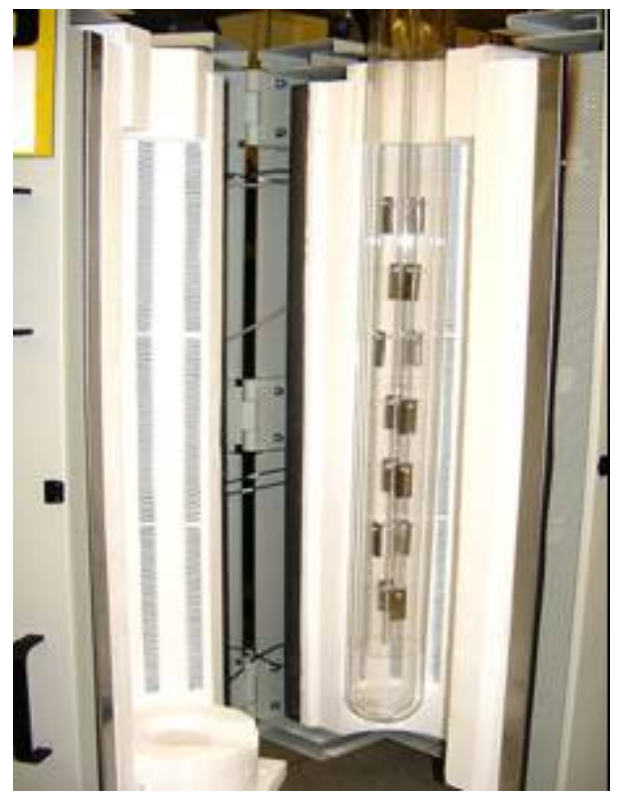

Figure 21. Arrangement of coupons in the INL furnace

Stability of the microstructure and properties of Inconel 617 and Haynes 230 after extended exposure to the elevated temperatures expected in the NGNP heat exchanger are also a potential issue. An aging program has been initiated for these alloys to characterize changes resulting from prolonged 
high temperature exposure. Furnace aging Inconel 617 in air results in formation of an adherent oxide scale and a carbide depleted zone beneath the oxide. There is some grain growth with increasing time at elevated temperature and the distribution of grain sizes becomes broader. There are modest changes in the mechanical properties for the aging conditions that have been examined. Decreased yield strength with increasing time at elevated temperature is consistent with the increasing grain size. Aging under load results in notable redistribution of carbides to some of the grain boundaries that experience tensile loading for some temperatures and applied stress values. Details of this phenomenon are being examined.

More details can be found in the report Summary of Studies of Aging and Environmental Effects on Inconel 617 and Haynes 230, INL/EXT-06-11750.

\subsubsection{Testing and Characterization of CMS Alloy 617 and Alloy 230}

Status and progress in testing and characterizing CMS Alloy 617 and Alloy 230 tasks in FY06 at ORNL and INL are described in Status of Testing and Characterization of CMS Alloy 617 and Alloy 230, ORNL/TM-2006-547. ORNL research has focused on CMS Alloy 617 development and creep and tensile properties of both alloys. In addition to refurbishing facilities to conduct tests, a significant amount of creep and tensile data on Alloy 230, worth several years of research funds and time, has been located and collected from private enterprise.

INL research has focused on the creep-fatigue behavior of standard chemistry Alloy 617 base metal and fusion weldments. Creep-fatigue tests have been performed in air, vacuum, and purified $\mathrm{Ar}$ environments at 800 and $1000^{\circ} \mathrm{C}$. Initial characterization and high-temperature joining work has also been performed on Alloy 230 and CCA Alloy 617 in preparation for creep-fatigue testing.

\subsection{NGNP Materials Review Committee}

The NGNP Materials Review Committee (MRC) met on August 29-30, 2006 at the Massachusetts Institute of Technology in Boston MA for an update on the NGNP program and to review 9 deliverable reports. The MRC comments were focused primarily on the technical and programmatic aspects of the report although editorial comments were passed along. The general feeling of the MRC was that the reports being distributed for review by the MRC are much better written than in the past with the need for fewer editorial comments.

The MRC made several observations and recommendations during their review that were not directly related to specific NGNP materials task, but could have programmatic impact. These are outlined in detail in the NGNP Materials Review Committee Report, Activities and Recommendations, written by the MRC chair, Russell H. Jones, GT-Engineering.

In addition, several action items and issues were generated during the meeting. These are included in the MRC Meeting Summary. No date has been set for the next MRC meeting. This will await the outcome of a decision on the future direction of the MRC by the NGNP program manager. 


\section{Significant Accomplishments - NGNP Licensing}

The Energy Policy Act of 2005 (Title VI, Subtitle C, Section 644) states that the "Nuclear Regulatory Commission shall have licensing and regulatory authority for any reactor authorized under this subtitle." This stipulates that the Nuclear Regulatory Commission (NRC) will license the Next Generation Nuclear Plant (NGNP) for operation, which is consistent with the Energy Reorganization Act of 1974 that assigns the responsibility for licensing new Department of Energy (DOE) reactors to the $\mathrm{NRC}$ if they are used to generate power for an electric utility system or operated in any manner to demonstrate the suitability for subsequent use by the commercial power industry. NRC licensing of the NGNP will demonstrate the efficacy of licensing future advanced gas-cooled reactor concepts for commercial applications.

This section describes the NGNP licensing-related activities that have taken place during the second half of FY-06.

\subsection{Licensing Strategy}

The following subsection presents a comparative evaluation of the different possible NRC licensing strategies that could be used by the NGNP project. This thinking provides the rational to support the strategy described in the NGNP Preliminary Project Management Plan.

\subsubsection{Choice of NRC Regulations (Customized Part 50 vs. New Part 53)}

In the past, nuclear power plants required two licenses; a construction permit, which allowed the facility to be built, and an operating license, which permitted operation of the facility once it was completed (Part 50).

Recently, the NRC has realized that risk-informed regulatory structures applied to license and regulate advanced reactors, regardless of their technology, could enhance the effectiveness, efficiency, and predictability (i.e., stability) of new plant licensing. Therefore, the NRC staff has started to develop an Advanced Reactor Regulatory Framework utilizing a top-down approach to creating a regulatory structure for a new generation of reactors. Such an approach could facilitate the implementation of performance based regulation, as well as ensure a greater degree of coherence among the resulting regulations for new reactors than found among current regulations. This new advanced reactor regulatory framework is expected to implement probabilistic risk assessment concepts (PRA) from the start.

If successful, this new licensing structure could be available for use early in the next decade. Therefore, it is possible that the NGNP could serve as excellent test case for utilization of this new licensing process (assuming that it is successfully implemented by the NRC). So, the first decision is to evaluate whether it makes sense to use the new Part 53 (see Table 1), or to use a customized set of requirements that are based on the original two-step process from Part 50 (see Table 2)). 
Table 1. Advanced Reactor Licensing Framework (10 CFR Part 53)

\begin{tabular}{|l|l|}
\hline \multicolumn{1}{|c|}{ Strengths } & \multicolumn{1}{|c|}{ Weaknesses } \\
\hline - $\begin{array}{l}\text { Would not be LWR specific; eliminates need to } \\
\text { submit exceptions to Part 50. }\end{array}$ & $\bullet \begin{array}{l}\text { Does not currently exist; there is no guarantee that } \\
\text { this framework will be created. }\end{array}$ \\
- $\begin{array}{l}\text { Risk-informed; regulatory emphasis would be on } \\
\text { design issues that matter; potentially would allow } \\
\text { for reduction in design conservatisms. }\end{array}$ & $\begin{array}{l}\text { If approved for development by NRC staff, there is } \\
\text { no guarantee that it will be available for use by } \\
\text { NGNP when needed. }\end{array}$ \\
- $\begin{array}{l}\text { Should be more comprehensive and easier to defend } \\
\text { to the public. }\end{array}$ & \\
$\begin{array}{l}\text { Using the NGNP as the test case for the new } \\
\text { framework would help refine and legitimize the } \\
\text { framework; this would provide benefit to the } \\
\text { industry. }\end{array}$ & \\
\hline
\end{tabular}

Table 2. Customized 10 CFR Part 50 Approach

\begin{tabular}{|l|l|}
\hline \multicolumn{1}{|c|}{ Strengths } & \multicolumn{1}{c|}{ Weaknesses } \\
\hline - $\begin{array}{l}\text { Part 50 process is well understood. } \\
\text { - } \begin{array}{l}\text { Minimizes the amount of time needed to reach the } \\
\text { construction phase. Results in shorter total project } \\
\text { durations for NGNP. }\end{array}\end{array}$ & $\begin{array}{l}\text { Current industry focus is on use of Part 52, not } \\
\text { Part 50. }\end{array}$ \\
& $\begin{array}{l}\text { Part 50 is LWR specific; many exceptions would be } \\
\text { needed to license a gas reactor ("customized"). } \\
\text { Large amount of time and money will be invested } \\
\text { before all of the design safety issues are resolved. }\end{array}$ \\
\hline
\end{tabular}

The advanced reactor framework may become a viable choice if the NRC were to make rapid progress in its development and if the NRC were to make commitments that the framework would be available for use when needed by the NGNP project.

\subsubsection{Two-Step (Part 50) or One-Step (Part 52) Licensing Structure}

In 1989, the NRC adopted a streamlined licensing process (Part 52) that encourages the use of standardized and pre-approved designs for any future plant proposals and provides for the issuance of a combined construction permit and operating license. Another feature of the streamlined process is possible early approval of sites for nuclear plants. This combined licensing process provides for the early resolution of virtually all issues before construction begins. This combined license also incorporates a program of tests, inspections, and related acceptance criteria that are necessary and sufficient to show that the plant has been properly built. These criteria must be met before plant operation can begin.

If the advanced reactor framework (Part 53) is not used to license the NGNP, then the question becomes: should we use a two-step (Part 50) or one-step (Part 52) licensing process? The answer to this question depends on how one views the associated risks and the differences in review schedules that result from the different processes.

The key to understanding Part 52 and how it relates to Part 50 is to realize that Part 52 is a process change and does not establish new design requirements (see Table 3). All technical requirements are referenced from the appropriate sections of Part 50. 
Table 3. Customized 10 CFR Part 52 Approach

\begin{tabular}{|l|l|}
\hline \multicolumn{1}{|c|}{ Strengths } & \multicolumn{1}{c|}{ Weaknesses } \\
\hline - $\begin{array}{l}\text { Current industry efforts focus on use of Part 52 } \\
\text { - } \begin{array}{l}\text { Compartmentalizes the risk; public can't reopen } \\
\text { previously resolved issues at later hearings. }\end{array}\end{array}$ & $\begin{array}{l}\text { Not all sections of Part 52 have been demonstrated } \\
\text { (especially the combined construction/operating } \\
\text { license [COL] and the associated inspections, test, } \\
\text { analyses, and acceptance criteria [ITAAC] process). }\end{array}$ \\
$\begin{array}{l}\text { Reduces risk; design issues are resolved before } \\
\text { construction begins. }\end{array}$ & $\begin{array}{l}\text { Part 52 references Part 50 for its technical } \\
\text { requirements; therefore, it is LWR specific; many } \\
\text { exceptions would be needed to license a gas reactor } \\
\text { ("customized"). }\end{array}$ \\
& $\begin{array}{l}\text { Increases the amount of time needed to complete the } \\
\text { NGNP project if the design is not finalized until the } \\
\text { 2013 timeframe; we can not apply for a COL until } \\
\text { design is final; construction can not start until COL } \\
\text { review is complete. }\end{array}$ \\
\hline
\end{tabular}

Use of the Part 52 COL process requires that the submittal include a description of the completed design in a final safety analysis report and the proposed ITAAC that will be used at the end of construction to prove that the plant was built in accordance with the approved design. Assuming that the NGNP design is not complete until the 2013 timeframe means that a COL can not be submitted for NRC review prior to this time. This need to wait for completion of the design (using Part 52) is what makes the two-step process (Part 50) more attractive. Using Part 50, we can be working on construction while the NRC staff is performing a final review of the design as part of the operating license application review. However, the construction permit application still needs to describe the preliminary design. Therefore, completion of the different stages of design development drives the schedule for when key licensing actions can be initiated, irrespective of which set of NRC licensing requirements are chosen.

\subsubsection{Effect of Commercial Partnership}

If a commercial partner with a relatively mature reactor design (that meets our requirements) were involved in the project, then this discussion could change completely. The Part 52 licensing process would become viable because we would not have to wait a long time for the design to be completed before submitting the COL. This would bring the project in alignment with current licensing projects (such as the new COLs based on AP1000, ESBWR, and EPR designs) and would better match the NRC's resource allocation structure.

In conclusion, if the NGNP design is not finalized until the 2013 timeframe, then a Part 50-based approach remains the best choice for completion of the overall project prior to 2021. If the design development time can be reduced, then use of the Part 52 process can be considered.

\subsection{Scheduling Analysis}

As discussed above, use of 10 CFR Part 50 has been initially judged as the best licensing approach for the NGNP. However, many variables can be considered. Toward the end of FY-06, DOE-NE requested that a comparative licensing schedule analysis be performed to address the following possibilities:

- Use of Part 50 assuming that a new gas reactor design is developed. 
- Use of Part 52 assuming that a new gas reactor design is developed.

- Use of Part 50 assuming that a (relatively) mature gas reactor design is used (i.e., a commercial partner provides a gas reactor design that relatively mature and meets our requirements).

- Use of Part 52 assuming that a mature gas reactor design is used.

Note: The purpose of this analysis is to look at the effects of different variables on potential licensing timetables. It is not intended to be a supporting justification, or a more detailed substitute for the current Option 2 schedule that is contained in the NGNP Preliminary Project Management Plan. This is only intended to be a relative (or comparative) analysis.

An initial analysis has been developed using a uniform set of assumptions provided below:

\section{New Design Development Assumptions}

- Conceptual Design -18 months

- Preliminary Design - 24 months

- Final Design - 30 months

\section{Mature Design Assumptions}

- $\quad$ Mature Design is ready by 2009

\section{Construction Assumptions}

- Long Lead Items - 24 months prior to start of construction

- Plant Construction - 40 months

- Startup Testing - 12 months after fuel load

\section{Licensing Assumptions}

- Develop Environmental Report - 36 months

- NRC Early Site Permit Review - 36 months

- Develop PSAR - 24 months

- NRC Construction Permit Review - 30 months

- Develop FSAR - 30 months

- Develop Operating License Application - 30 months

- Develop Combine Operating License Review - 30 months 
- $\quad$ NRC Operating License Review - 60 months

- $\quad$ NRC Combined Operating License Review - 60 months

Using these assumptions in the appropriate sequences for the different scenarios will provide a more refined basis for deciding on the best approach for developing and licensing the NGNP before the 2021 timeframe identified in the Energy Policy Act of 2005. Initial analysis show that is could be possible to have a mature design licensed by the end of 2015 using the Part 50 licensing (assuming that the design was ready by 2009). However, this analysis does not consider the various options related to the hydrogen production facility.

Further analysis is needed to consider the impacts that will result from development of the hydrogen production facility. It is reasonable to expect the NRC staff to have many questions regarding the possible secondary heat loads that may be used prior to licensing the reactor part of the NGNP facility. Results from this analysis will be provided to DOE-NE for review in early FY-07.

\subsection{Site Characterization}

The NRC NEPA Regulations (10 CFR Part 51) require that the NRC prepare an Environmental Impact Statement (EIS) for a permit to construct a nuclear power reactor. The applicant is required to submit an Environmental Report (ER) to aid the NRC in complying with NEPA, and the NRC is responsible for evaluating the reliability of any of the information that it uses to prepare the EIS.

This subsection provides an overview of the preliminary site activities that have taken place in FY06, and the site-related plans for FY-07.

\subsubsection{New Production Reactor (NPR) Site E}

In 1983, a site selection was performed by the DOE for the New Production Reactor (NPR) at the INL. In 1989, the original site selection process was reviewed to determine if the primary site selected in 1983 was still considered the best site in light of the most recent site characterization data (see Report EGG-NPR-8517, Rev. 1, "Site Selection Report for the New Production Reactor at the Idaho National Engineering Laboratory," dated July 1989).

This report determined that there was no reason to alter the previously selected primary location (called "Site E") for the NPR. It is important to note that this activity was taken with the understanding that suitability would be based on NRC siting criteria. Site E is close to established roads, the railroad, and the INL site electrical transmission loop. Considerable resources were expended in characterizing the selected site that is located east of the INTEC facility. Given the type of facility that planned, it is logical that Site E would be a prime candidate for locating the NGNP facility.

Based on the work that was done in the 1980s, it would be cost beneficial to gather any existing data from the NPR effort and not redo the site characterization activities. However, much of that data is currently controlled by the Idaho Cleanup Project (ICP). Therefore, activities have been initiated to determine the location of existing NPR site characterization data.

The current status is as follows:

- A large number (approximately 700 boxes) of NPR documents are located in the INL's records storage facility. These boxes contain a variety of information (including plant design data) that 
will need to be reviewed to identify and separate out the site characterization data that is of interest to the NGNP project.

- ICP has control of some of the Site E characterization and environmental data. These data are located (along with other site data) in a controlled area in Idaho Falls (Building TS-B). ICP personnel are tasked to electronically scan records that support their activities and to subsequently dispose of the original hard copies once the scanning is complete. We do not know (yet) if any NPR data has been processed in this manner. However, preventing the potential destruction of any original NPR-related site characterization documents is a high-priority issue. Given the costs of re-creating the data, saving the well logs has the highest priority.

- The project must identify where to organize and control our project records (over the long term) that will be needed to support the NRC licensing process. The space needed and the control requirements that must be applied to meet NQA-1 are not trivial. Initial inquiries have found that the laboratory resources for a large controlled library are scarce. This issue will require management attention.

- The ICP has a well-established site characterization database that should be a useful resource for general site data that will be needed by the NGNP environmental report.

- We know that the NPR project did not complete their seismic studies before the project was terminated. Therefore, this is one area that will require new work activities, even if Site $\mathrm{E}$ is selected for the NGNP facility.

\subsubsection{FY-07 Site Selection/Characterization Activities}

It is anticipated that the following site-related tasks will be initiated in FY-07. This work has been identified in Work Package G-IN07NG0802. In general, this work package addresses the initial work needed to gather existing characterization data that was developed during the NPR project. This includes identifying new activities needed to develop an environmental report and meet current licensing requirements.

Once the existing data is gathered, it will be evaluated to ensure that the site is still acceptable in today's regulatory environment. Work activities needed to update or add additional supporting data will be identified.

The FY-07 work tasks are summarized below:

- Develop plan to gather existing NPR site data,

- Gather existing NPR site data,

- Develop site selection/characterization plan,

- Identify site monitoring needs,

- Procure monitoring equipment, and

- Develop site selection/characterization status report. 


\section{Significant Accomplishments - Advanced Gas Reactor (AGR) Fuel Development and Qualification}

\subsection{Project Management}

\subsubsection{INL Quality Assurance}

The ORNL final certified data package for AGR-1 fuel was received August 31, 2006. A review of the data was conducted by two technical leads and quality assurance. Several items were identified as needing clarification for final data acceptance. Data package revisions were received from ORNL September 20, 2006 and Source Inspection No. 5 was completed.

An unscheduled surveillance was completed during September. The surveillance was to verify that the AGR-1 test train assembly was ready for insertion on September 28, 2006.

\subsubsection{ORNL Quality Assurance}

The ORNL program was audited by a team led by DOE-NE QA the week of September 18 . The team identified two notable practices, six observations, and four findings with one finding remedied prior to the conclusion of the audit. No findings were identified with the potential to impact the compacts previously shipped to INL.

\subsection{Fuel Development and Fabrication}

\subsubsection{Kernel Fabrication}

6.2.1.1 Kernel Fabrication Development and Production. This month BWXT completed characterization of kernels from the last development test (59337) and began fabricating kernels for future coater tests. The Phase 2 development tests showed that good quality kernels could be produced over a wide range of broth parameters, and that the "ideal broth zone" established for UO2 kernel formation was also valid for UCO kernel formation. Evaluating all the characterization data from Phase 2 development tests, a slight improvement in properties was seen for three runs that had HMTA to uranium ratios of 1.51-1.64 and uranium concentrations of 1.13 to 1.17 moles/liter. Based on these results, the target broth conditions selected for future runs was an HMTA to uranium ratio of 1.55 and a uranium concentration in the broth of 1.15 moles/liter. These conditions are being used in runs to make $425-\mu \mathrm{m}$ natural uranium UCO kernels for coater scale up tests. Results from the first four runs to produce kernels for coater scale up tests are shown in Table 4.

Table 4. Characterization results for initial four batches of kernels for coater scale up tests.

\begin{tabular}{|c|c|c|c|c|c|c|c|c|}
\hline $\begin{array}{c}\text { Batch } \\
\text { Number }\end{array}$ & $\begin{array}{c}\text { Green } \\
\text { Kernel } \\
\text { Density, } \\
\text { g/cm }\end{array}$ & $\begin{array}{c}\text { Uranium } \\
\text { wt } \%\end{array}$ & $\begin{array}{c}\mathrm{O} / \mathbf{U} \\
\text { ratio }^{(1)}\end{array}$ & $\begin{array}{c}\mathrm{C} / \mathrm{U} \\
\text { ratio }^{(1)}\end{array}$ & $(\mathbf{O}+\mathbf{C}) / \mathbf{U}$ & $\begin{array}{c}\text { Sintered } \\
\text { Kernel } \\
\text { Density, } \\
\text { g/cm }\end{array}$ & $\begin{array}{l}\text { Average } \\
\text { Diameter } \\
\text { (microns) }\end{array}$ & $\begin{array}{c}\text { Average } \\
\text { Sphericity }\end{array}$ \\
\hline 59340 & 1.15 & 89.3 & 1.51 & 0.37 & 1.88 & 10.7 & 415 & 1.004 \\
\hline 59341 & 1.13 & 89.3 & 1.51 & 0.37 & 1.88 & 10.7 & 416 & 1.005 \\
\hline 59342 & 1.14 & 89.2 & 1.54 & 0.36 & 1.90 & 10.6 & 423 & 1.005 \\
\hline 59343 & 1.17 & 89.2 & 1.53 & 0.36 & 1.89 & 10.6 & & \\
\hline
\end{tabular}


Typical mounted and loose kernel images are shown in Figures 22 and 232.
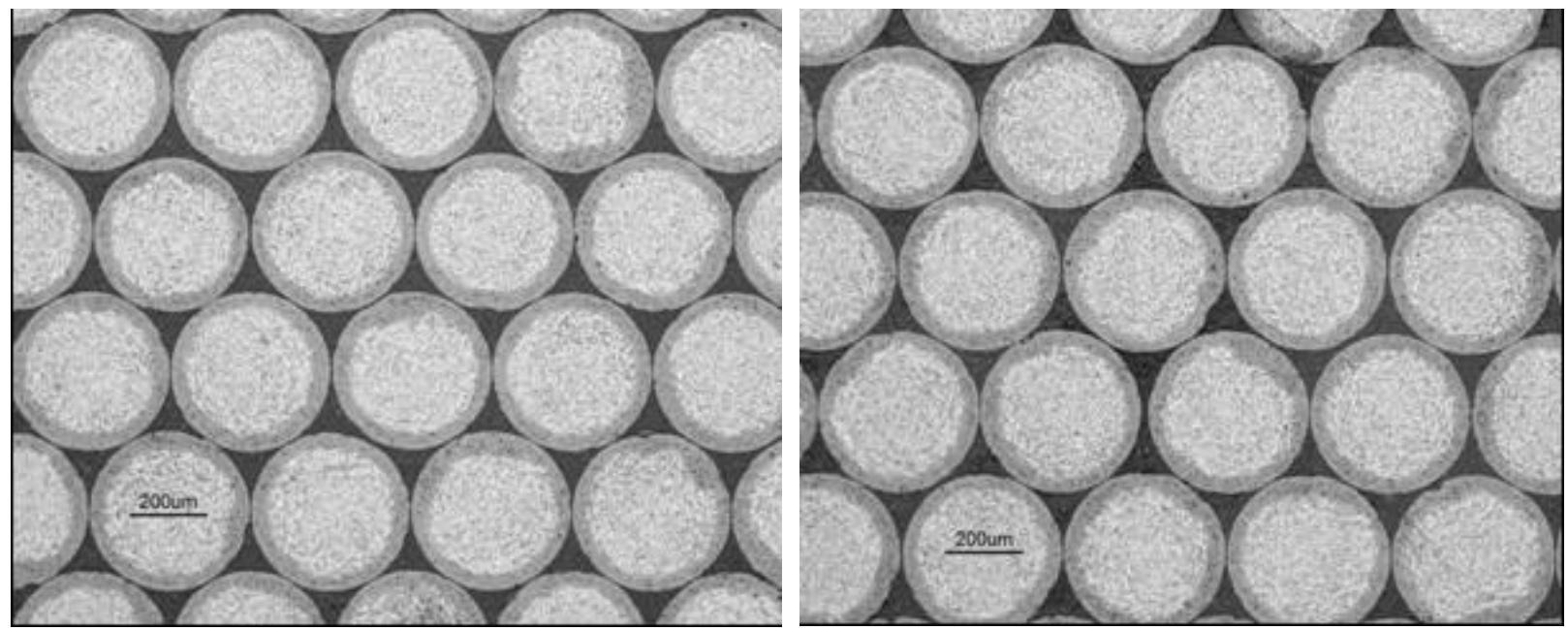

Figure 22. Mounted kernels from batches 59340 and 59342.
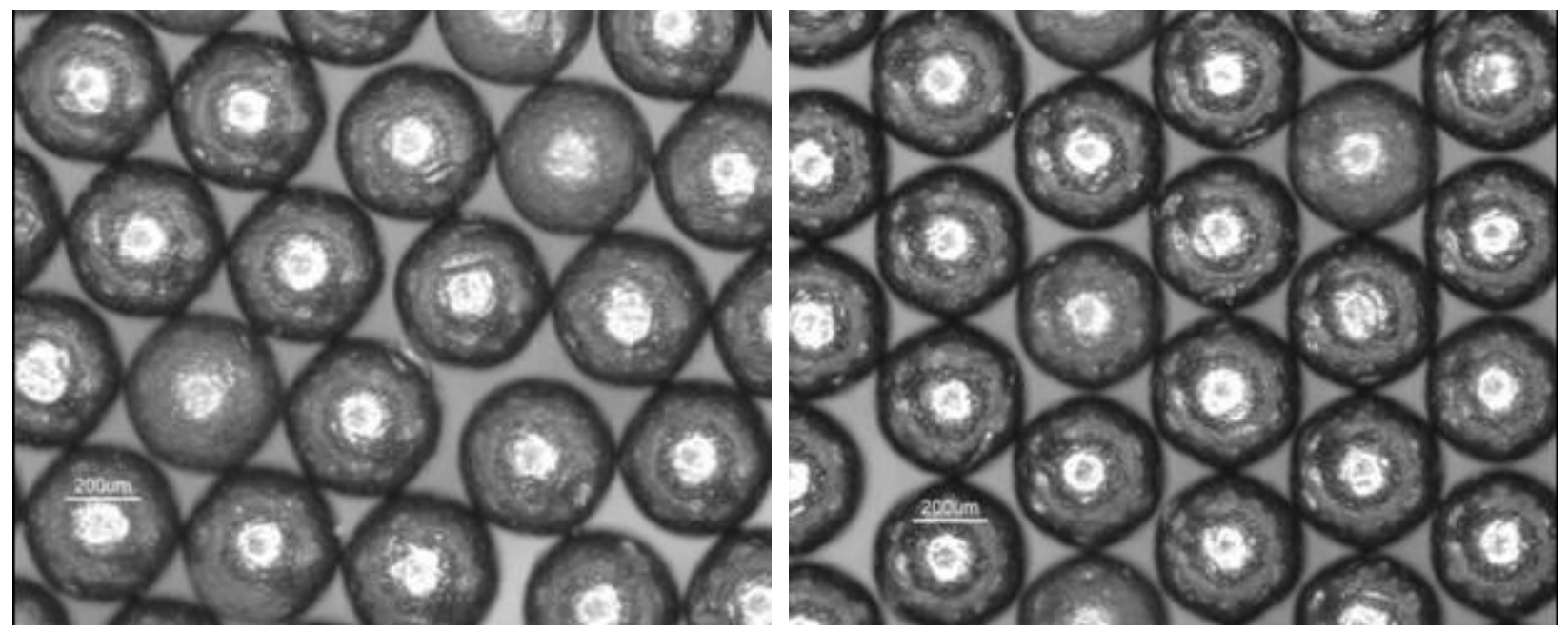

Figure 23. Loose kernels from batches 59340 and 59342.

\subsubsection{Coater Scale Up.}

\section{BWXT Coater Modifications}

BWXT completed planned coater modifications to the point that coater tests can begin the first week of October. The coater lid assembly with a hot sampler was received and installed. Cold tests were performed of the hot sampler. The new, larger capacity MTS system was received, installed and tested. Work is still in progress procuring a high speed pressure transducer; this instrument will be added to the furnace at a later date. 


\section{Coater Crucible Design EDF}

Revision 1 of EDF-6666 Six-inch TRISO Fuel Coater Design for AGR-2 was issued to update and expand the appendices containing drawings of the coater crucibles planned to be tested.

\section{Coater Test Plan}

Review comments on EDF-7202, Test Plan for Validation of AGR 6-inch Diameter Coater Design, were resolved and the test plan was issued.

\subsubsection{BWXT Particle Characterization Assessment and Upgrades. EDF- 7316,} Assessment of BWXT Particle Characterization Capabilities, was completed and issued. Much of the assessment is based on discussion at a meeting held at BWXT facilities on April 4-5 in which INL, ORNL, BWXT and GA personnel systematically discussed characterization for each property of the fuel specification. The notes from this meeting, as well as notes from a follow-up visit by BWXT personnel to the ORNL characterization laboratory, are attached to the EDF.

6.2.1.4 AGR-1 Final Data Package. The final data package for AGR-1 fuel was received and reviewed. Identified discrepancies were corrected, and INL issued Source Inspection report \#5 stating that the data package contains all required information identified in PLN-1930, Quality Assurance Source Inspection Plan for AGR-1 Fuels, and that the data demonstrates that the fuel is in compliance with the AGR-1 fuel specification.

6.2.1.5 AGR-3 and AGR-4 Fuel Specification and Sampling Plan. Revision 1 of the AGR-3 and AGR-4 fuel specification and revision 1 of the AGR-3 and AGR-4 Sampling Plan were issued to correct the $\mathrm{SiC}$ gold spot specification and to incorporate as an appendix, a review of past irradiation performance of designed-to-fail particles.

\subsubsection{Fuel Coating}

No report.

\subsubsection{Characterization}

6.2.3.1 Buffer Density Verification. AGR-3 and AGR-4 buffer was deposited using the same process conditions as those used for AGR-1. AGR-1 baseline buffer was qualified (three batches) using the NUCO350 kernels and verified with the LEU01 kernels (one batch). These measurements were made over a year ago. Baseline buffer was deposited on the DUN350 kernels to verify that buffer density is still within the expected range for these process conditions. The DUN kernels are also closer in size to the new batch of LEU03 kernels used for AGR-3 and AGR-4. The measured buffer density on the new batch of buffer-coated $350 \mu \mathrm{m}$ DUO2 was in agreement with previous results.

Table 5. Measurements made on buffer-coated kernels

\begin{tabular}{|l|l|l|l|l|l|}
\hline & \multicolumn{3}{|c|}{ NUCO350 batches } & LEU01 batch & DUN350 batch \\
\hline $\begin{array}{l}\text { Buffer density } \\
(\mathrm{g} / \mathrm{cc})\end{array}$ & $1.08 \pm 0.04$ & $1.11 \pm 0.05$ & $1.11 \pm 0.04$ & $1.10 \pm 0.03$ & $1.11 \pm 0.06$ \\
\hline
\end{tabular}

6.2.3.2 LEU03 Kernel Characterization. The LEU03 kernel composite used for AGR-3 and AGR-4 was characterized. Size, shape, average weight and envelope density were measured. This 
information is needed for fabrication and characterization of the coatings and compacts. The results have been summarized in a report which will be issued in October.

6.2.3.3 Measurements of Heat Treatment Effects on Pyrocarbon Anisotropy A series of anisotropy measurements were made on coated particles available from the unused AGR-1 variant for an interrupted process. Diattenuation of IPyC on particles removed before $\mathrm{SiC}$ deposition was compared to IPyC diattenuation after $\mathrm{SiC}$ deposition $\left(2\right.$ hours at $\left.1500^{\circ} \mathrm{C}\right)$ and after simulated compact heat treatment for 1 hour at $1800^{\circ} \mathrm{C}$. OPyC diattenuation was compared before and after the simulated compact heat treatment. It was observed that the diattenuation increased with this heat treatment (Figure 24). Details will appear in an upcoming journal article.

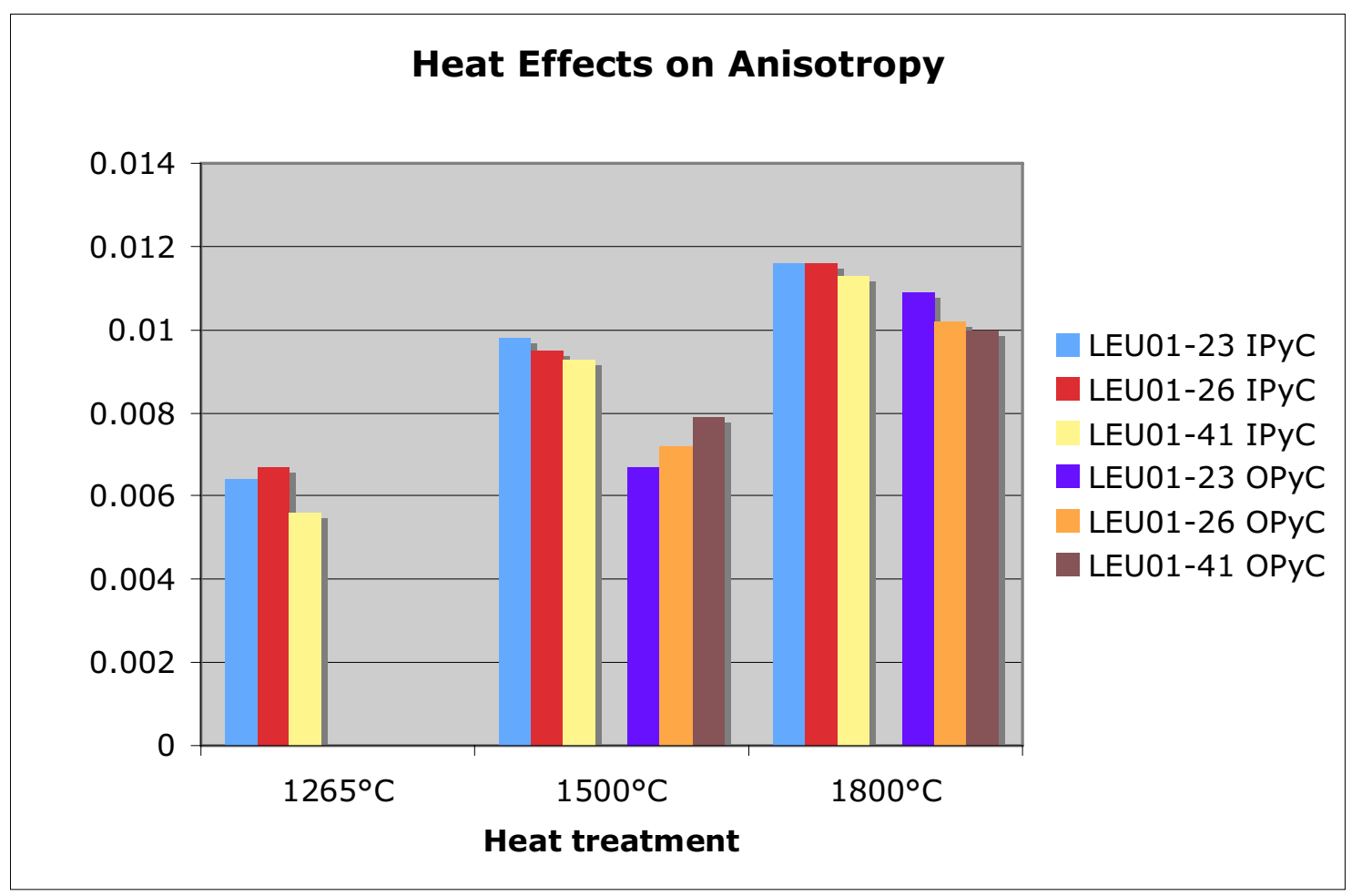

Figure 24. Effects of heat treatment on pyrocarbon anisotropy.

6.2.3.4 X-ray Imaging of Compacts. X-ray images were obtained of the 12 archive compacts from the AGR-1 baseline compact lot LEU01-46T-Z (Figures 25 and 26) and three of the archive compacts from the AGR-1 variant 2 compact lot LEU01-48T-Z (Figure 27). The compacts are oriented in the images as they were oriented in the compact mold. These images show a fairly level distribution of particles at the top of the compact. The particles are distributed less uniformly in the bottom of the compact, presumably due to the shifting of the end cap matrix powder as particles were poured into the mold.

The baseline compacts show an average top end cap thickness of about $2.0 \pm 0.2 \mathrm{~mm}$. The baseline compacts show a minimum bottom end cap thickness that ranged from 1.5-2.0 $\mathrm{mm}$ with some areas as thick as $3.5 \mathrm{~mm}$. 
The baseline compacts were fabricated with $0.40 \mathrm{~g}$ of matrix in each end. The variant 2 compact end caps were fabricated with $0.30 \mathrm{~g}$ of matrix. The variant 2 compacts show an average top end cap thickness of about $1.5 \pm 0.2 \mathrm{~mm}$. The variant 2 compacts show a minimum bottom end cap thickness that ranged from $1.0-1.5 \mathrm{~mm}$ with some areas as thick as $2.5 \mathrm{~mm}$.

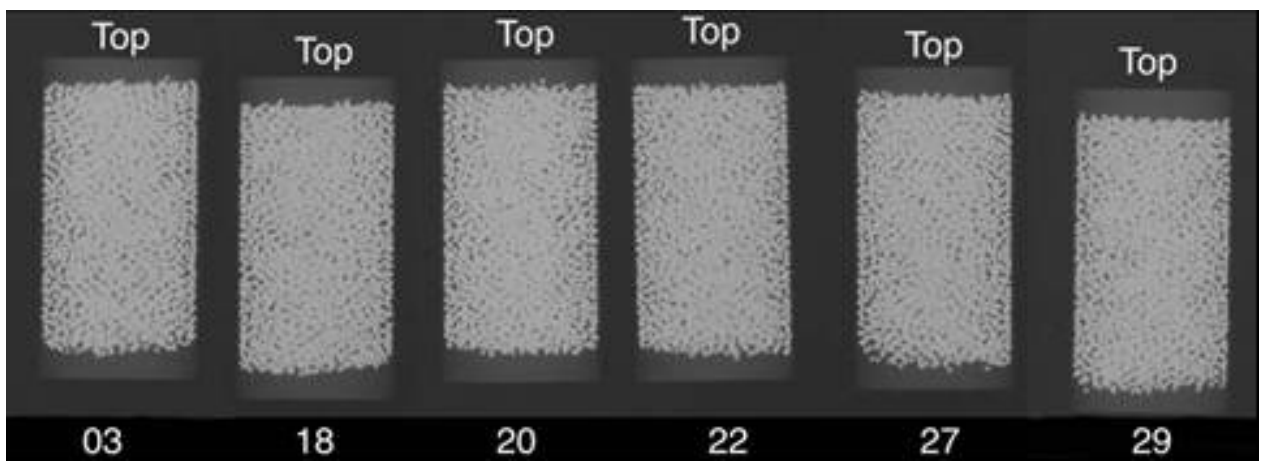

Figure 25. X-ray images of archive compacts from AGR-1 baseline compact lot LEU01-46T-Z.

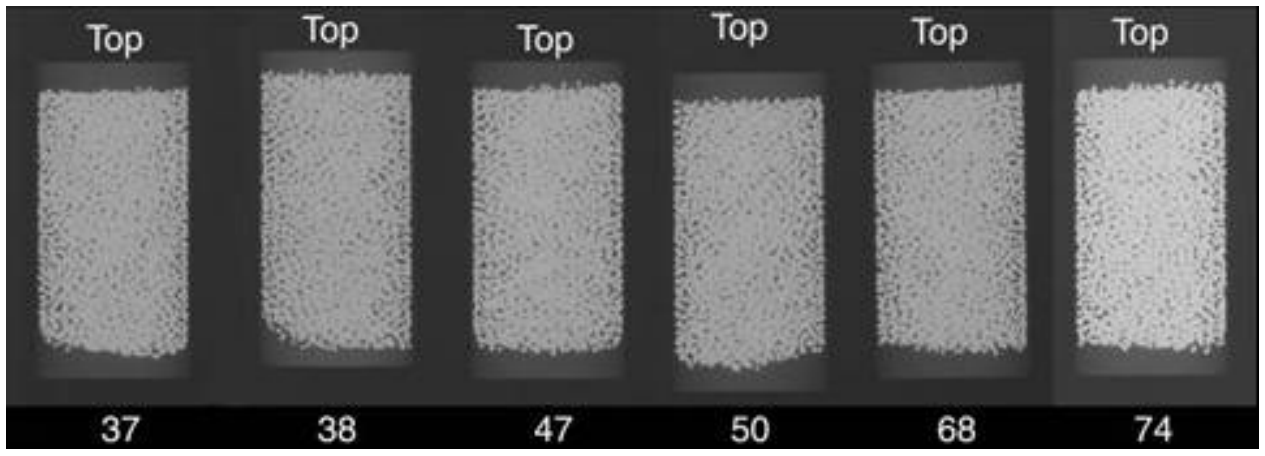

Figure 26. X-ray images of archive compacts from AGR-1 baseline compact lot LEU01-46T-Z.

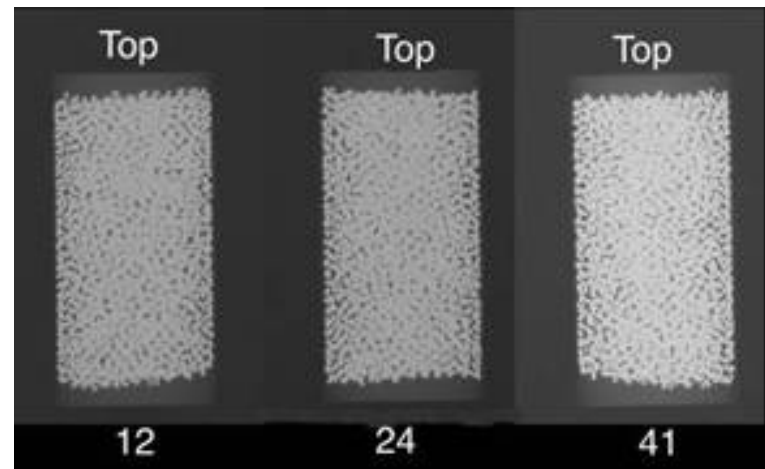

Figure 27. X-ray images of archive compacts from AGR-1 Variant 2 compact lot LEU01-48T-Z.

These end cap thickness values refer to the thickness of the unfueled region at the ends of the compacts and are measured from the outermost kernels to the end of the compact. The particle coating on the outer most kernels is included and accounts for about $0.2 \mathrm{~mm}$ of the reported values. The SiC coating layer can be barely discerned in the x-ray images (Figure 28). The coated particles appear to extend to the 
walls of the cylindrical compact, with little or no overcoat covering the outer pyrocarbon layer where it contacts the surface.

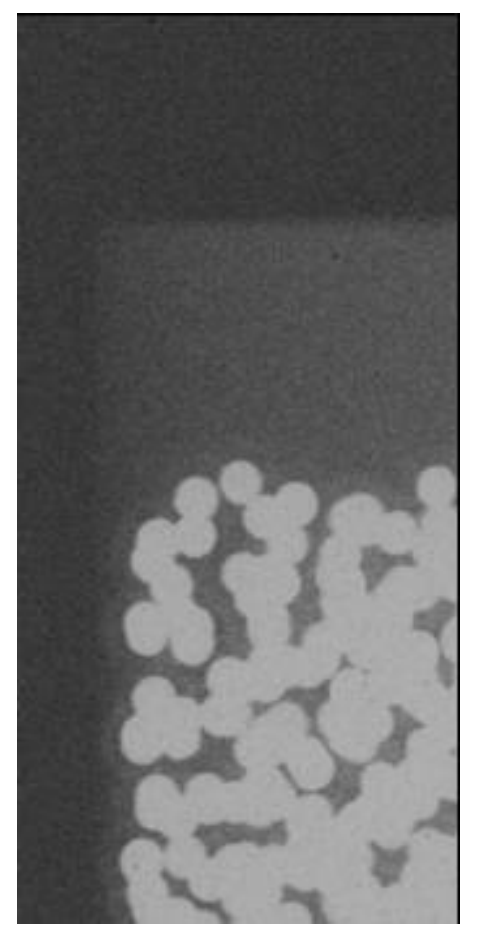

Figure 28. Expanded image of LEU01-46T-Z03 showing SiC coating layer.

\subsubsection{Compacting}

No report.

\subsection{Fuel and Materials Irradiation}

The AGR-1 Reactor Physics and Thermal Confirmatory Analyses were completed in August, and Engineering Design Files (EDFs) for each analysis were written and submitted for technical reviews, which were completed in early September. Final approvals and signatures were obtained on the analyses during the week of September 18th as needed to support the Experiment Safety Assurance Package (ESAP) review process.

Development of the ESAP was completed and submitted for review in late August. The peer, nuclear engineering and Safety and Operational Review Committee (SORC) reviews were all conducted in parallel. Comments from the peer and nuclear engineering reviews were incorporated prior to the SORC review meeting, conducted on September 21st. Comments from the SORC review were incorporated and final approvals and signatures were obtained on September 28th.

Development of the operating procedures was completed and submitted to the Reactor Technology Complex (RTC) document control organization for review and comment in August. Comments from the RTC reviewers were incorporated and the last operating procedures approved and released for use on September 27th. These procedures as well as the test train drawings and spares of the test train hardware were utilized by the RTC training organization to train the ATR operators on the AGR-1 experiment. The 
training session for fifth (and last) ATR operating shift was completed on September 28th, which resulted in $84 \%$ of the ATR operating crew being trained for the AGR-1 experiment. The remaining operators will be trained in make-up sessions during their next training session.

All four of the valve panels for the gas temperature control system were installed in the ATR facility (two in the nozzle trench and two in the sub-pile corridor) and all four panels were interconnected with multi-tube (plastic sheath containing seven different color coded $1 / 8^{\prime \prime}$ tubes). The panels were also connected to the fission product monitors in the $2 \mathrm{C}$ secondary cubicle and to the building ventilation systems as needed for purge connections, relief valves, system exhaust, etc. The control system is now ready for SO testing, which is being completed as much as possible during the current ATR reactor outage with the experiment not installed. The testing will be completed during the next ATR outage after the experiment has been installed and flow can be established through all of the experiment capsules.

Installation of the Fission Product Monitors (seven total) was delayed until late August when radiation fields (from some temporary loop decontamination equipment) outside the $2 \mathrm{C}$ primary cubicle could be reduced with temporary shielding. The spectrometer shields for the FPMs were installed in early September and the control system tubing connections and detector chambers were installed in late September. After the detector cables were installed from the control cabinet to the seven FPMs and all other major activities that could cause possible harm to the delicate instruments, the spectrometer detectors and gross detectors were installed in the shields. Pictures of the completed FPM installation are shown in Figures 29-33.

Assembly of the test train was initiated and assembly of capsules 1,2, 3, 5 and 6 were completed in August. Fabrication of the graphite holder for capsule 4 was completed in the machine shop and capsule 4 was assembled in early September. The welds between the tail piece and capsule 1 and the weld joining capsule 1 to capsule 2 had been completed in August. The welds joining the rest of the capsules as well as the welds in the leadout were completed during the week of September 18th. Prior to making the final two welds on the leadout (next to the penetration cavity), 


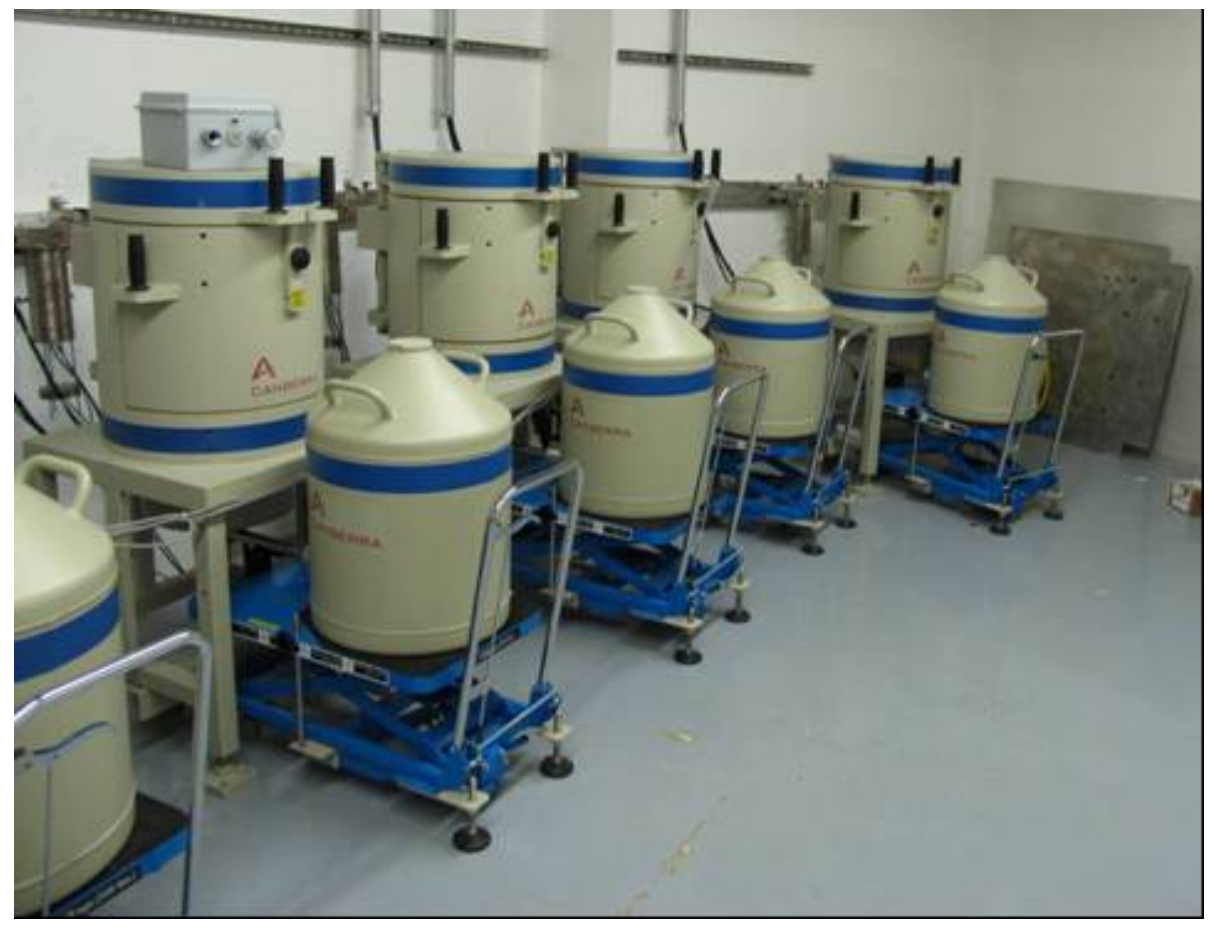

Figure 29. FPMs shown installed in the $2 \mathrm{C}$ Secondary Cubicle

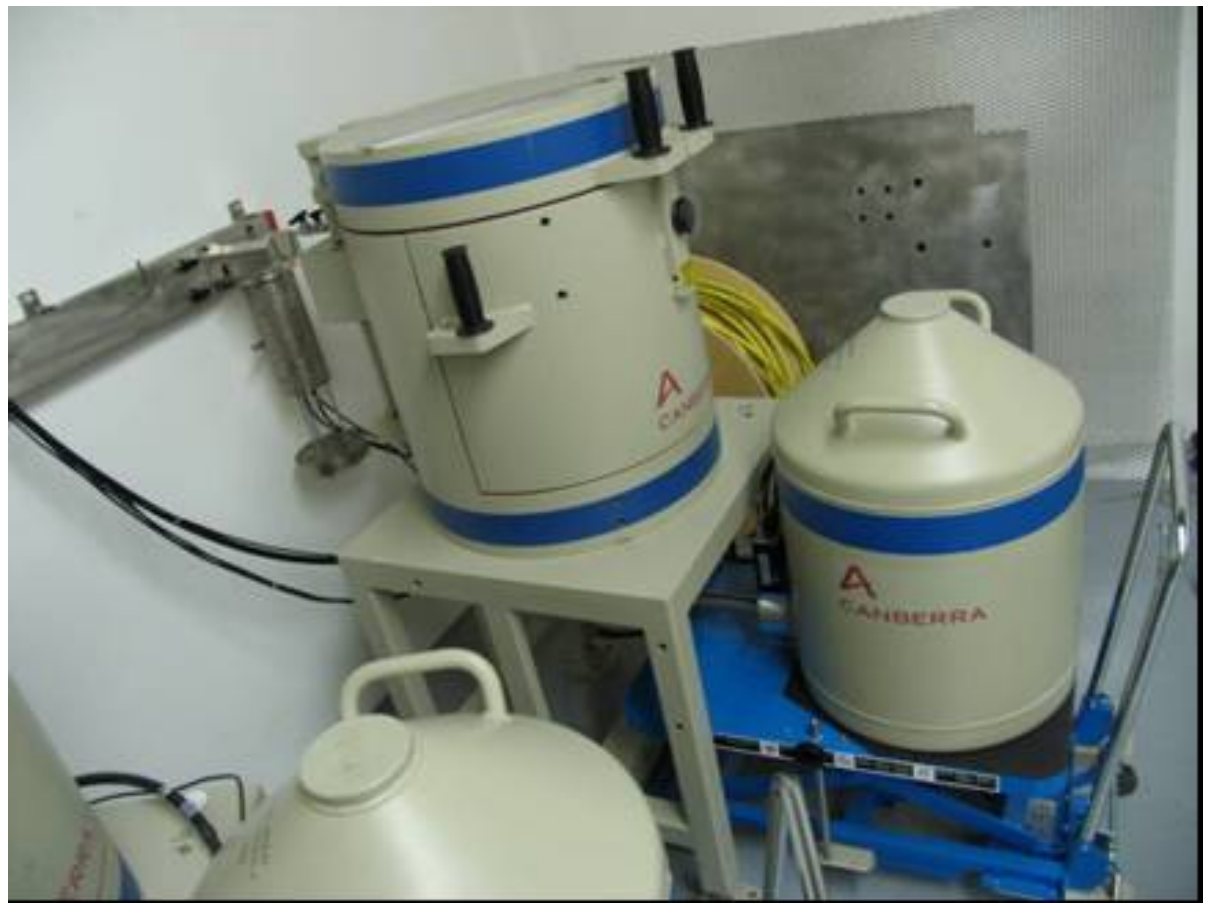

Figure 30. Single FPM showing the gross monitor (with shielding installed - located next to the tubing channel) and the spectrometer shield with the liquid nitrogen dewar. 


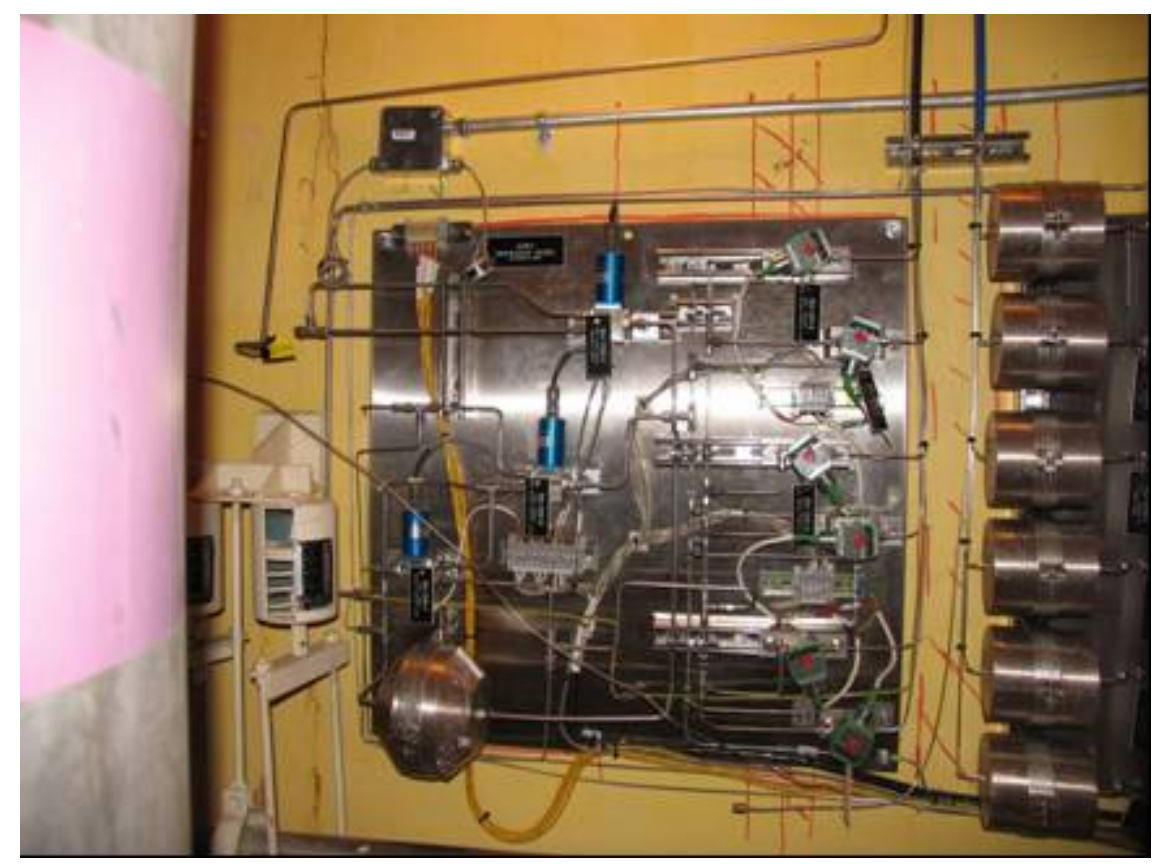

Figure 31. Filter Panel in the subpile corridor contains the filters and valving to redirect any capsule to the seventh FPM.

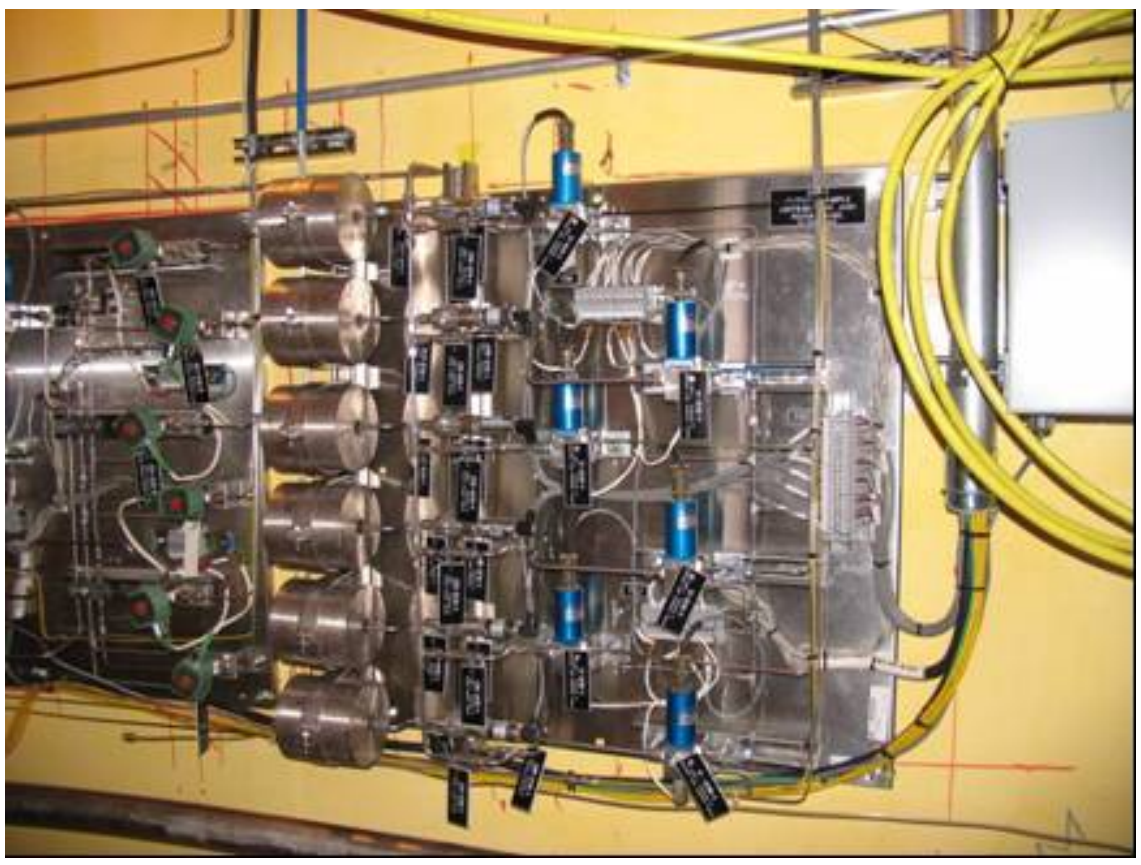

Figure 32. Distribution Panel in the subpile corridor - it contains the valving to obtain a grab sample from any capsule, and the zeolilte filter for the exhaust of all capsule gas lines prior to entering the ATR stack exhaust. 


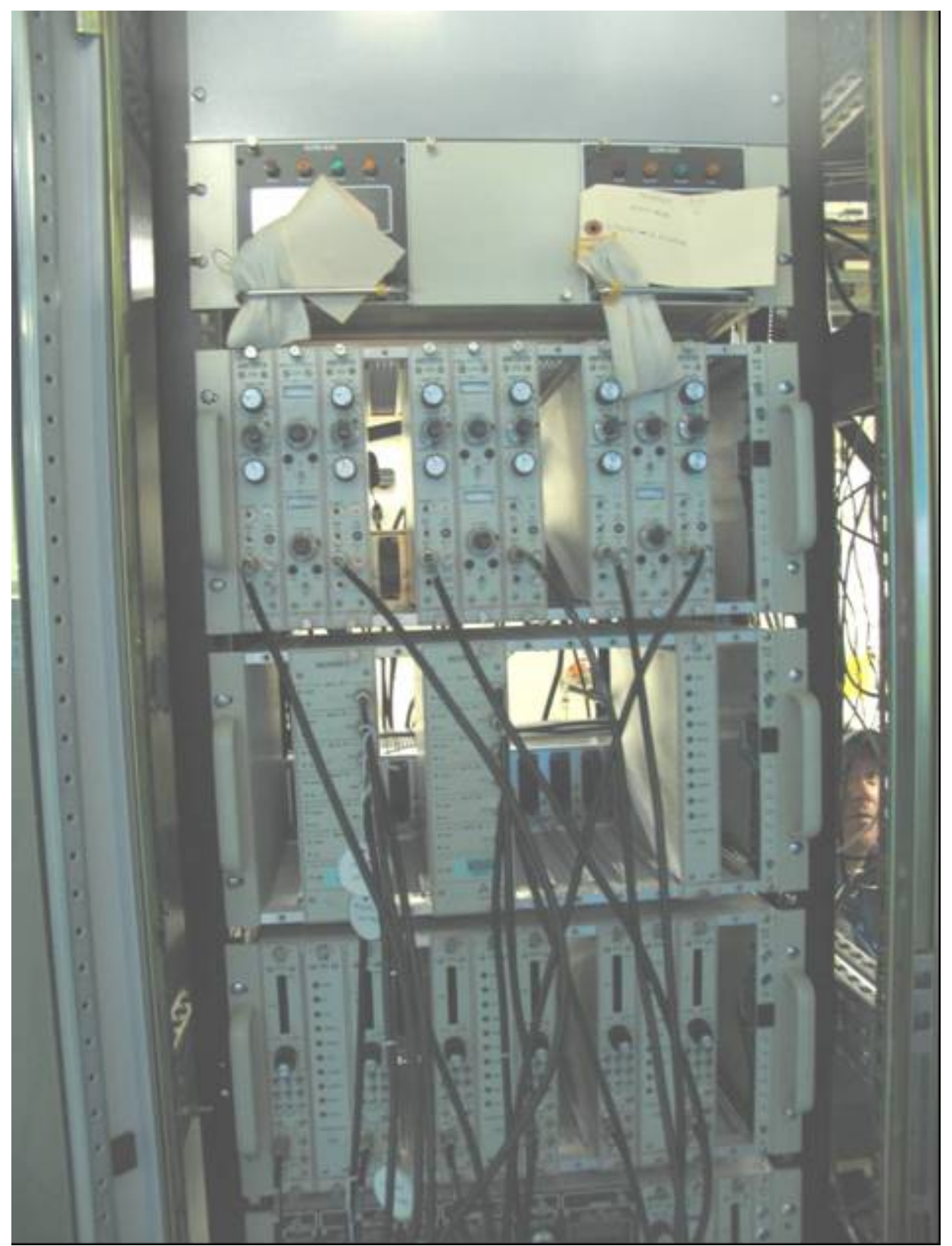

Figure 33. Inside of FPM control cabinet showing the electronics supporting each of the seven FPMs.

Dimensional checks were performed to ensure the experiment assembly would meet the requirements. A slight adjustment of the curve in the leadout was all that was necessary to meet the final dimensions. The final connection of the thermocouple leads and gas lines were made to the tubing attachment flange and the pressure test and helium leak test of the experiment assembly were performed and completed on September 26th. Final documentation signatures and Quality Assurance buy-off of the test train assembly was completed on September 27th. Pictures showing the final experiment assembly are shown below in Figures 34-40. 


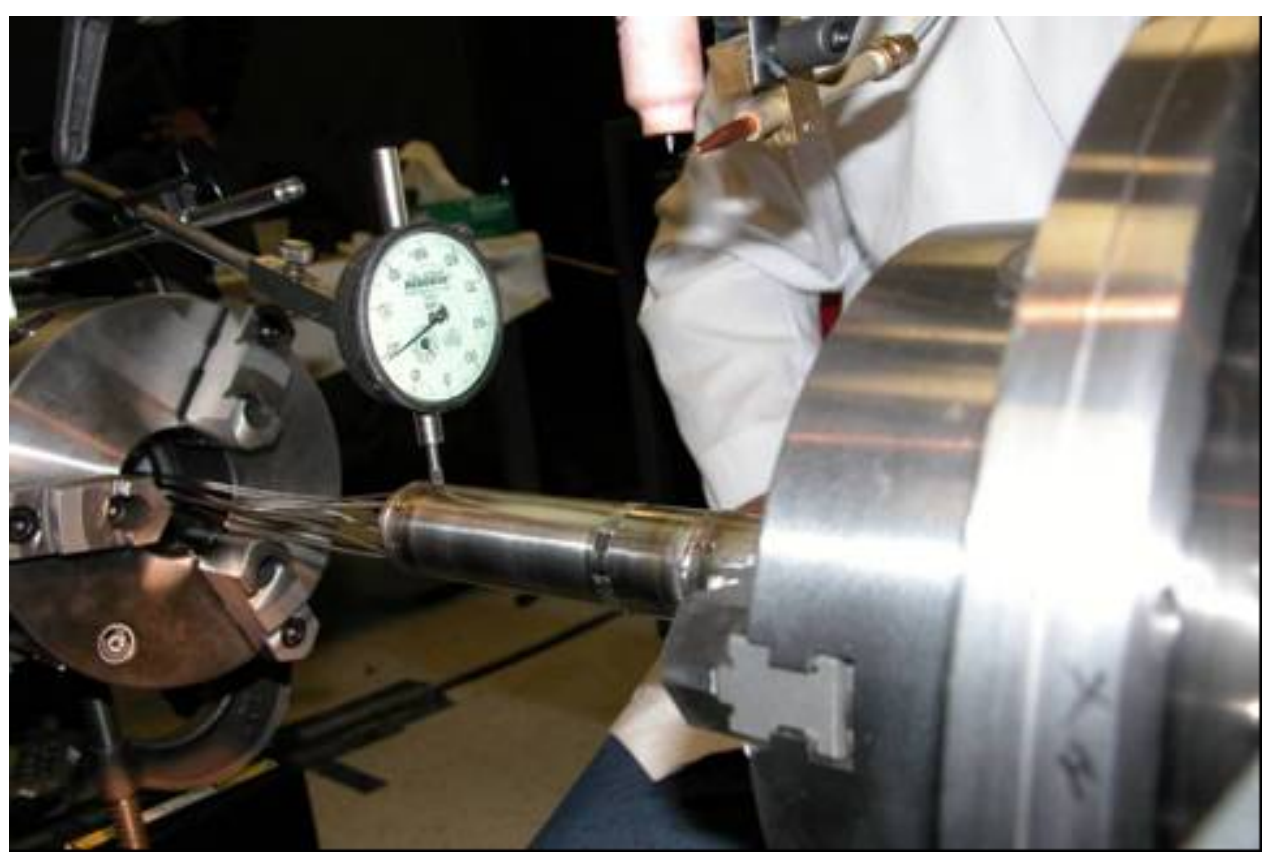

Figure 34. Straightness of the test train is checked after each weld joint. Adjustment is accomplished by striking an arc on the weld to "pull" the assembly back in line.

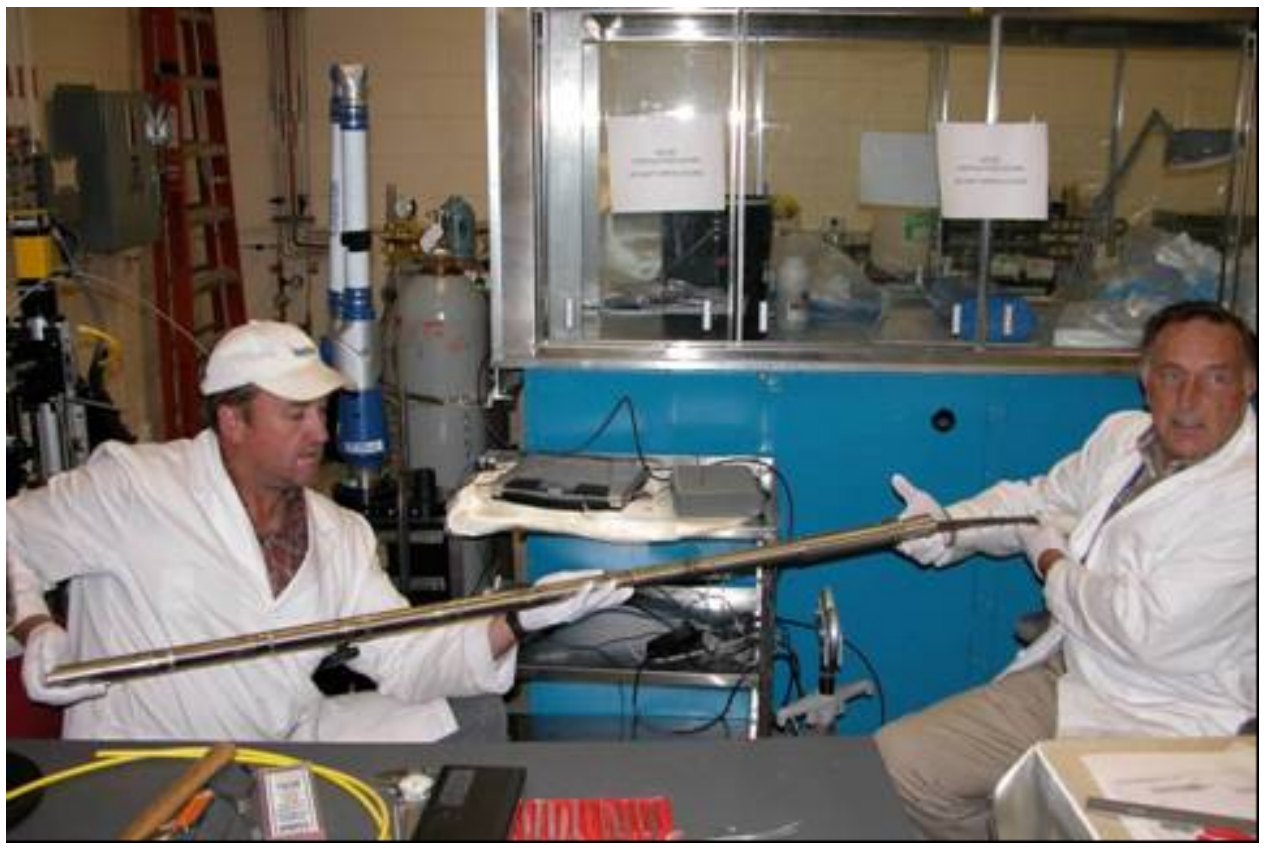

Figure 35. The fueled portion of the test train has 13 welds and is straight to within 0.020 inch. 


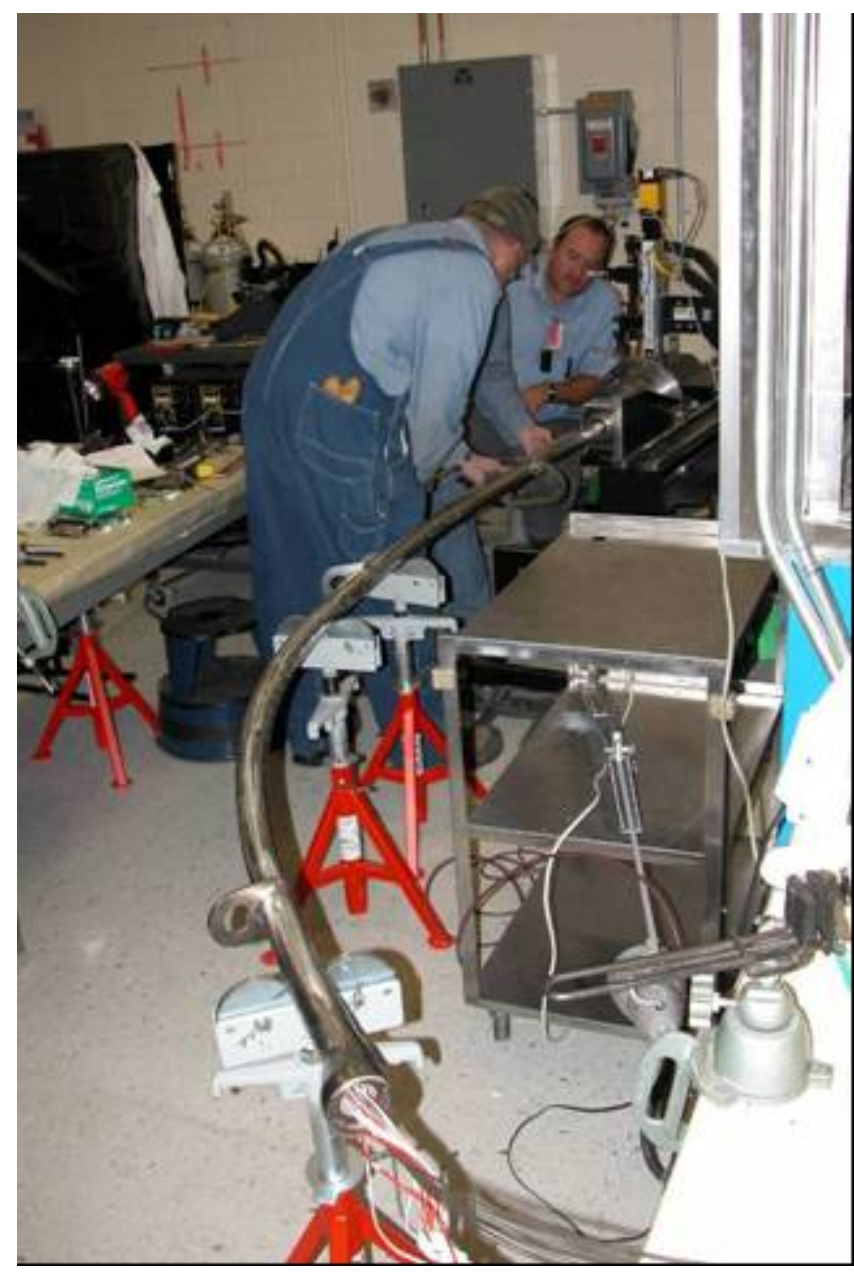

Figure 36. The next phase of the assembly is to install the pipe that will connect the test train to the reactor vessel wall. 


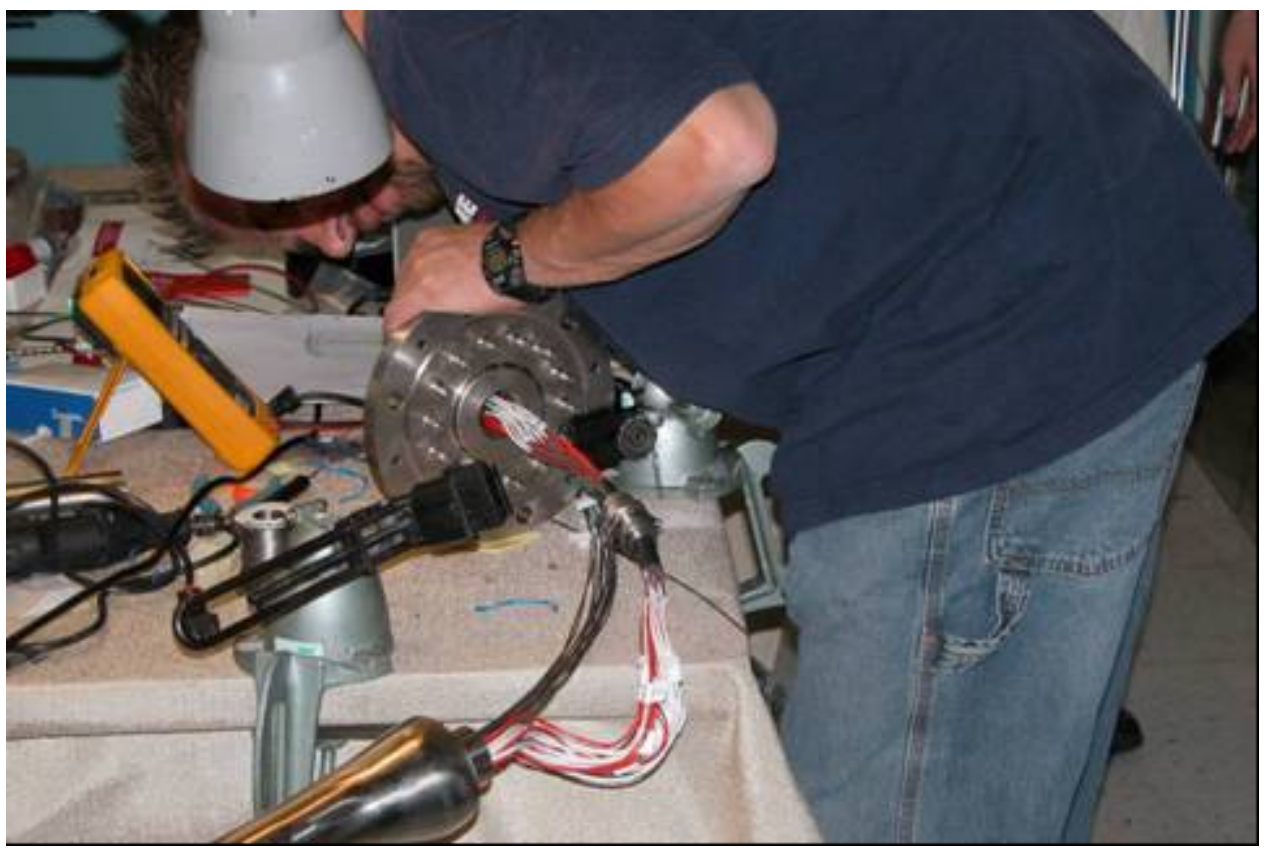

Figure 37. The thermocouple connectors are assembled after the thermocouple wires and gas lines are pulled through the upper piping.

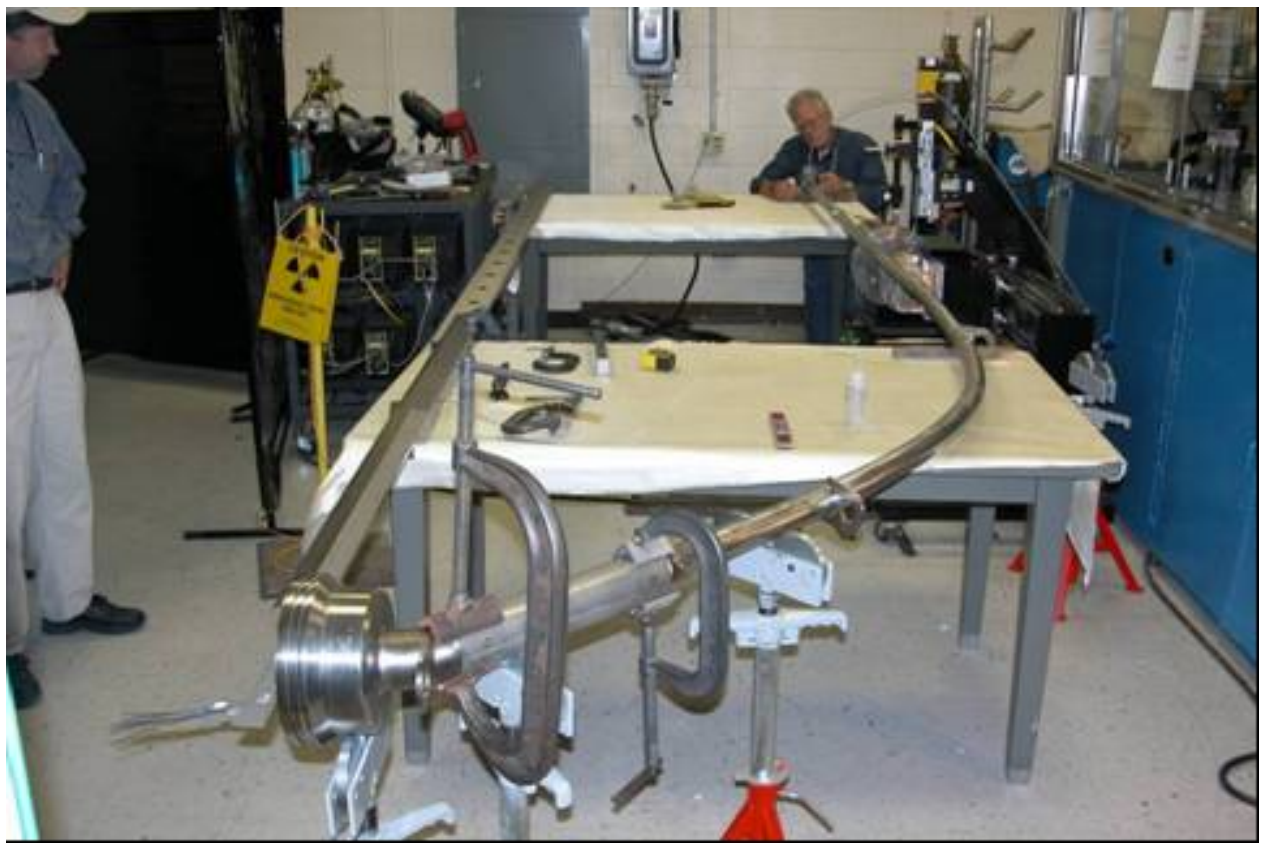

Figure 38. The final welds are configured and welded. 

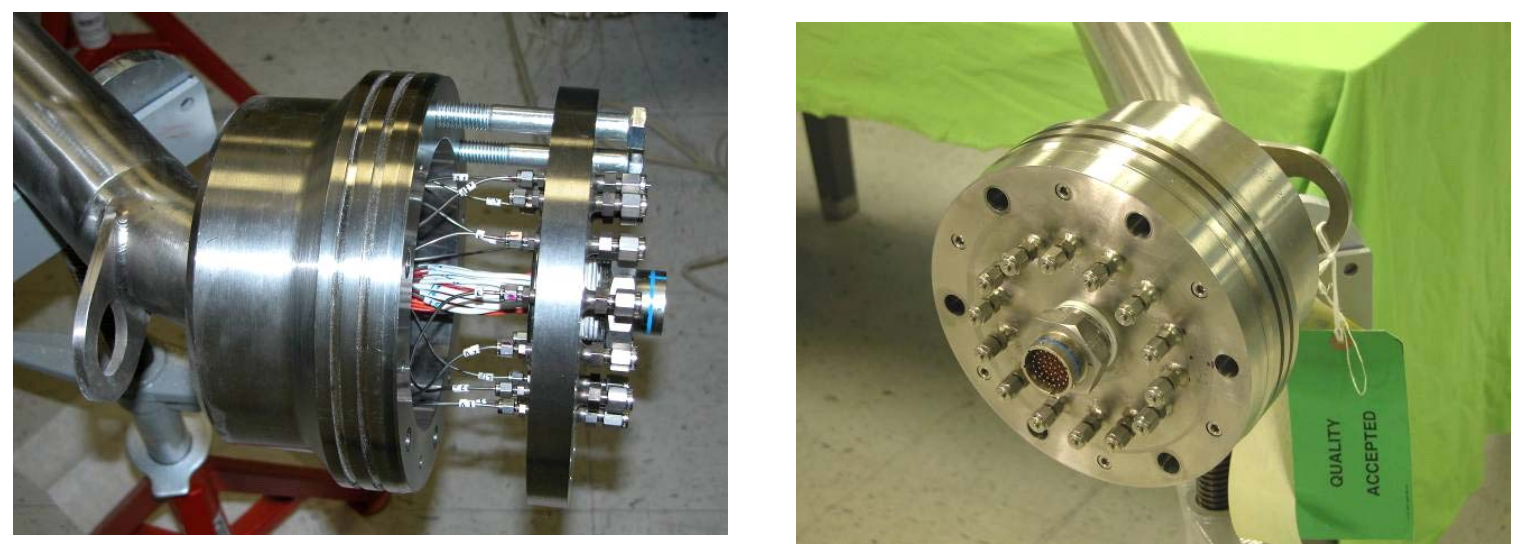

Figure 39. The gas lines are connected and the thermocouple connectors are hooked up before bolting the flange closed. The completed head has 14 gas line connections and 18 thermocouple connections.

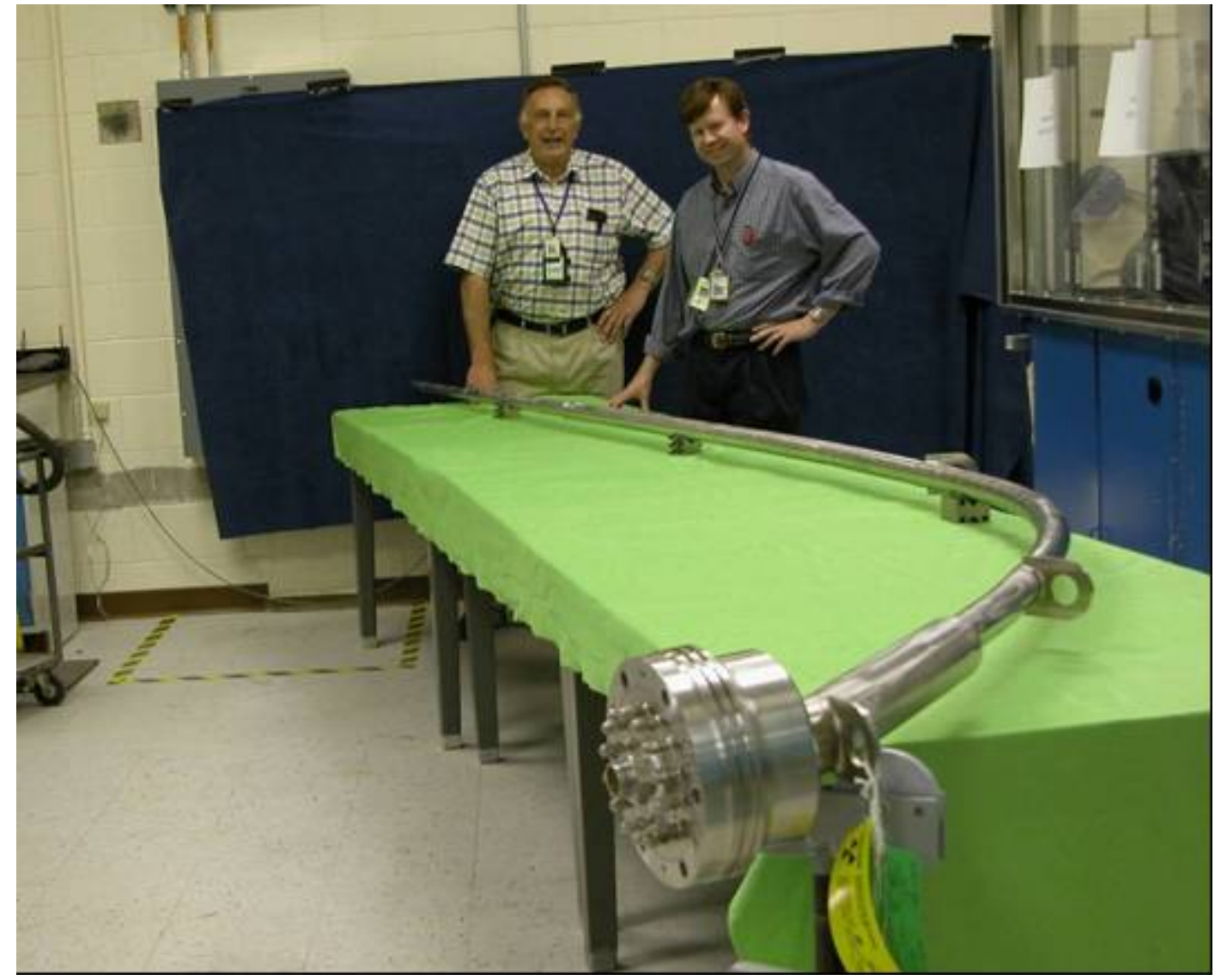

Figure 40. The test train is now ready for insertion in the reactor.

\subsection{Safety Testing and Post Irradiation Examination}

A progress summary report (INL/EXT-06-11823) was issued describing PIE planning activities from FY06 and the proposed approach for developing a plan to upgrade PIE capabilities at the participating laboratories. The objective is to have a plan in place at the end of the period of continuing 
resolution. Based on the approach to develop a facility development plan outlined in the progress report, work has begun on a draft AGR-1 PIE specification. This will document the data requirements for the AGR-1 post-irradiation examination.

To help assess costs involved with various lab facility upgrades, cost estimation activities continued this month. This includes an assessment of the costs required to complete installation of a pneumatic sample insertion system on the TRIGA reactor at the Hot Fuel Examination Facility at INL. The final version of a report summarizing the ORNL PIE capabilities (ORNL/TM-2006/526) was also issued. This report includes order of magnitude cost estimates to develop various equipment.

\subsection{Fuel Performance Modeling}

The PARFUME code has been modified and extended to allow simulation of accident conditions that could be associated with irradiation of TRISO-coated fuel particles. These modifications and extensions include coding for the analysis of (1) stress and displacement within the fuel particles, (2) the effects of gold spots, (3) the effects of SiC thinning, and (4) fission product (FP) transport through individual fuel particles and the surrounding graphite materials ultimately leading to a release from the fuel. The analytical efforts conducted to date in incorporating these modifications into PARFUME are described in EDF-7338.

The new FP transport models were exercised demonstrating capabilities that will be needed to complete the accident condition benchmark exercise under the International Atomic Energy Agency (IAEA) Coordinated Research Program (CRP). As a demonstration of PARFUME capabilities, the FP transport models were used to calculate Cs release from the German FRJ2-K13 irradiation experiment. Specifically, calculations were completed to determine the release fraction from Capsule 2. A comparison of calculated results with the end of irradiation experimental measurement is shown in Figure 41. As indicated, calculated results compare very closely with the reported release fraction. These results provide some validation for the FP transport models implemented in PARFUME. 


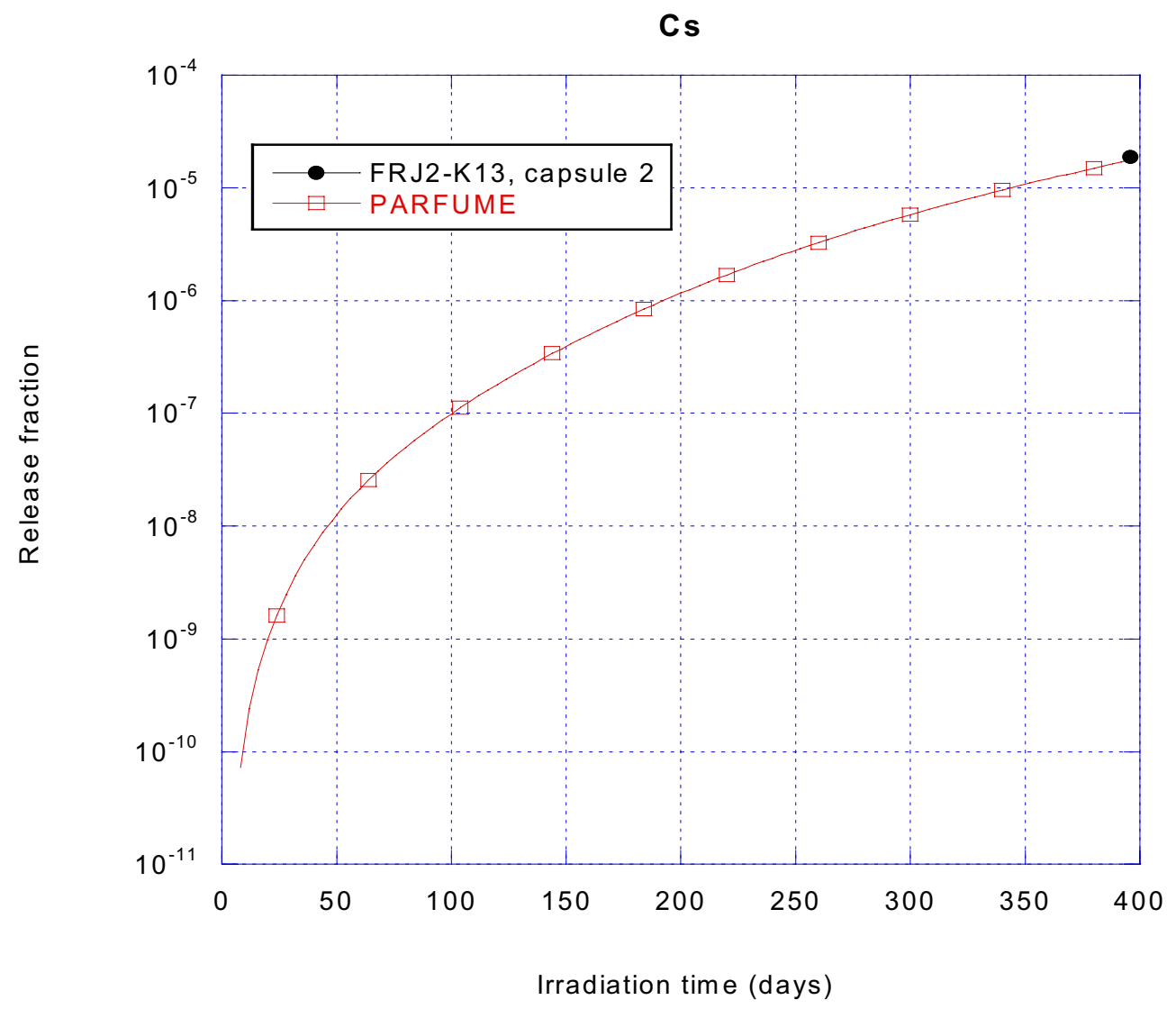

Figure 41. Cs release from irradiation experiment FRJ2-K13, Capsule 2.

To document results of calculations performed by General Atomics (GA) for the fuel performance code accident condition benchmark cases defined as a part of the IAEA CPR on coated particle fuel technology (CRP-6), report PC-000538, Rev. 0 was issued. The results are preliminary because definitions of the accident conditions benchmark cases for CRP-6 have not been finalized. (Preliminary definitions were provided to GA by INL for use in the calculations). The three benchmark cases for planned heating tests were not performed because the heating test conditions have not been defined.

The approach employed in this study was to use the PISA code to calculate IPyC, $\mathrm{SiC}$ and OPyC stress-related failure and the CAPPER code to calculate $\mathrm{SiC}$ failure due to thermo-chemical effects during the irradiation phase defined for each benchmark case. The OPyC failure fraction obtained from PISA and the $\mathrm{SiC}$ failure fraction obtained by combining the results from PISA and CAPPER were input to the SORS code to define the failure fractions at the start of the heating phase. Coating failure, fission gas (e.g., Kr-85) release and fission metal (e.g., Cs-137, Sr-90, and Ag-110m) release during the heating phase were calculated by SORS. The results reported for each benchmark case included coating failure fractions at the end of the irradiation phase, the incremental coating failure during the heating phase, and the fractional Kr-85, Cs-137, Sr-90, and Ag-110m release during the heating phase. The results reported in PC-000538 also included a comparison of the calculated and measured Cs-137 and Kr-85 release for the HFR-K3 and HFR-P4 heating tests (benchmark cases 19, 20, 23, and 24) and a comparison of the calculated and measured Cs-137 and Ag-110m release for the HRB-22 heating tests (benchmark cases 21 and 22). No Sr-90 release comparisons were made because of the unavailability of Sr-90 release data for these tests. 
In discussions between GA and INL staff, it was agreed that the fuel failure fraction and the fractional release fractions for Cs-137, Sr-90, Ag-110m, and Kr-85 should be the comparison metrics for the benchmark cases. It was also agreed that the definitions of the benchmark cases are problematic in that they couple fission product release predictions for the accident phase with the fuel failure predicted for the irradiation phase. Thus, it may be difficult to determine if differences in the fission product release predictions by the participants in the CRP- 6 accident conditions code benchmarking are because of differences in the manner in which the various accident conditions codes calculate fuel failure and fission product release or because the fuel failure fractions at the onset of the accident phase are different due to differences in the various fuel performance codes used by the participants for calculating fuel failure during normal reactor operating conditions. Consequently, it would be better if the fuel particle failure fractions at the onset of the accident phase were defined for each benchmark case for use by all participants. This would decouple the normal operation code and accident code fuel performance predictions and allow a direct comparison of the results obtained with the various accident conditions codes. A common set of fission product diffusion coefficients should also be defined for use by all CRP6 participants.

\subsection{Fission Product Transport and Source Term}

A report (Document 911095, Rev. 0) to define the requirements for an experimental program to measure the sorptivities of key radionuclides on fuel-compact matrix, core graphite, and primary circuit metal alloys was completed by GA. The defined experimental program is responsive to R\&D tasks 3.5.4.1 and 3.5.7.1 in the AGR Technical Program Plan. In addition to providing test requirements, document 911095 describes the use of sorption isotherms in the prediction of fission product release and plateout and discusses the past experience in performing fission product sorption measurements. This information was presented in order to provide a context for development of the specific details of the experimental program. This information is of particular importance because tests of this nature have been conducted over the past four decades with mixed results, and the generic problems inherent in these measurements must be avoided to ensure a high probability of success. In particular, experimental techniques that permit measurements to be performed at very low fission product partial pressures $(<<10$ $10 \mathrm{~atm})$ must be developed and qualified. 


\section{Preconceptual Engineering Services Subcontract}

Work began on the development of Statement of Work for the NGNP Preconceptual Design Studies began in early March with the assembling of available information. A day long meeting was conducted on March 13, 2006 to obtain input from the various NGNP R\&D Leads and their support personnel, the NGNP licensing engineer, the NGNP Systems Integration Manager, the INL NE Associate Lab Director, and the appointed Project Manager. This meeting produced a list of several special studies that needed to be conducted as part of the Preconceptual Design Studies that will provide initial requirements and help to focus the R\&D effort. A report in the form of a set of meeting minutes was produced to document the results of the meeting. The studies identified are as follows:

1. Electrical vs. Hydrogen
a. Reactor Power levels
b. Capability for large electrical or large hydrogen production.
c. Power Conversion and heat sink.

2. Reactor Design (trade off between Prismatic and Pebble Bed)

3. IHX
a. Heat transfer medium
b. Integrate current studies

4. Hydrogen Economics and Knowledge

\section{a. Risks of Technical Development}

5. Indirect vs. Direct

6. Product Stream

\section{Define Fuel Cycle for NGNP.}

As the scope of work developed, several reviews by the same resources were conducted to obtain comments to help focus the Statement of Work. A general description of the scope of work follows:

- The pre-conceptual design work will include evaluation of a range of design parameters and alternatives, and based on the justification for the parameters and alternatives so-developed, prepare a pre-conceptual design for the NGNP prototype facilities. The design parameters and alternatives to be evaluated will include thermal power level, reactor outlet and inlet temperatures, primary and secondary system pressures, reactor design (e.g., pebble bed compared to prismatic block), power conversion concept (e.g., direct compared to indirect cycle, power conversion machinery concept), process heat transfer and transport concepts (e.g., intermediate heat exchanger concepts, heat transport media), and hydrogen production capability. An important purpose of the evaluation of parameters and alternatives is to determine the most appropriate configuration of the prototype to enable subsequent commercialization of NGNP technologies (e.g., scaling and licensing considerations). Research \& development needs deemed necessary to select such parameters and among such alternatives will be identified. 
- The subcontractor shall conduct concept design studies as described above to define the commercial scale prototype reactor, electrical power generation system, process heat transfer and transport systems, and the hydrogen generation plant for the NGNP using very high temperature reactor technology. The subcontractor shall also provide input regarding the appropriate overall licensing strategy that should be followed for the NGNP prototype.

- The pre-conceptual design shall establish the basic reactor geometry and layout; perform reactor physics, thermal fluids studies, and heat balance and emissions calculations; provide subsystem identification and relative sizing (heat exchangers, pumps, compressors, piping, structural, etc.) including balance of plant support facilities; provide general site layout, subsystem/plant interfaces, etc. The modular reactor design shall be based on a single module capacity. The optimal size and design temperature for the reactor type shall be determined for a "commercial scale prototype reactor" for electrical power generation and optimal hydrogen production efficiencies and other industry applications of high temperature process heat. The smallest practical hydrogen plant to demonstrate production as a commercial prototype shall be recommended. The nuclear system concept designs shall include concept design layout for the optimal sized hydrogen production plant for commercial scale demonstration for the NGNP and shall specifically address separation distance required if any, between the nuclear plant and the hydrogen plant, based on safety and licensing requirements. The overall nuclear system design work shall assemble current research \& development, design information and information status (what is known and what is unknown) into a single report.

- This work will include industry literature research on current and emerging technologies for very high temperature reactors, hydrogen and electricity production, other industry high temperature process heat applications study, the site study at the INL, capital cost estimates, operating cost estimates, life cycle cost estimates, economic analysis, and project schedule, all at a preconceptual design level of detail.

- Information from the concept designs will provide a foundation to define the next level of technical and functional requirements, provide NGNP management with important information required to make decisions mandated in the Energy Policy Act of 2005, and provide NGNP program management with geometric data, identification of critical Structures, Systems, and Components (SSC) and data that are needed to further direct and focus planned research and development in the areas of reactor safety and design methods, fuels, materials, and licensing.

An Expression of Interest (EOI) was prepared with extensive reviews from within the INL and DOE and was issued on June 22, 2006. Ten national and international vendor teams from industry responded to the EOI. Of these ten vendor teams, six were qualified and responsive to the requirements identified in the EOI. A Request for Proposals (RFP) was prepare, which also went through extensive reviews by INL and DOE. The RFP was issued on July 26, $2006 \mathrm{t}$ six companies. Two of the companies opted out during the bid preparations period and did not submit proposals. Four proposals were received, as scheduled, by the INL on August 21, 2006.

An INL selection board was formed in early August and selection board evaluations began soon after receiving the proposals. Of the four proposals received one was found to be non-responsive to the scope of work issued by the selection board. Oral presentations were conducted on August 30 and September 6, 2006. All three of the remaining proposals were found to be excellent with one clear leader. A subcontract was awarded to the Westinghouse Electric Company Team on September 28, 2006. The subcontract award and letters of intent achieved the objectives and met the BEA NGNP level 2 and \$374 K PEMP milestone to award the Preconceptual Design Studies subcontract by September 30, 2006. A 
kickoff meeting to finalize the vendors work plan and agree on details of the scope was conducted at Cambridge, MA on October 18 and 19, 2006.

It was decided that an additional perspective on a Prismatic type reactor and the varying expertise from all three companies would be of value in focusing the NGNP R\&D work and in the preparation of a set of technology independent functions and requirements for Conceptual Design. Therefore letters of intent to award subsequent subcontracts to the AREVA NP INC., Team and the General Atomics Team were also sent out.

In order to stay with in the funding available for the Preconceptual Design Studies and satisfy the constraints of continuing resolution, the rigor and scope for the latter two studies has been reduced from the original Statement of Work. The reduce scope, in the form of an addendum to the original Statement of Work, was prepared during the early part of October and sent out to AREVA and General Atomics about the 5th of October. The two vendors are preparing revisions to their original work plans and discussions and negotiations are continuing. It is planned to award a reduced scope subcontract to AREVA by mid November and also to General Atomics by early to mid December. 


\section{NGNP FY 2006 Budget}

NGNP budget results for FY 2006 are shown in Figure 41, with project sales for the month of September shown in Figure 42.

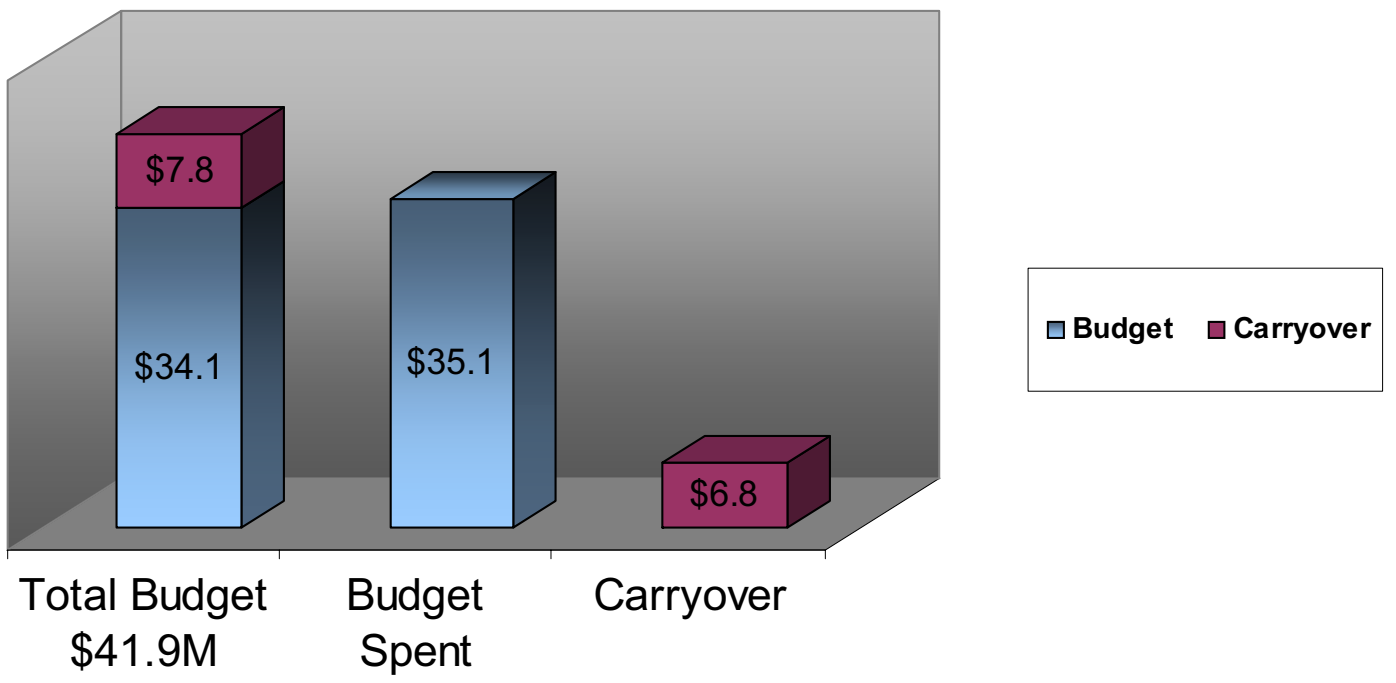

Figure 41. NGNP FY2006 Budget

\section{September Sales}

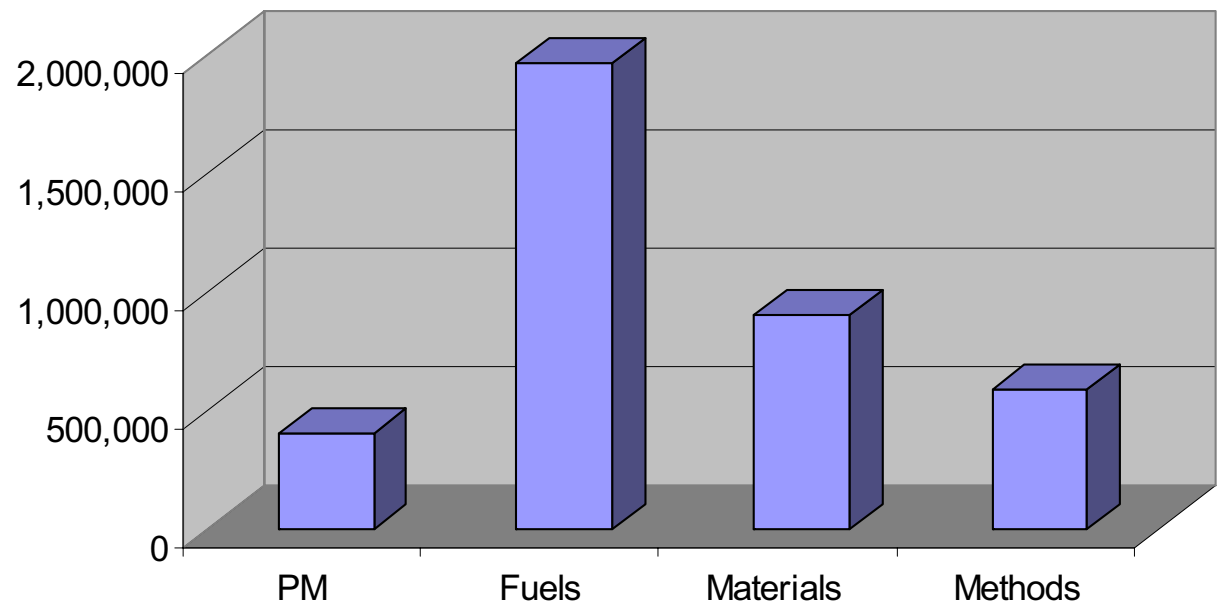

Figure 42. September Sales 


\section{90-DAY (1 ${ }^{\text {ST }}$ Quarter FY 2007) LOOK AHEAD}

\subsection{Project Management}

- Establish the project WBS in the financial and HR systems to reflect new organization

- Implement the QA Corrective Action Plan

- Develop an alternate SOW for the project, reflecting the expected budget after CR

\subsection{NGNP Design Methods}

- Not provided.

\subsection{NGNP Materials}

- Complete the assembly of the AGC-1 muck up with heat shield.

- Conduct a design review for the AGC-1 capsule.

- Engage the Hydrogen team to develop a joint interface requirements document

\subsection{NGNP Licensing}

- Engage the NRC in the development of the Licensing Strategy

\subsection{AGR Fuel Development and Qualification}

- Begin the NGNP fuel acquisition study.

- Begin 6-inch diameter coater tests at BWXT.

- Prepare report documenting kernel fabrication development.

- Conduct an audit of the BWXT quality assurance program.

- Review the BWXT coater control system design and test plan for the control system.

- Begin development at ORNL of an overcoating process for particles with $425 \mu \mathrm{m}$ kernels.

- Test and install the high-speed pressure transducer on the BWXT coater.

- Initiate a study on the applicability of LWR methods and data for calculating radionuclide transport and deposition within the VLPC of a VHTR during a core heat-up accident. 


\subsection{Preconceptual Engineering Services Subcontract}

\section{Westinghouse Subcontract}

- Special Studies work began on October 24th.

- Weekly telecon status meetings will be held each Thursday at 8:00 am MST.

- Outlines for the Special Studies and the Plant Design Requirements Document (PDRD will be presented at the November 2nd status meeting.

- December 6th and 7th meeting at Stoughton Massachusetts to present preliminary Special Studies results.

- January 10th kickoff meeting at Technology Insights San Diego office for the 50\% Design Review of the Special Studies.

- January 19th design review comments and resolutions completed.

- Special Studies issued by February 9th.

\section{$\underline{\text { AREVA Subcontract }}$}

- Subcontract award is anticipated the week of November 9th or 17th depending upon Terms \& Conditions negotiations and Work Plan finalization.

- December 5th meeting at AREVA Lynchburg office to review preliminary studies results.

- Late January 50\% Design Review (date to be determined in Final Work Plan).

\section{General Atomics}

- November 3rd General Atomics will submit draft estimate of the reduced statement of work and associated work plan.

- November 28th meeting at General Atomics main office in San Diego to resolve work plan comments.

- December 6th subcontract award and notice to proceed.

- January 9th meeting at General Atomics main office in San Diego to review preliminary results of the special studies. 


\section{DISTRIBUTION}

DOE-HQ

Cook, T. L.

Feltus, M. A.

Versluis, R. M.

Griffith, A.

\section{NE-ID}

Aljayoushi, J.

Fineman, C. P. (4)

Kincaid, K. L.

McClellan, G. R.

Vivian, K. A.

\section{ORNL}

Balls, J.

Bell, G. L.

Burchell, T.D.

Corwin, W.

Ingersol, D. T.

Klett, J. W.

McGreevy, T. E.

Nanstad, R. K.

Ren, W.

Snead, L. L.

Williams, D.

\section{INL}

Bennett, R. G.

Kearns, P. K.

Lake, J. A.

Leahy, T. J.

McCarthy, K. A.

\section{NGNP Team}

Bayless, P. D.

Braase, L. A.

Bragassa, J. L.

Bratton, R. L.

Clemons, G. C.

Cox, J. R.

Cole, L. T.

Drigert, M. W.

Ebner, M. A.

Ginosar, D. M.

Gougar, H. D.

Harrell, D. J.

Herring, S. J.

Ingersoll, D. T.

Johnson, R. W.

Klett, J. W.

Lake, J. A.

Lessing, P. A.

McCreery, G. E.

McGreevy, T. E.

Nanstad, R.K.

Nigg, D. W.

O'Brien, J. E.

Oh, C. H.

Ougouag, A. M.

Park, C. V.

Petti, D. A.

Piet, S. J.

Ren, W.

Rittenhouse, P. L.

Schultz, R. R.

Sherman, S.

Smartt, H. B.

Snead, L. L.

Sterbentz, J. W.

Stewart F. F.

Stoneberg, W.L.

Stoots, C. M.

Terry, W. K.

Totemeier, T. C.

Watkins, A. D.

Weaver, K. D.

Windes, W. E.

Wolf, J. R.

Wright, R. N.

Yoon, W. Y. 